NBER WORKING PAPER SERIES

\title{
THE GREAT DEPRESSION AND THE FRIEDMAN-SCHWARTZ HYPOTHESIS
}

Lawrence J. Christiano

Roberto Motto

Massimo Rostagno

Working Paper 10255

http://www.nber.org/papers/w10255

\author{
NATIONAL BUREAU OF ECONOMIC RESEARCH \\ 1050 Massachusetts Avenue \\ Cambridge, MA 02138 \\ January 2004
}

The views expressed in this paper do not necessarily reflect those of the European Central Bank or the Eurosystem. We are very grateful for advice and encouragement from David Altig, Klaus Masuch and HansJoachim Klöckers. The careful editorial assistance of Monica Crabtree is much appreciated. Also, we are indebted for discussions and suggestions from Gadi Barlevy, Michael Bordo, V.V. Chari, Harris Dellas, Riccardo DiCecio, Martin Eichenbaum, Jonas Fisher, Andreas Fischer, Frank Schorfheide, Christopher Otrok, Lee Ohanian, Francesco Lippi, Ramon Marimon, Thomas Sargent, Christopher Sims, Lars Svensson, and Mike Woodford. In addition, we have benefited from the feedback of audiences in seminar presentations at the American Economic Association Meetings in San Diego; the Bank of Canada; the Bank of Japan; Bocconi University; Columbia University; Duke University; the European Central Bank Workshop on Asset Prices and Monetary Policy; the Federal Reserve Bank of Cleveland-Journal of Money, Credit and Banking Conference on Recent Developments in Monetary Macroeconomics; the First ECB-IMOP Workshop on Dynamic Macroeconomics in Hydra; the Second Conference of the Euro Area Business Cycle Network at the European Central Bank; Harvard University; and the International Monetary Fund. Christiano is grateful for the support of an NSF grant to the National Bureau of Economic Research. The views expressed herein are those of the authors and not necessarily those of the National Bureau of Economic Research.

(C2004 by Lawrence J. Christiano, Roberto Motto, and Massimo Rostagno. All rights reserved. Short sections of text, not to exceed two paragraphs, may be quoted without explicit permission provided that full credit, including (C) notice, is given to the source. 
The Great Depression and the Friedman-Schwartz Hypothesis

Lawrence J. Christiano, Roberto Motto, and Massimo Rostagno

NBER Working Paper No. 10255

January 2004

JEL No. E31, E40, E51, E52, E58, N12

\section{ABSTRACT}

We evaluate the Friedman-Schwartz hypothesis that a more accommodative monetary policy could have greatly reduced the severity of the Great Depression. To do this, we first estimate a dynamic, general equilibrium model using data from the 1920s and 1930s. Although the model includes eight shocks, the story it tells about the Great Depression turns out to be a simple and familiar one. The contraction phase was primarily a consequence of a shock that induced a shift away from privately intermediated liabilities, such as demand deposits and liabilities that resemble equity, and towards currency. The slowness of the recovery from the Depression was due to a shock that increased the market power of workers.

We identify a monetary base rule which responds only to the money demand shocks in the model. We solve the model with this counterfactual monetary policy rule. We then simulate the dynamic response of this model to all the estimated shocks. Based on the model analysis, we conclude that if the counterfactual policy rule had been in place in the 1930s, the Great Depression would have been relatively mild.

Lawrence J. Christiano

Department of Economics

Northwestern University

Evanston, Il 60208

and NBER

1-christiano@northwestern.edu

Roberto Motto

European Central Bank

Postfach 160319

D-60066 Frankfurt am Main

Germany

roberto.motto@ecb.int
Massimo Rostagno

European Central Bank

Postfach 160319

D-60066 Frankfurt am Main

Germany

massimo.rostagno@ecb.int 


\section{Contents}

1 Introduction $\quad 2$

2 Key Macroeconomic Variables in the Interwar Period 6

2.1 Aggregate Quantities . . . . . . . . . . . . . . . . . 6

2.2 Exogenous Monetary Policy Shocks in the Great Depression . . . . . . . . 8

2.3 The Sticky Wage Mechanism . . . . . . . . . . . . . . . . . . . . . . 9

2.4 Other Variables and Mechanisms . . . . . . . . . . . . . . . . . 13

3 The Model Economy $\quad 15$

3.1 Firms ................................. 17

3.2 Capital Producers . . . . . . . . . . . . . . . . . . . . . . . . . . . . . . . . . . .

3.3 Entrepreneurs . . . . . . . . . . . . . . . . . . . . . . 19

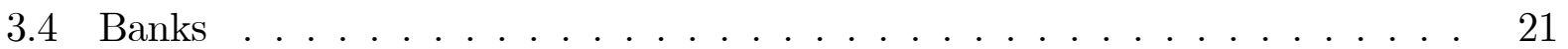

3.5 Households . . . . . . . . . . . . . . . . . . . . . . . . . . . . . . . . . . . . . .

3.6 Final-Goods-Market Clearing . . . . . . . . . . . . . 25

3.7 Exogenous Shocks . . . . . . . . . . . . . . . . . 26

3.8 Monetary Policy . . . . . . . . . . . . . . . . . . . . . . . . . . . . . . . . . . .

3.9 Equilibrium and Model Solution . . . . . . . . . . . . . . . 28

4 Model Estimation and Fit $\quad 29$

4.1 Parameters of the Nonstochastic Part of the Model . . . . . . . . . . . . 30

4.2 Parameters of Exogenous Stochastic Processes . . . . . . . . . . . . . . . 32

4.2.1 Methodology . . . . . . . . . . . . . . . 32

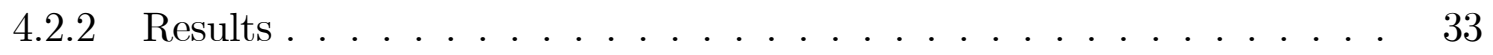

4.3 General Observations about Model Fit . . . . . . . . . . . . . . . 36

5 The U.S. Great Depression from the Perspective of the Model 37

5.1 Real Shocks . . . . . . . . . . . . . . . . . . . 37

5.2 Financial Market Shocks . . . . . . . . . . . . . . . . . . . 39

5.3 Monetary Shocks . . . . . . . . . . . . . . . . 40

6 Counterfactual Analysis $\quad 43$

$\begin{array}{llr}7 & \text { Conclusion } & 46\end{array}$

$\begin{array}{ll}\text { A Appendix: Model Solution } & 48\end{array}$

A.1 Model Steady State . . . . . . . . . . . . . . . . . . . . . . . . . . . . . . . . . 49

A.1.1 Firms . . . . . . . . . . . . . . . . 51

A.1.2 Capital Producers . . . . . . . . . . . . . . . . . . 52

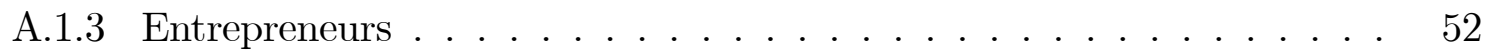

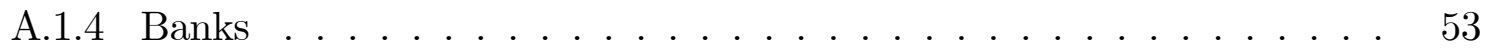

A.1.5 Households . . . . . . . . . . . . . . . . . . 54

A.1.6 Monetary Authority . . . . . . . . . . . . . . . . 55

A.1.7 Resource Constraint and Zero Profits . . . . . . . . . . . . . . 55

A.2 Linearizing the Model Economy . . . . . . . . . . . . . . . . . . 55 


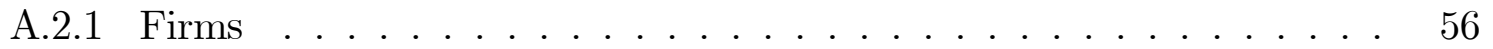

A.2.2 Capital Producers . . . . . . . . . . . . . . . . . 56

A.2.3 Entrepreneurs . . . . . . . . . . . . . . . . . 56

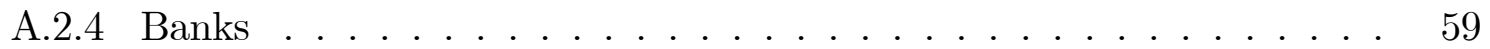

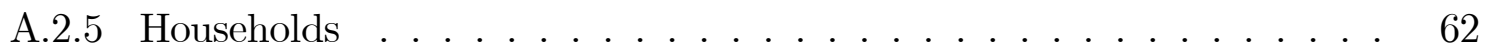

A.2.6 Monetary Policy . . . . . . . . . . . . . . . 65

A.2.7 Aggregate Restrictions . . . . . . . . . . . . . . . . . . 65 


\section{Introduction}

The purpose of this paper is to contribute to the construction of dynamic general equilibrium models useful for the analysis of policy questions. We do this by developing a standard monetary business cycle model in three directions: We add several shocks, a banking sector and financial frictions. We subject this model to what is perhaps the toughest possible test. We fit the model to U.S. data from the 1920s and 1930s and ask whether a different monetary policy might have moderated the output collapse experienced in the Great Depression. ${ }^{1}$ Our analysis suggests that the answer is "yes." This is consistent with the hypothesis of Friedman and Schwartz (1963).

Apart from its intrinsic historical interest, there are two reasons we examine the U.S. economy in the 1930s. First, there is a general consensus that the Great Depression was a consequence of the interaction of several shocks with financial markets, labor markets, and the banking system. As a result, this episode constitutes a natural laboratory for studying a model like ours. Second, there is widespread interest in understanding whether monetary policy authorities in a low-interest-rate environment have the power to resist deflation and output collapse. This is the situation confronted by the US monetary authorities in the 1930s.

The counterfactual monetary policy that we study temporarily expands the growth rate in the monetary base in the wake of a money demand shock. To ensure that this policy does not violate the zero lower-bound constraint on the interest rate, we consider policies which increase the monetary base in the periods after a shock. ${ }^{2}$ By injecting an anticipated inflation effect into the interest rate, this delayed-response feature of our policy prevents the zero bound constraint from binding along the equilibrium paths that we consider. Of course, for the anticipated inflation effect to be operative, the public must believe that the central bank will in fact raise the future growth rate of the monetary base. In our analysis, we assume the central bank has this credibility. ${ }^{3}$

\footnotetext{
${ }^{1}$ There are numerous other quantitative analyses of the Great Depression, with perhaps the first being Lucas and Rapping (1972). In addition, there is the work of Bordo, Choudhri, and Schwartz (1995), Bordo, Erceg, and Evans (2000), Christiano (1999), Cole and Ohanian (1999, 2001, 2003, 2003a), McCallum (1990), and Sims (1999).

${ }^{2}$ An alternative strategy for stimulating the economy when the nominal rate of interest is near zero is to drive the rate to its lower bound and hold it there for a while (see Eggertsson and Woodford (2003) for a discussion). Because the policy involves an occasionally binding constraint, studying it requires confronting substantial computational challenges, which we have not pursued here. Computational strategies for imposing constraints that bind occasionally are discussed in Christiano and Fisher (2000).

${ }^{3}$ Recently, several analysts have voiced skepticism that the sort of monetary policy we study has credibility. They argue that central bankers - either as a result of a careful assessment of their incentives and constraints, or because of an unreasoned preference - may have an unshakable commitment to low inflation at all times. (See, for example, Krugman 1998, Eggertsson 2003, Eggertsson and Woodford 2003, Sims 1999, and others.) There are two ways to interpret the fact that we abstract from these concerns in our study. First, a convincing demonstration that temporarily high inflation in the wake of certain types of shocks would have had desirable
} 
In our model we focus on monetary policy alone, in isolation from fiscal policy. Implicitly, we assume that the fiscal authorities accommodate any fiscal implications of monetary policy by a suitable adjustment in taxes. ${ }^{4}$ We abstract from the distortionary effects of the latter, by assuming the adjustments are done with lump sum taxes. The notion that the fiscal authorities passively (in the sense of Leeper 1991) adjust the variables in their budget constraint to accommodate changes in circumstances is consistent with accounts of the 1930 s. $^{5}$

Although our estimated model has eight shocks, two of them turn out to be particularly significant. The first is a "liquidity preference shock", which plays an important role in the contraction phase of the Great Depression. ${ }^{6}$ This shock drives households to accumulate currency at the expense of demand deposits and other liabilities (time deposits) that are used to fund entrepreneurs who own and operate the economy's stock of capital. ${ }^{7}$ The impact on the real economy of these responses to the liquidity preference shock is determined by the nature of intermediation in our model.

Demand deposits are issued by banks, which use the proceeds to fund working-capital loans to goods-producing firms. We capture this by adopting a version of the fractional reserve banking model of Chari, Christiano, and Eichenbaum (1995). Our model allows us to study the mechanism whereby households' shift away from demand deposits leads to a slowdown in economic activity. Time deposits are issued by banks for the purpose of financing entrepreneurs, who own and operate the economy's stock of capital. Entrepreneurs

consequences during the Great Depression may help promote the institutional or other changes necessary for such a policy to be credible in the future. Second, a case can be made that the policy would in fact have been credible in the U.S. in the 1930s. Reinforced by the gold standard, the price level had been stable throughout the previous decade. So, it might have seemed natural for the public to expect at least some inflation after the initial price level drop in the early 1930s. Moreover, as the Great Depression proceeded, a political constituency in favor of inflation began to take hold (Kennedy 1999.) Much of this constituency was in the Democratic Party, which was the party of the president after Roosevelt was elected in the fall of 1932. On this basis, we conjecture that a policy of temporary inflation, even one that somewhat exceeded what was implied by a price level target, would not have been incredible in the U.S. in the 1930s. (However, as argued recently by Orphanides 2003, such a policy would have required some changes at the Federal Reserve, whose officials had a low tolerance for inflation.)

${ }^{4}$ That the operating characteristics of monetary policy depend sensitively on the assumptions one makes about fiscal policy has been emphasized recently in the literature on the fiscal theory of the price level. See, for example, Leeper and Sims (1994), Sims (1994), and Woodford (1994, 1996). (Christiano and Fitzgerald 2000 provide a critical review).

${ }^{5}$ Concerns about fiscal solvency motivated Herbert Hoover to ask for the sizeable tax increase that became the Revenue Act of 1932 (Kennedy 1999, p. 79). Roosevelt was also concerned about fiscal solvency. He pushed for one bill to reduce government spending and another to raise taxes because "For three long years the Federal Government has been on the road toward bankruptcy." (Kennedy 1999, p. 138). These bills were the Economy Act of March 20, 1933 and the Beer-Wine act of March 22, 1933.

${ }^{6}$ For a related discussion, see Field (1984), who argues that a money demand shock played an important role during this time.

${ }^{7}$ This is consistent with Sims (1999), who finds that disturbances that resulted in a flow out of bank deposits and into currency were important during the Great Depression. 
require bank financing because their own net worth is insufficient to finance the purchase of the economy's capital stock. We capture the financial arrangements associated with entrepreneurs with a version of the agency cost model of financial frictions of Bernanke, Gertler, and Gilchrist (1999) (BGG). ${ }^{8}$

We now briefly summarize the ways in which households' shift away from time deposits leads to a decline in economic activity. The 'first round' effect of the shift is obvious: by reducing the funding available to entrepreneurs, the shift leads to a fall in capital purchases and, hence, investment. The financial frictions induce additional effects which magnify this initial decline in investment. These 'accelerator effects' occur as the initial decline in investment leads to a fall in entrepreneurial net worth. This fall occurs through three channels. First, the initial decline in entrepreneurial demand for capital produces a fall in its price. This reduces the net worth of entrepreneurs by reducing the market value of their physical assets. ${ }^{9}$ Second, net worth is reduced by the "debt deflation" effect emphasized by Irving Fisher (1933). In the model, we specify that the return received by households on time deposits is nominally non-state contingent. Moreover, the liquidity preference shock generates a surprise fall in the price level as spending declines. This surprise fall in the price level increases the real payoff to creditors (households) at the expense of debtors (entrepreneurs). Although there is generally a presumption in macroeconomics that reallocations of wealth of this type are neutral in the aggregate, in our model they are not. This is because the reallocation takes funds away from agents who have access to investment opportunities (i.e., the entrepreneurs) and gives them to people who do not (i.e., the households). ${ }^{10} \mathrm{~A}$ third factor down driving net worth is the general slowdown in economic activity which, by reducing the rental rate of capital, leads to a reduction in entrepreneurial income. ${ }^{11}$

Households' attempts to obtain more currency also induces them to cut back on consumption expenditures, which further depresses aggregate spending. These effects of the liquidity preference shock produce, with one exception, responses that resemble the behavior of the

\footnotetext{
${ }^{8}$ This work builds on Gale and Hellwig (1985) and Townsend (1979). Related models include those of Carlstrom and Fuerst $(1997,2000)$.

${ }^{9}$ Cole and Ohanian (2001) cite evidence that business loans remained relatively strong during the contraction phase of the depression. They suggest that this evidence represents an embarassment for models of financial frictions. It is useful to note that it is not necessarily a problem for the model considered here. In the model, the fall in asset prices triggered by a liquidity preference shock is expected to be undone over time. By creating anticipated capital gains, this raises the prospective return on capital. The nature of the loan contract is such that when this happens, the amount of loans an entrepreneur receives for a given level of net worth goes up. During the first few years of the Great Depression people, in fact, did think that the end of the output decline was near, and things would return to normal soon (see Kennedy 1999.)

${ }^{10}$ This is where our model differs from that in BGG. Because their model is non-monetary, they cannot capture the debt-deflation mechanism. Our way of incorporating this mechanism is consistent with the remarks in the conclusion of BGG.

${ }^{11}$ In our model there are additional sources of non-neutrality associated with the entrepreneurs. These stem from the fact that the liquidity preference shock generates a rise in bankruptcies, which generate real resource costs.
} 
U.S. economy from late 1929 to 1933 . The exception is that the mechanism implies a rise in the interest rate, whereas interest rates actually fell sharply during this period. It turns out, however, that the rise in the interest rate in response to a liquidity preference shock is small and transient, and is soon followed by a persistent fall. Although we have not confirmed this, we suspect this fall in the interest rate is a consequence of the accelerator mechanism implied by the financial frictions. Consistent with the analysis in Friedman and Schwartz (1963), our counterfactual experiment suggests that failure of the Federal Reserve to respond appropriately to this and other money demand shocks in the 1930s was the reason that the slump that began in 1929 ultimately became the Great Depression. ${ }^{12}$

As in the case of the other shocks in our model, our analysis is silent about the fundamental origins of the liquidity preference shock. We suspect that a more careful analysis of this shock would lead to the conclusion that it is not invariant to the nature of monetary policy, as we assume here. In fact, a more accommodative monetary policy might have reduced the volatility of the liquidity preference shock, as well as of other monetary shocks in the model. So, we think of our analysis as placing a lower bound on what monetary policy might have achieved in the 1930s. In addition, an implication of our analysis is that a deeper study of the microeconomic sources of liquidity preference and other monetary shocks would lead to a better understanding of the Great Depression, and possibly other business cycle episodes as well.

The second shock that plays an significant role in our analysis is particularly important in the expansion phase of the Great Depression. A puzzle during this phase is that hours worked recovered only slightly in the period, 1933-1939. The estimated model's answer to this puzzle is that there was a rise in the market power of workers. This feature of the model accords well with the widespread notion that the policies of the New Deal had the effect of pushing up wages and reducing employment by giving workers greater bargaining power (Cole and Ohanian 2003.)

In fact, the above story oversimplifies somewhat the account of the Depression implicit in our estimated model. There are many details that the liquidity preference and market power shocks miss. Six other shocks in the model fill in those details. All these shocks are pinned down by the fact that we consider a large range of data in the analysis. The thirteen variables that we consider are the Dow Jones Industrial average, aggregate output, aggregate employment, the aggregate real wage, a short-term interest rate, the premium on Baa bonds, the monetary base, M1, inflation, investment, consumption, demand deposits,

\footnotetext{
${ }^{12}$ To the extent that the Fed chose not to accommodate money demand shocks because it felt constrained by the gold standard, our analysis of the contraction phase of the Great Depression is consistent with the analysis of Eichengreen and others, who lay the blame for the Great Depression with the gold standard.

There is some debate over how binding a restriction the gold standard was for monetary policy (Bordo, Choudhri, and Schwartz 1995).
} 
and bank reserves. We display our model's implications for all these variables. The large number of variables imposes substantial discipline on the analysis.

The outline of the paper is as follows. In the next section, we present an informal discussion of the data on the Great Depression, as a way to motivate key features of our model. Section 3 presents the formal model economy. Section 4 discusses the assignment of parameter values and model fit. Section 5 discusses the explanation of the Great Depression that is implicit in our estimated model. Section 6 discusses the counterfactual analysis. Section 7 concludes. Various technical details are relegated to appendices.

\section{Key Macroeconomic Variables in the Interwar Pe- riod}

We now briefly review the relevant data and literature that motivate the general design of our model. It is worth emphasizing both what is in the model, as well as what is not. In terms of the latter, the model we construct abstracts from international considerations. This choice is motivated by the arguments of Bordo, Choudhri, and Schwartz (1995), Romer (1993), and others, which claim that the U.S. Great Depression can be understood in domestic terms only. Also, we are sympathetic to the arguments in Romer (1993) and Temin (1976), which maintain that exogenous monetary policy disturbances were probably not an important impulse driving the Great Depression. ${ }^{13}$ Our model abstracts completely from such shocks. We explain what it is about the data that leads us to leave them out. In addition, our model de-emphasizes somewhat the classical sticky wage mechanism by which spending shocks have traditionally been assumed to affect real output and employment. ${ }^{14}$ We explain what it is about the data that leads us to assign a relatively greater role to alternative mechanisms. As we review the data, we describe the impulse and propagation mechanisms that we think do warrant further consideration and which are included in our model.

\subsection{Aggregate Quantities}

Our data are displayed in Figure 1. For convenience, the fourth-quarter observations for 1929 and later are indicated by an asterisk $(*)$. Consider the real per capita Gross National Product (GNP) data, which are normalized to unity in $1929 .{ }^{15}$ Note that these fall by one-

\footnotetext{
${ }^{13}$ Sims (1999) uses methods based on vector autoregressions to conclude that monetary policy shocks were not an important source of variation in economic activity.

${ }^{14}$ See Bordo, Erceg, and Evans (2001) for a formal representation of the notion that the Great Depression reflected the effects of contractionary shocks to monetary policy operating on the economy through a sticky wage mechanism.

${ }^{15}$ Nominal GNP data were taken from Balke and Gordon (1986). GNP was converted to 1929 dollars using the GNP deflator taken from the National Bureau of Economic Research's Macro History database at http://www.nber.org/databases/macrohistory/contents/. Real GNP was converted to per capita terms by a
} 
third from 1929 to 1933 . The recovery is very slow, and by 1939 output is only barely back to its 1929 level. To understand the composition of these fluctuations, consider the data on consumption and investment in Figure 1. Consumption includes household consumption of nondurables and services, while investment includes business investment plus household purchases of durable goods. The consumption and investment data have been divided by the level of output in 1929 to give an indication of their magnitude in relation to output. Note that the drop in consumption is relatively small, falling from about 65 percent of the 1929 level of GNP in 1929 to about 50 percent of the 1929 level of GNP in 1933. The behavior of investment is more dramatic. It drops 80 percent, falling from 25 percent of the 1929 level of GNP in 1929 to 5 percent of that level in 1933. These are the observations that have motivated researchers to speculate that the key to understanding the start of the Great Depression lies in understanding the dynamics of investment (see Romer 1993 and Temin 1976.) Another way to see just how much investment fell is to compare the fall in the investmentto-output ratio from 1929 to 1933 with the fall in that ratio in other recessions. Table 1 displays the investment-to-output ratio at NBER peaks and troughs for the 1929 recession and for 9 other postwar recessions. In recessions since the Great Depression, reductions in the investment-to-output ratio have been no greater than 3 percentage points. Results in Cole and Ohanian (2001, Table 1) indicate that the fall in the investment-to-output ratio in the 1920-1921 recession was also relatively small. By contrast, the drop in the investmentto-output ratio in the Great Depression, which was 19 percentage points, was an order of measure of population from Chari, Kehoe, and McGrattan (2002), who derive it from Kendrick (1961) (the data were taken from Ellen McGrattan's website). Their measure of population is linearly interpolated to construct quarterly figures. Nominal investment includes household purchases of durable goods, investment in equipment, investment in residential and nonresidential structures, and change in inventories. It was taken from Balke and Gordon (1986). It was converted to per capita 1929 dollars using the GNP deflator and the measure of population. Nominal consumption is household consumption of nondurable goods and services and is taken from Balke and Gordon (1986). It is converted to per capita 1929 dollars using the GNP deflator and the measure of population. Hours worked is the number of hours of all employees, plus the self employed, plus those involved in unpaid family work. It includes government hours, except for hours worked in the military. It is expressed as a ratio to the annual endowment of hours and taken from Chari, Kehoe, and McGrattan (2002), who build on data from Kendrick (1961). The Dow Jones is taken from the NBER dataset. It is converted to real per capita terms using the GNP deflator and population. Monetary variables are taken from Friedman and Schwartz (1963) and are converted to per capita terms using our population measure. The short-term interest rate is the three-month rate on Treasury securities and it is taken from the NBER database. The interest rate spread is the difference between yields on Baa and Aaa corporate bonds, which are obtained from the NBER database. The real wage is hourly compensation. It is constructed as follows. Total compensation from NIPA, available at an annual frequency starting from 1929, is divided by our measure of hours worked and interpolated to obtain quarterly figures using the related series of average hourly earnings in manufacturing from Hanes (1996). For the period 1923-1928 we used average hourly earnings in manufacturing from Hanes (1996). The two series were spliced together. Finally, the series is converted to real terms using the GNP deflator. We did not use earnings in manufacturing from Hanes (1996) for the whole sample because wages in manufacturing experienced a much stronger rise than wages in the other sectors during the 1930s (see Cole and Ohanian 1999.) On the other hand, the measure of hourly compensation we constructed is not totally satisfactory, as self-employed and unpaid family workers are included in hours worked but are excluded from the NIPA measure of total compensation. 
magnitude greater than that which occurred in these other recessions.

Figure 1 also displays economy-wide per capita hours worked, normalized to unity in 1929. Employment dropped by roughly 25 percent from 1929 to 1933. Notably, hours worked in the 1930s never recovered much from their low level in 1933. By 1939 they settled to a level about 20 percent below their level in 1929. This observation has led many to conjecture that one set of factors at work in the recovery phase of the Great Depression may have been institutional and other changes that led to a permanent reduction in "normal" hours worked per person. Our model is designed to accommodate such factors using a device that is in the spirit of the analysis of Cole and Ohanian (2003). In particular, we do so by adopting a model specification which allows households' labor market power to fluctuate over time.

\subsection{Exogenous Monetary Policy Shocks in the Great Depression}

There is a general consensus that the initial phase of the contraction began with the slowdown in economic growth in the summer of 1929, just before the stock market crash. Many researchers follow Keynes's (1930, p. 196) assessment that that slowdown reflected the effects of high interest rates engineered by the Federal Reserve. Some argue that monetary policy shocks also played an important role in other phases of the Great Depression. In our analysis of the Great Depression we abstract from monetary policy shocks altogether. This subsection reviews our reasons for doing this.

Figure 1, panel F shows that real M1 was roughly constant during the initial phase of the contraction, 1929-1932 (and also more generally, from about 1926 to the end of 1932). In view of the substantial drop in output that occurred, this implies that M1 velocity fell. Models that have performed well with postwar U.S. data generally imply that an exogenous, contractionary monetary policy shock leads to a fall in real balances and a rise in velocity. ${ }^{16}$ This is not to say that monetary policy was not tight at all during this period. For example, the real value of the monetary base (not shown in Figure 1) did fall, although only by a small amount. ${ }^{17}$ Still, it seems unlikely that an exogenous contractionary shock to monetary policy was an important impulse for the Great Depression. To the extent that there was some tightness in monetary policy, it was relatively small, certainly by the historical standards of the time (see Romer 1990 for additional discussion).

The spike in the interest rate in late 1931 is sometimes explained as reflecting a contractionary response by the Federal Reserve to the British decision to abandon the gold standard. Since British monetary policy was not in any obvious way related to economic developments in the U.S., it is natural in an analysis of the U.S. Depression experience to

\footnotetext{
${ }^{16}$ See, for example, Christiano, Eichenbaum, and Evans (2003).

${ }^{17}$ In $1929 \mathrm{IV}$ the real monetary base was 5 percent lower than it was in 1928I. Also, Bernanke (2002) reports that the Fed's portfolio of government securities fell in the period before the crash.
} 
treat Britain's action as an exogenous shock to U.S. financial markets. But should it be treated as a shock to money supply or money demand? The continued robust growth in the real, per capita monetary base is not consistent with the money supply interpretation. In $1931 \mathrm{IV}$, the real monetary base stood 5 percent higher than it had in 1931III. Then, over the next two quarters the real, per capita monetary base grew at quarterly rates of 1 percent and 6 percent, respectively. This and other data suggest that the 1931 interest rate spike is better thought of as reflecting a shock to money demand. For example, during this period, the currency-to-deposit ratio began to rise, and bank reserves in 1931IV were 2 percent below their level in 1931III. These observations are consistent with the notion that there was a shift in preferences away from demand deposits. Clearly, this is one way to think of the bank runs occurring at this time. In addition, it is a way to think of the run on the dollar which was believed to have been triggered by the British decision on gold.

There are two other episodes that are often interpreted as reflecting the operation of monetary policy shocks. The first is the sharp increase in money growth in April to July of 1932, and the second is a sharp decrease in the period January to March 1933. These monetary actions are thought to be responsible for the "double dip" nature of the Great Depression. Although it is not evident in the data presented in Figure 1, data on manufacturing output show a dip in output in 1932, followed by a rise, and then another dip in 1933. ${ }^{18}$ This pattern closely follows the variations in money growth. In our analysis we interpret these as reflecting the interaction of nonmonetary policy shocks with the monetary authority's monetary policy rule.

Finally, there is the switch to a faster money growth rate following the U.S. departure from the gold standard in April of 1933 (see Figure 1, panel F). In our analysis we model monetary policy as a single regime, and so we abstract from the apparent change in regime that occurred in 1933. Incorporating a regime switch into the analysis would be a useful step, which we leave to future research. Addressing this properly requires taking a potentially controversial stand on the exact nature of the change in monetary policy, as well as on the nature of the public's perception of that change.

\subsection{The Sticky Wage Mechanism}

In our terminology, the sticky wage mechanism reflects two features. First, firms are assumed to always be on their labor demand schedule, which itself is not perturbed by shocks to aggregate spending. Second, nominal wages are sticky. ${ }^{19}$ As a result, the only way for a negative aggregate spending shock to reduce employment and output is for the shock to

\footnotetext{
${ }^{18}$ See, for example, Figure IV in Mills (1934).

${ }^{19}$ The two assumptions just described correspond to equations (1) and (2) of the model used by Bernanke and Carey (1996). They state that in using this model to analyze the Great Depression, they are following the lead of Eichengreen and Sachs (1985).
} 
drive the price level down and the real wage up. ${ }^{20}$ The problem is that there is no evidence, either in the U.S. time-series or in a cross-section of countries, that the contraction phase of the Great Depression is associated with a sharp rise in the real wage (for a discussion of the cross-section, see Cole and Ohanian 2003a.) These considerations lead us to emphasize model features which have been employed in analyses of postwar data, which allow spending shocks to shift the labor demand schedule. In models with these features, it is not necessary for the real wage to rise when a spending contraction reduces output. ${ }^{21}$

Panel L in Figure 1, displays the economy-wide real wage. Note that there is no evidence that it surges above trend as output and employment begin their plunge after 1929. Indeed, this measure of the real wage was actually low in 1932 and 1933, when the economy hit bottom. Aggregate data for the manufacturing sector do provide some evidence of a rise in the real wage after 1929. For example, according to Cole and Ohanian (1999, Table 11) the manufacturing wage compiled by Hanes (1996), converted to real terms using the GNP deflator, is about 5 percent above trend during the period 1930-1932. ${ }^{22}$ However, the work of Bresnahan and Raff (1991), Lebergott (1989), and Margo (1993) suggests that this rise may, for compositional reasons, overstate what happened to the typical manufacturing worker's real wage. In particular, Bresnahan and Raff (1991) and Lebergott (1989) report evidence that low-wage jobs were terminated first, injecting an upward bias in standard industry-wide average estimates. Margo (1993, p. 44) concludes that eliminating the bias due to compositional factors like this ' ...would produce an aggregate decline in nominal wages between 1929 and 1932 as much as 48 percent larger than that measured by the Bureau of Labor Statistics.' If the bias were only a little more than one-tenth of Margo's estimate, then the rise in the measured manufacturing real wage turns into an outright fall for the typical worker. ${ }^{23}$

\footnotetext{
${ }^{20}$ Although the sticky wage mechanism is often attributed to Keynes, he himself changed his mind about the relationship between real wages and output after the famous critique by Dunlop and Tarshis. At that time, Keynes blamed Alfred Marshall for the idea that real wages and output necessarily move in opposite directions. He referred to Marshall's view as a "dogma" which was, in fact, not consistent with the data. Upon examining data from 1880 and after, Keynes concluded that the negative relationship between real wages and output held only in the first six years of this period, "the formative period in Marshall's thought in this matter....but has never once held good in the fifty years since [Marshall] crystallized it!" (Keynes 1939, p.38).

${ }^{21}$ Using postwar U.S. data, Christiano, Eichenbaum, and Evans (2003) present evidence based on minimal model assumptions (using vector autoregression techniques) to argue that a contractionary shock to monetary policy produces a small drop in the real wage. They estimate a dynamic, stochastic, general equilibrium model that is consistent with this finding.

${ }^{22}$ Cole and Ohanian assume a trend growth rate of 1.9 percent per year for the manufacturing real wage.

${ }^{23}$ One way to make Margo's estimate concrete is as follows. According to Cole and Ohanian (1999, Table 11), the detrended real wage in 1932 stood at 105, with its 1929 value equal to 100. Margo's calculation suggests that if composition biases are eliminated from the data, then if the typical wage earner's wage in 1929 were 100 , that worker earned only $0.52 \times 105=54.6$ in 1932 .

Unlike the Bureau of Labor Statistics data that Margo is referring to, Hanes' (1996) data attempt to correct for some sources of composition bias. The exact magnitude of the composition bias is controversial,
} 
As emphasized by Bordo, Erceg, and Evans (2001), there is another issue that must be addressed before one can draw definite conclusions from the behavior of manufacturing real wages. Most of the analyses cited in the previous paragraph convert the nominal manufacturing wage to a real wage using an aggregate measure of prices. However, the conventional theory pertains not to this, but to the real wage measured in terms of the price of the firm's product. So, it is important to consider the behavior of the manufacturing wage in relation to some measure of the manufacturing price level. According to Mills (1934, Table 5), the price index of manufactured goods was 91, 78, 70, and 72 in the years 1930-1933, with the price normalized at 100 in 1929. The measure of the GNP deflator used by Cole and Ohanian (1999, Table 8) is 97, 88, 78, and 77 for the same years, and with the same normalization. Evidently, with the Mills estimate of manufacturing prices, the manufacturing real wage is higher by only 5-10 percent. This increase is still substantially smaller than Margo's estimate of the magnitude of the composition bias. $^{24}$

The disaggregated manufacturing data also raise questions about the sticky wage mechanism. Under the mechanism, a drop in output is fundamentally driven by a fall in the price level, so that those sectors where price falls the most should have experienced the biggest output decline. Mills (1934, Figure V) presents evidence that conflicts with this prediction. He shows that in 1932-1933, production in durable and nondurable manufacturing was about 76 and 31 percent, respectively, below their 1929 levels. The magnitude of the associated price declines was the reverse of what the sticky wage mechanism predicts. Mills reports that the price of durables fell only about 22 percent, while the price of nondurables fell about 65 percent.

The U.S. time-series data on the recovery phase of the Great Depression also pose a problem for the sticky wage mechanism. Note from Figure 1, panel L, that there is no evidence of a surge down in the real wage, as employment begins to recover in 1934-1936.

In sum, it does not look as though the shock or shocks that are responsible for the U.S. Great Depression operated through the sticky wage mechanism. There just does not seem to be a tight negative relationship between the real wage one the one hand, and output and employment on the other. Accordingly, we adopt a model environment with the property that variables other than just employment and the real wage enter the labor demand curve. These variables include capacity utilization and variable markups, as well as the interest rate. The latter enters because our model takes into account the fact that firms must borrow working-capital to finance their variable costs. In our model, markups vary because of with at least one author (Dighe 1997) claiming it is negligible.

${ }^{24}$ Sometimes, the wholesale price index is used to deflate the manufacturing real wage (see Bernanke and Carey 1996, and Bordo, Erceg, and Evans 2001.) However, as emphasized by Mills (1934, table 2), the prices of manufactured goods rose substantially relative to wholesale prices. So, deflating nominal manufacturing wages using the wholesale price index overstates the real cost of labor to manufacturing firms. 
fluctuations in the monopoly power of firms, as well as because of frictions in price setting.

Incorporating variable capital utilization into an analysis of the Great Depression is quite natural. Bresnahan and Raff (1991) show that about 30 percent of the reduction in jobs in the automobile industry was associated with plant closing, i.e., idle plant and equipment. In his classic analysis of total factor productivity, Solow (1957) assumes that the rate of capital utilization is the same as the rate of utilization of the labor force, and so he measures capital utilization by 1 minus the unemployment rate. This number, of course, falls dramatically during the Great Depression. Variations in the markup are also natural to consider in view of the many legislative and other changes in the 1930s, affecting the degree of competition among firms. ${ }^{25}$

It has long been recognized that there is a simple alternative way to reconcile the sticky wage mechanism with an absence of correlation between the real wage and output. That is to assume that there are exogenous shocks to labor supply, i.e., technology shocks. ${ }^{26}$ As Bordo, Erceg, and Evans (2001) note, the fact that the real wage did not surge above trend in 19301931 could be reconciled with the sticky wage mechanism, if we assume there was a negative shock to technology at the time. Nevertheless, we are skeptical that technology shocks played an important role during the Great Depression. Analysts have generally concluded that technological change continued in the 1930s at the same or higher rate than in the 1920s. For example, Field (2001) concludes, "In spite of tremendous losses due to underutilized labor and capital, the 1930s were, paradoxically, also an extraordinarily fertile period from the standpoint of technical change, one in which a disproportionately large number of key product and process innovations took place." (See also, Field 2003.) Other researchers reached similar conclusions. ${ }^{27}$ For example, Solow (1957, p. 316) concludes from his total factor productivity measurements, that "...there is some evidence that technical change (broadly interpreted) may have accelerated after 1929." Other researchers who similarly concluded that the pace of technical change continued without interruption after 1929 include Mills (1934; see especially his Table 4) and Bliss (1934; see especially his Table III). Despite this skepticism, we do include technology shocks into our model. We will let the data determine whether they are important.

\footnotetext{
${ }^{25}$ For an excellent review, see Kennedy (1999).

${ }^{26}$ This approach has been advocated in Cole and Ohanian (1999, 2003a).

${ }^{27}$ An example is Bliss (1934, p. 6): "A period of depression is conducive to improvement in labor productivity. Faced with narrowing profit margins, businessmen strive for cheaper, more direct, more efficient methods of production. With overhead costs per unit increasing special effort is made to reduce direct costs per unit, largely by laying off the less efficient workers and by improving management." Commenting on his estimates that the productivity of employed labor exhibited strong growth in the period 1929-1932, Bliss (1934, p. 7) remarks, "Taken together, these estimates indicate an increase in output per man-hour of approximately 25 percent in four years, an amazing advance indeed." Mills attributed some, but not all, of the advance in productivity to temporary factors.
} 


\subsection{Other Variables and Mechanisms}

There are several variables that exhibit dramatic fluctuations during the Great Depression. One suspects that they point to important sources of shocks or sources of propagation for other shocks. For example, Panel H in Figure 1 displays the Dow Jones Industrial Average (DOW), deflated by the GNP deflator. Note how dramatically the stock market fell from 1929 to 1933. The magnitude of the drop is similar to that of investment. It is therefore not surprising that several researchers have argued that financial asset markets must be part of any explanation of the Great Depression..$^{28}$ We integrate financial markets into our environment using the modeling strategy of Bernanke, Gertler, and Gilchrist (1999).

Friedman and Schwartz (1963) draw attention to the very large movements in the currencyto-deposit ratio and the reserves-to-deposit ratio (see Panels I and J, respectively). We follow Friedman and Schwartz (1963) and others in pursuing the idea that these movements have much to do with the dynamics of the Great Depression. As discussed above, to some extent they reflect the consequences of the bank runs in the 1930s. We do not pursue a "deep" theory of bank runs in this paper. Instead, we model the movements in the currency-to-deposit ratio and in the reserves-to-deposit ratio as reflecting various exogenous shocks to money demand.

Discussions of risk play a role in analyses of the Great Depression (see, for example, Romer 1990.) According to evidence in Harrison and Weder (2003), concerns about risk were probably not an important factor at the very beginning of the depression, in late 1929 or early 1930. For example, the premium on Baa over Aaa corporate bonds does not exhibit a sharp rise until the first wave of bank runs, in late 1930 (see Figure 1, panel K). However, the premium is so much larger in the mid-1930s than it was throughout the 1920s, that it may have played a role in prolonging the Great Depression, perhaps by keeping investment low. ${ }^{29}$ Our way of introducing financial asset markets into the analysis allows for increased risk to affect investment.

In the previous subsection we discussed how the behavior of the real wage leads us to incorporate mechanisms that shift labor demand. A similar issue arises in the case of labor supply. The data suggest finding mechanisms that shift labor supply or, put households "off their labor supply schedule." The question that must be confronted from the point of view of labor supply is why did household labor effort fall so sharply, even though the real wage continued on its trend set in the 1920s? Of course, this is a classic puzzle that

\footnotetext{
${ }^{28}$ See, for example, Bernanke (2002), Cecchetti (1998), Fisher (1933), Mishkin (1978), Romer (1993), and Temin (1976).

${ }^{29} \mathrm{~A}$ related possibility is raised by the analysis in Bernanke (1983). This suggests that the rise in the risk premium and the fall in investment may both have been a consequence of the damage done to the banking system by the banking panics. See Gertler (2001) for a more extensive discussion of the premium in Baa over Aaa bonds. He expresses skepticism that the premium reflects risk alone.
} 
confronts equilibrium analyses of business cycles generally. Hall (1997) gave the puzzle a quantitative expression by showing that an equilibrium approach to business fluctuations leads to the implication that households are hit by a shock that resembles an increased preference for leisure in a recession (see also Ingram, Kocherlakota, and Savin 1997 and Parkin 1988.) Applying the approach of Hall, who works with postwar data, Chari, Kehoe, and McGrattan (2002) and Mulligan (2002) find that the early phase of the Great Depression is also characterized by an upward shift in the preference for leisure. This shift has various interpretations. For example, it can be interpreted as reflecting an increase in the labor market power of households, which leads them to restrict the supply of their labor services. Following Gali, Gertler and Lopez-Salido (2002), it can also reflect that households are, in effect, "off their labor supply schedules," because of the presence of sticky wages. These considerations lead us to incorporate household labor market power and frictions in wage setting into our model.

An unusual feature of the Great Depression is that, in the estimation of Chari, Kehoe, and McGrattan (2002) and Mulligan (2002), the shock that resembles a preference for leisure does not fall again in the recovery phase, as Hall shows it does in postwar recessions. This is a manifestation of the fact that employment rose so little (see Panel D, Figure 1) in the recovery phase, even though real wage continued strong. The standard explanation is that this reflects the effects of New Deal programs designed to prop up the real wage. ${ }^{30}$ This is another reason that our model specification allows for fluctuations in household labor market power.

The preceding considerations suggest to us that a model that captures the key forces in play during the Great Depression must have several features:

- It must capture the determinants of investment behavior. To be interesting, these determinants should include a possible role for changes in the value of financial assets and in perceptions of risk.

- The real side of the economy should incorporate disturbances to the labor demand schedule, including time-varying markups, capacity utilization, and other variables.

- The model should include frictions in the setting of wages and should allow for fluctuations in the monopoly power of households.

- The model should incorporate a banking system which is rich enough that one can consider the interactions between real economic activity and various monetary aggregates such as currency, bank reserves, and demand deposits.

\footnotetext{
${ }^{30}$ See Bordo, Erceg and Evans (2000), Cole and Ohanian (2003), and Temin (1989, 1990).
} 
A model that integrates all these features in a coherent way would constitute a credible laboratory for assessing whether an improved monetary policy might have ameliorated the Great Depression. In this paper we take a step towards constructing such a model by combining the models of Christiano, Eichenbaum, and Evans (2003), BGG and Chari, Christiano, and Eichenbaum (1995).

\section{The Model Economy}

In this section we describe our model economy and display the optimization problems solved by intermediate- and final-goods firms, entrepreneurs, producers of physical capital, banks, and households. Final output is produced using the usual Dixit-Stiglitz aggregator of intermediate inputs. Intermediate inputs are produced by monopolists, who set prices using a variant of the approach described in Calvo (1983). These firms hire the services of capital and labor, and we assume that a fraction of these costs ("working-capital") must be financed in advance through banks. Labor services are an aggregate of specialized services, each of which is supplied by a monopolist household. Households set wages subject to the type of frictions modeled in Calvo (1983). ${ }^{31}$

Capital services are supplied by entrepreneurs, who own the physical stock of capital and choose how intensely to utilize it. Our model of the entrepreneurs closely follows BGG. In particular, the entrepreneurs have their own financial wealth, but not enough to finance the full amount of capital they own. Part of what they own must be financed by bank loans. Lending to entrepreneurs involves agency costs, because the capital purchased by entrepreneurs is subject to an idiosyncratic productivity shock. The only way the lender can observe this shock is by expending valuable resources in monitoring, so that it is efficient to adopt a lending contract that economizes on monitoring costs. We assume the borrower receives a standard debt contract, which specifies a loan amount and an amount to be repaid in the event the borrower is solvent. A borrower who cannot repay is said to be bankrupt, and turns over everything to the lender, after being monitored. The rate of return paid by solvent entrepreneurs must be high enough to cover the cost of funds to the bank, as well as monitoring costs net of whatever the bank can salvage from bankrupt entrepreneurs. The excess of this rate of return over the cost of funds to the bank is the external finance premium. Being an endogenous variable, the magnitude of the premium is a function of all the shocks in the model. Among these, one that plays a notable role is the variance of the idiosyncratic shock to entrepreneurial productivity. We assume that this is the realization of a stochastic process. The bank obtains the funds that it lends to entrepreneurs by issuing time deposit

\footnotetext{
${ }^{31}$ This aspect of the model follows Christiano, Eichenbaum, and Evans (2003), who in turn build on Erceg, Henderson, and Levin (2000).
} 
contracts to households. Because these contracts pay a nominal non-state contingent return, the model can at least qualitatively account for the debt deflation phenomenon emphasized by Fisher (1933), as discussed in the introduction.

As in most models of credit market frictions, there is a tendency for entrepreneurs to "grow" away from the financial constraint by accumulating enough wealth. To ensure that the credit market restrictions remain binding, we follow BGG in assuming that a randomly selected fraction of entrepreneurial financial wealth is destroyed exogenously each period. The fraction is itself subject to stochastic fluctuations. A jump in the rate of destruction of entrepreneurial financial wealth resembles in some respects the bursting of a stock market bubble.

The frictions in the entrepreneurial sector have the effect of amplifying the output effects of certain types of shocks. This is the "accelerator effect" emphasized by BGG. To see this, it is useful to understand the evolution of entrepreneurial net worth. In a given period, net worth is equal to what it was in the previous period, plus earnings from renting capital, plus the current market value of the stock of capital, minus obligations to banks arising from past loans. As a result, a shock that reduces the rental rate of capital or its market value produces a fall in investment by reducing entrepreneurial net worth. Similarly, as noted above, a shock that reduces the aggregate price level reduces net worth by raising the real value of entrepreneurial debt payments. Thus, the financial frictions amplify the effects of shocks that reduce output and either the rental rate of capital or the aggregate price level.

In addition to amplifying the effects of certain shocks originating outside the entrepreneurial sector, the model also posits new shocks that originate within the sector itself, and which can be useful for understanding macroeconomic dynamics. A "bursting stock market bubble" has a depressive effect on investment because the destruction of entrepreneurial wealth inhibits the ability of entrepreneurs to buy capital. Also, an increase in the riskiness of entrepreneurs leads to a fall in investment because the rise in interest payments to banks cuts into their net worth.

The actual production of physical capital is carried out by capital-producing firms, which combine old capital and investment goods to produce new, installed, capital. The production of new capital involves adjustment costs, so that the price of capital increases with the amount of capital sold. There are no financing problems or agency costs in the capitalproducing sector. Inputs in this sector are financed out of contemporaneous receipts from production.

All financial intermediation activities occur in a representative, competitive "bank." This bank is involved in two separable activities. In one it makes loans to entrepreneurs, which are financed by issuing time deposits to households. In the other, it makes working-capital loans to intermediate-goods producers, which are financed by issuing demand deposits to 
households. Total demand deposits are composed of these household demand deposits, plus firm demand deposits created automatically when a bank extends working-capital loans. Banks are required to set aside a fraction of total demand deposit liabilities in the form of reserves. Associated with demand deposits is a flow of transactions services. The bank produces these using a neoclassical production function involving labor, capital, and reserves in excess of what is required. The presence of excess reserves in the production function is meant to capture, in a reduced-form way, the liquidity needs that arise in a banking system where banks clear demand deposit checks among each other. The bank's assets and liabilities match in their maturity structure and are risk free.

We now discuss the different sectors of the model in more detail.

\subsection{Firms}

A final good, $Y_{t}$, is produced by a perfectly competitive, representative firm. It does so by combining a continuum of intermediate goods, indexed by $j \in[0,1]$, using the technology

$$
Y_{t}=\left[\int_{0}^{1} Y_{j t}^{\frac{1}{\lambda_{f, t}}} d j\right]^{\lambda_{f, t}} .
$$

Here, $1 \leq \lambda_{f, t}<\infty$, and $Y_{j t}$ denotes the time- $t$ input of intermediate good $j$. Let $P_{t}$ and $P_{j t}$ denote the time- $t$ price of the consumption good and intermediate good $j$, respectively. The firm chooses $Y_{j t}$ and $Y_{t}$ to maximize profits, taking prices as given. The parameter, $\lambda_{f, t}$, is a realization of a stochastic process, to be discussed below. Because a higher value of $\lambda_{f, t}$ implies that intermediate goods are less substitutable for each other, intermediate-goods firms have more market power, the higher is $\lambda_{f, t}$.

The $j^{\text {th }}$ intermediate good is produced by a monopolist who sets its price, $P_{j t}$, subject to Calvo-style frictions that will be described shortly. The intermediate-goods producer is required to satisfy whatever demand materializes at its posted price. Given quantity demanded, the intermediate-goods producer chooses inputs to minimize costs. The production function of the $j^{\text {th }}$ intermediate good firm is:

$$
Y_{j t}=\left\{\begin{array}{ll}
\epsilon_{t} K_{j t}^{\alpha}\left(z_{t} l_{j t}\right)^{1-\alpha}-\Phi z_{t} & \text { if } \epsilon_{t} K_{j t}^{\alpha}\left(z_{t} l_{j t}\right)^{1-\alpha}>\Phi z_{t} \\
0, & \text { otherwise }
\end{array}, 0<\alpha<1,\right.
$$

where $\Phi$ is a fixed cost and $K_{j t}$ and $l_{j t}$ denote the services of capital and labor. The variable, $z_{t}$, is the trend growth rate in technology, with

$$
z_{t}=\mu_{z} z_{t-1}
$$

The variable, $\epsilon_{t}$, is a stationary shock to technology. The time-series representation of $\epsilon_{t}$ is discussed below. 
Intermediate-goods firms are competitive in factor markets, where they confront a rental rate, $\operatorname{Pr}_{t}^{k}$, on capital services and a wage rate, $W_{t}$, on labor services. Each of these is expressed in units of money. Also, each firm must finance a fraction, $\psi_{k}$, of its capital services expenses in advance. Similarly, it must finance a fraction, $\psi_{l}$, of its labor services in advance. The interest rate it faces for this type of working-capital loan is $R_{t}$.

We adopt the variant of Calvo pricing proposed in Christiano, Eichenbaum, and Evans (2003). In each period, $t$, a fraction of intermediate-goods firms, $1-\xi_{p}$, can reoptimize its price. The complementary fraction must set its price equal to what it was in time- $t-1$, scaled up by the inflation rate from $t-2$ to $t-1, \pi_{t-1}$.

\subsection{Capital Producers}

There is a large, fixed number of identical capital producers. They are competitive and take prices as given. They are owned by households, who receive any profits or losses in the form of lump-sum transfers. Capital producers purchase previously installed capital, $x$, and investment goods, $I_{t}$, and combine these to produce new installed capital. Investment goods are purchased in the goods market at price $P_{t}$. The time- $t$ price of previously installed capital is denoted by $Q_{\bar{K}^{\prime}, t}$. New capital, $x^{\prime}$, is produced using the following technology:

$$
x^{\prime}=x+F\left(I_{t}, I_{t-1}\right)
$$

The presence of lagged investment reflects that there are costs to changing the flow of investment. Since the marginal rate of transformation from previously installed capital to new capital is unity, the price of new capital is also $Q_{\bar{K}^{\prime}, t}$. The firm's time- $t$ profits are:

$$
\Pi_{t}^{k}=Q_{\bar{K}^{\prime}, t}\left[x+F\left(I_{t}, I_{t-1}\right)\right]-Q_{\bar{K}^{\prime}, t} x-P_{t} I_{t} .
$$

The capital producer's problem is dynamic because of the adjustment costs. It solves:

$$
\max _{\left\{I_{t+j}, x_{t+j}\right\}} E_{t}\left\{\sum_{j=0}^{\infty} \beta^{j} \lambda_{t+j} \Pi_{t+j}^{k}\right\},
$$

where $E_{t}$ is the expectation conditional on the time- $t$ information set, which includes all time- $t$ shocks.

Let $\bar{K}_{t+j}$ denote the beginning-of-time $t+j$ physical stock of capital in the economy, and let $\delta$ denote its rate of depreciation. From the capital producer's problem it is evident that any value of $x_{t+j}$ whatsoever is profit maximizing. Thus, setting $x_{t+j}=(1-\delta) \bar{K}_{t+j}$ is consistent with profit maximization and market clearing. The stock of capital evolves as follows

$$
\bar{K}_{t+1}=(1-\delta) \bar{K}_{t}+F\left(I_{t}, I_{t-1}\right)
$$




\subsection{Entrepreneurs}

The details are presented in BGG, so our discussion of the entrepreneurs can be brief. Because of linearity assumptions, aggregate decisions can be represented as functions of aggregates only. This greatly simplifies the computational analysis. In addition, we exploit this property of the model in the following presentation. At the end of time-t, the state of an entrepreneur is summarized by his net worth, $N_{t+1}$ (see Figure 2). The net worth, in combination with a bank loan, is used to purchase the time- $t$ stock of installed capital, $\bar{K}_{t+1}$. After the purchase, each entrepreneur draws an idiosyncratic shock which changes $\bar{K}_{t+1}$ to $\omega \bar{K}_{t+1}$. Here, $\omega$ is a unit mean, lognormal random variable distributed independently over time and across entrepreneurs. The standard-deviation of $\log (\omega)$ at date $t, \sigma_{t}$, is itself a stochastic process. Although the realization of $\omega$ is not known at the time the entrepreneur makes its capital decision, the value of $\sigma_{t}$ is known. The properties of this random variable are described below. In a slight abuse of previous notation, we write the distribution function of $\omega$ as $F_{t}$ :

$$
\operatorname{Pr}[\omega \leq x]=F_{t}(x) .
$$

After observing the time- $t+1$ aggregate shocks, the entrepreneur decides on the time- $t+1$ level of capital utilization, $u_{t+1}$, and then rents out capital services, $K_{t+1}=u_{t+1} \bar{K}_{t+1}$. High capital utilization gives rise to high costs in terms of goods, according to the following convex function:

$$
a\left(u_{t+1}\right) \omega \bar{K}_{t+1}, a^{\prime}, a^{\prime \prime}>0 .
$$

The entrepreneur chooses $u_{t+1}$ to solve:

$$
\max _{u_{t+1}}\left[u_{t+1} r_{t+1}^{k}-a\left(u_{t+1}\right)\right] \omega \bar{K}_{t+1} P_{t+1} .
$$

For an entrepreneur who receives idiosyncratic productivity shock, $\omega$, the rate of return on capital purchased in time- $t$ is:

$$
\begin{aligned}
1+R_{t+1}^{k, \omega} & =\left\{\frac{\left[u_{t+1} r_{t+1}^{k}-a\left(u_{t+1}\right)\right]+(1-\delta) q_{t+1}}{q_{t}} \frac{P_{t+1}}{P_{t}}\right\} \omega \\
& =\left(1+R_{t+1}^{k}\right) \omega,
\end{aligned}
$$

say, where $q_{t}$ is Tobin's $q$ :

$$
q_{t}=\frac{Q_{\bar{K}^{\prime}, t}}{P_{t}}
$$

Here, $R_{t+1}^{k}$ is the average rate of return on capital across all entrepreneurs.

We suppose that $N_{t+1}<Q_{\bar{K}^{\prime}, t} \bar{K}_{t+1}$, where $Q_{\bar{K}^{\prime}, t} \bar{K}_{t+1}$ is the cost of the capital purchased by entrepreneurs with net worth, $N_{t+1}$. Since the entrepreneur does not have enough net worth to pay for his capital, he must borrow the rest:

$$
B_{t+1}=Q_{\bar{K}^{\prime}, t} \bar{K}_{t+1}-N_{t+1} \geq 0
$$


We suppose that the entrepreneur receives a standard debt contract from the bank. This specifies a loan amount, $B_{t+1}$, and a gross rate of interest, $Z_{t+1}$, to be paid if $\omega$ is high enough. Entrepreneurs who draw $\omega$ below a cutoff level, $\bar{\omega}_{t+1}$, cannot pay this interest rate and must give everything they have to the bank. The cutoff is defined as follows:

$$
\bar{\omega}_{t+1}\left(1+R_{t+1}^{k}\right) Q_{\bar{K}^{\prime}, t} \bar{K}_{t+1}=Z_{t+1} B_{t+1}
$$

The bank finances its time- $t$ loans to entrepreneurs, $B_{t+1}$, by borrowing from households. We assume the bank pays households a nominal rate of return, $R_{t+1}^{e}$, that is not contingent upon the realization of $t+1$ shocks. As noted above, this is the assumption that allows our model to articulate Fisher's (1933) "debt deflation" hypothesis. With this assumption, we depart from BGG, who assume that the return received by the household is noncontingent in real terms. We suspect that our specification is easier to reconcile with competition in banking than BGG's. In an environment like ours, which is dominated by shocks which drive consumption and the price level in the same direction, a nominally non-state contingent return to households has the effect of shifting business cycle risk from households to entrepreneurs. This is efficient and an outcome of competition when, as is the case in our model, entrepreneurs are risk-neutral and households are risk-averse. We have not explored whether the distribution of risk associated with our market arrangements is optimal or even close to optimal. We leave this for future work.

In the usual way, the parameters of the entrepreneur's debt contract are chosen to maximize entrepreneurial utility, subject to zero profits in each state of nature for the bank and to the requirement that $R_{t+1}^{e}$ be uncontingent upon time- $t+1$ shocks. This implies that $Z_{t+1}$ and $\bar{\omega}_{t+1}$ are both functions of time- $t+1$ aggregate shocks. A feature of the loan contract is that

$$
\frac{Q_{\bar{K}^{\prime}, t} \bar{K}_{t+1}}{N_{t+1}}
$$

is independent of the entrepreneur's net worth. Aggregation in the model is trivial because of the fact that borrowing and capital purchases are proportional to an entrepreneur's level of net worth.

The law of motion for aggregate $N_{t+1}$ is

$$
\begin{aligned}
N_{t+1}= & \gamma_{t}\left\{\left(1+R_{t}^{k}\right) Q_{\bar{K}^{\prime}, t-1} \bar{K}_{t}\right. \\
& \left.-\left[1+R_{t}^{e}+\frac{\mu \int_{0}^{\bar{\omega}_{t}} \omega d F_{t-1}(\omega)\left(1+R_{t}^{k}\right) Q_{\bar{K}^{\prime}, t-1} \bar{K}_{t}}{Q_{\bar{K}^{\prime}, t-1} \bar{K}_{t}-\bar{N}_{t}}\right]\left(Q_{\bar{K}^{\prime}, t-1} \bar{K}_{t}-N_{t}\right)\right\}+W_{t}^{e} .
\end{aligned}
$$

Here, $\gamma_{t}$ reflects that at the end of the period, after the entrepreneur has sold his capital, paid off his debt and earned rental income, he exits the economy with probability $1-\gamma_{t}$. At the same time a fraction, $1-\gamma_{t}$, of entrepreneurs enters. The fraction, $\gamma_{t}$, who survive and 
the fraction, $1-\gamma_{t}$, who enter both receive a transfer, $W_{t}^{e}$. Without this transfer, entering entrepreneurs would have no net worth, and so they would not be able to buy any capital, ever. Also, among the $\gamma_{t}$ entrepreneurs who survive there are some who are bankrupt and have no net worth. Without a transfer they, too, would never again be able to buy capital.

The first term in braces in (5) represents the revenues from selling capital, plus the rental income of capital, net of the costs of utilization, averaged across all entrepreneurs. The object in square brackets is the average gross rate of return paid by all entrepreneurs on time- $t-1$ loans, $\left(Q_{\bar{K}^{\prime}, t-1} \bar{K}_{t}-\bar{N}_{t}\right)$. This aggregates over payments received from entrepreneurs who are bankrupt, as well as those who are not. The $\left(1-\gamma_{t}\right)$ entrepreneurs who are selected for death, consume:

$$
P_{t} C_{t}^{e}=\Theta\left(1-\gamma_{t}\right) V_{t}
$$

where $V_{t}$ is their net worth. In practice, we set $\Theta=0$.

Following BGG, we define the "external finance premium" as the term involving $\mu$ in square brackets in (5). It is the difference between the "internal cost of funds," $1+R_{t}^{e}$, and the expected cost of borrowing to an entrepreneur. The reason for calling $1+R_{t}^{e}$ the internal cost of funds is that, in principle, one could imagine the entrepreneur using his net worth to acquire time deposits, instead of physical capital (the model does not formally allow this). In this sense, the opportunity cost of the entrepreneur's own funds is $1+R_{t}^{e}$.

\subsection{Banks}

We assume that there is a continuum of identical, competitive banks. Banks issue deposit liabilities, $D_{t}^{h}$, to households. Part of this is set aside in the form of reserves, and the other is used to finance working-capital loans. Working capital loans are extended to firms in the form of demand deposits, $D_{t}^{f}$. The management of total deposit liabilities, $D_{t}$, requires capital services, $K_{t}^{b}$, labor, $l_{t}^{b}$, and excess reserves, $E_{t}^{r}$, according to the following technology:

$$
\frac{D_{t}}{P_{t}} \leq x^{b}\left(\left(K_{t}^{b}\right)^{\alpha}\left(z_{t} t_{t}^{b}\right)^{1-\alpha}\right)^{\xi_{t}}\left(\frac{E_{t}^{r}}{P_{t}}\right)^{1-\xi_{t}}
$$

where

$$
D_{t}=D_{t}^{h}+D_{t}^{f}
$$

In (6), $0<\alpha<1$, and $x^{b}$ is a constant. In addition, $\xi_{t} \in(0,1)$ is a shock to the relative value of excess reserves, $E_{t}^{r}$. The stochastic process governing this shock will be discussed later. As noted above, we include excess reserves as an input to the production of demand deposit services as a reduced-form way to capture the precautionary motive of a bank concerned about the possibility of unexpected withdrawals.

Demand deposits pay interest, $R_{a t}$. We denote the interest rate on working-capital loans, net of interest on the associated demand deposits, by $R_{t}$. Since firms receive interest on 
the deposits associated with their loans, the gross interest payment on loans is $R_{t}+R_{a t}$. The maturity of time- $t$ working-capital loans and the associated demand deposit liabilities coincide. A time- $t$ working-capital loan is extended prior to production in time- $t$ and pays off after production in time- $t$. The household deposits funds into the bank before production in time- $t$ and liquidates the deposit after production occurs.

Turning to time deposits, we assume the bank faces no costs for maintaining this type of liability. The maturity structure of time deposits coincides with that of the standard debt contract offered to entrepreneurs. Thus, time deposits and entrepreneurial loans are created at the end of a given period's goods market. This is when newly constructed capital is sold by capital producers to entrepreneurs. Time deposits and entrepreneurial loans pay off near the end of next period's goods market, when the entrepreneurs sell their undepreciated capital to capital producers (who use it as raw material in the production of new capital). The timing of the payoff on the entrepreneurial loan coincides with the timing of the payoff on time deposits. The maturity structure of the two types of bank liabilities can be seen in Figure 3.

The entrepreneur/time-deposit side and the working-capital/demand-deposit side of the bank can be considered separately. The former was considered in the previous subsection. The profit maximization problem arising from the latter is:

$$
\max _{A_{t}, S_{t}^{w}, K_{t}^{b}, l_{t}^{b}}\left\{R_{t} S_{t}^{w}-R_{a t} D_{t}^{h}-R_{t}^{b} F_{t}-\left[\left(1+\psi_{k} R_{t}\right) P_{t} r_{t}^{k} K_{t}^{b}\right]-\left[\left(1+\psi_{l} R_{t}\right) W_{t} l_{t}^{b}\right]\right\}
$$

subject to (6), where

$$
E_{t}^{r}=D_{t}^{h}+F_{t}-\tau\left(D_{t}^{h}+S_{t}^{w}\right)
$$

Here, $K_{t}^{b}$ and $l_{t}^{b}$ denote capital and labor services hired by the banking sector. Note our assumption that a fraction of these must be paid in advance with working-capital. Also, $S_{t}^{w}$ represents working-capital loans, so that $S_{t}^{w}=D_{t}^{f}$. The term, $F_{t}$, denotes loans of reserves between banks. Since banks are all identical, equilibrium requires $F_{t}=0$. Still, the presence of $F_{t}$ allows us to define the interest rate on interbank loans, $R_{t}^{b}$.

The clearing condition in the market for working-capital loans is:

$$
S_{t}^{w}=\psi_{l} W_{t} l_{t}+\psi_{k} P_{t} r_{t}^{k} K_{t}
$$

where $l_{t}$ and $K_{t}$ denote economy-wide aggregate labor and capital services. Here, $S_{t}^{w}$ represents the supply of loans, and the terms on the right of the equality in (7) represent total demand. 


\subsection{Households}

There is a continuum of households, each indexed by $j \in(0,1)$. Households consume; decide how to allocate their wealth between demand deposits, currency, and time deposits; and supply a specialized labor input, $h_{j t}$. Since the household is a monopoly supplier of its labor service, it can set its wage rate. We assume that it faces Calvo (1983)-type frictions in the setting of this wage. Since this uncertainty is idiosyncratic in nature, different households work different amounts and earn different wage rates. So, in principle, they are also heterogeneous with respect to consumption and asset holdings. A straightforward extension of the arguments in Erceg, Henderson, and Levin (2000) establishes that the existence of statecontingent securities ensures that in equilibrium households are homogeneous with respect to consumption and asset holdings. We assume, though we do not discuss, the presence of these securities. Given these considerations, our notation assumes that households are homogeneous with respect to consumption and asset holdings, and heterogeneous with respect to the wage rate that they earn and the hours they worked.

The preferences of the $j^{\text {th }}$ household are given by:

$$
E_{t} \sum_{l=0}^{\infty} \beta^{l-t}\left\{\log \left(C_{t+l}-b C_{t+l-1}\right)-\zeta_{t+l} \frac{\psi_{L}}{2} h_{j, t+l}^{2}-v_{t} \frac{\left[\left(\frac{P_{t+l} C_{t+l}}{M_{t+l}}\right)^{\theta_{t+l}}\left(\frac{P_{t+l} C_{t+l}}{D_{t+l}^{h}}\right)^{1-\theta_{t+l}}\right]^{1-\sigma_{q}}}{1-\sigma_{q}}\right\},
$$

where $C_{t}$ denotes time- $t$ consumption; $v_{t}$ is a unit-mean liquidity preference shock; and $\zeta_{t}$ is a shock with mean unity to the preference for leisure. This shock is isomorphic to a shock to the household's degree of monopoly power in the supply of $h_{j t}$. When $b>0$, (8) allows for habit formation in consumption. ${ }^{32}$ The term in square brackets captures the notion that currency, $M_{t}$, and demand deposits, $D_{t}^{h}$, contribute to utility by facilitating transactions. It is because $v_{t}$ affects the magnitude of these non-pecuniary liquidity services that we refer to it as a liquidity preference shock.

We now discuss the household's time- $t$ sources and uses of funds. At the beginning of the period, the household is in possession of the economy's stock of high-powered money, $M_{t}^{b}$, which it splits into currency, $M_{t}$, and deposits with the bank, $A_{t}$, subject to the following liquidity constraint:

$$
M_{t}^{b} \geq M_{t}+A_{t}
$$

The central bank credits the household's bank deposit, $D_{t}^{h}$, with $X_{t}$ units of high-powered

\footnotetext{
${ }^{32}$ Various authors, such as Fuhrer (2000), McCallum and Nelson (1999), and Christiano, Eichenbaum, and Evans (2003), have argued that $b>0$ is important for understanding the monetary transmission mechanism in the postwar period. In addition, habit formation is useful for understanding other aspects of the economy, including the size of the premium on equity (see, for example, Boldrin, Christiano and Fisher 2001.)
} 
money, so that

$$
D_{t}^{h}=A_{t}+X_{t}
$$

As already mentioned, the household receives interest, $R_{a t}$, on these deposits. Additional sources of funds include profits from producers of capital, from banks, from intermediategoods firms, and from the net payoff on the state contingent securities mentioned above. Households also receive lump-sum transfers corresponding to the net worth of the entrepreneurs who exit the economy in the current period. Finally, the households pay a lump-sum tax to finance transfer payments to surviving entrepreneurs and to the newly born entrepreneurs.

The household can use its funds to purchase consumption goods, $P_{t} C_{t}$, or accumulate high-powered money, $M_{t+1}^{b}$. In addition, it can use its funds to acquire time deposits, $T_{t}$. These pay a rate of return, $R_{t+1}^{e}$, at the end of the time- $t+1$ goods market. The rate of return, $R_{t+1}^{e}$, is known in time-t.

These observations are summarized in the following asset accumulation equation:

$$
\begin{aligned}
& \left(1+R_{a t}\right) D_{t}^{h}+\left(1+R_{t}^{e}\right) T_{t-1}+\left(1-\tau^{l}\right) W_{j, t} h_{j, t}+M_{t}+\text { Lump }_{t} \\
\geq & M_{t+1}^{b}+T_{t}+P_{t} C_{t}
\end{aligned}
$$

where Lump $_{t}$ summarizes the lump sum transfers. The household's problem is to maximize (8) subject to (9), (10), and (11).

We now turn to the way the $j^{\text {th }}$ household sets its time- $t$ wage, $W_{j, t}$. We follow closely the setup in Erceg, Henderson, and Levin (2000). In time-t, the household can, with probability $1-\xi_{w}$, choose its wage rate optimally. It turns out that each household that sets its wage optimally sets it to the same value, which we denote, $\tilde{W}_{t}$. With probability $\xi_{w}$, the household must follow a rule of thumb by setting its time- $t$ wage to what it was in the previous period, scaled up by $\pi_{t-1} \mu_{z}$. That is, for these households, $W_{j, t}=\pi_{t-1} \mu_{z} W_{j, t-1}$. The household must in each period satisfy its demand curve:

$$
h_{j, t}=\left(\frac{W_{j, t}}{W_{t}}\right)^{\frac{\lambda_{w}}{1-\lambda_{w}}} l_{t}^{s}
$$

where $W_{t}$ is the aggregate wage index, which turns out to be:

$$
W_{t}=\left[\left(1-\xi_{w}\right)\left(\tilde{W}_{t}\right)^{\frac{1}{1-\lambda w}}+\xi_{w}\left(\pi_{t-1} \mu_{z} W_{t-1}\right)^{\frac{1}{1-\lambda w}}\right]^{1-\lambda_{w}} .
$$

Also, $l^{s}$ in (12) represents employment services, which are related to the differentiated labor services of households according to the following technology:

$$
l^{s}=\left[\int_{0}^{1}\left(h_{j}\right)^{\frac{1}{\lambda w}} d j\right]^{\lambda_{w}}, 1 \leq \lambda_{w}<\infty .
$$


The household takes the aggregate wage and employment index as given. The household that reoptimizes its wage, $\tilde{W}_{t}$, does so by optimizing (8) subject to (11) and the various frictions discussed above. In the linear approximation of our model's solution, $\lambda_{w}$ and the preference parameter, $\zeta$, are observationally equivalent. From here on, we treat $\zeta$ as the realization of a stochastic process and refer to it as a measure of household labor market power. For further details on the sticky wage part of our model, see Christiano, Eichenbaum, and Evans (2003) or Erceg, Henderson, and Levin (2000).

\subsection{Final-Goods-Market Clearing}

Here, we develop the aggregate resource constraint, relating the quantity of final goods produced to the quantity of aggregate labor and capital services, as well as to the distribution of production among intermediate-goods firms and to the distribution of employment among households. Our approach follows Yun (1996). In particular,

$$
Y_{t}=\left(p_{t}^{*}\right)^{\frac{\lambda_{f}}{\lambda_{f}-1}}\left[z_{t}^{1-\alpha} \epsilon_{t}\left(\nu_{t} K_{t}\right)^{\alpha}\left(\nu_{t}\left(w_{t}^{*}\right)^{\frac{\lambda_{w}}{\lambda_{w}-1}} l_{t}\right)^{1-\alpha}-z_{t} \Phi\right], w_{t}^{*}=\frac{W_{t}^{*}}{W_{t}}, p_{t}^{*}=\frac{P_{t}^{*}}{P_{t}} .
$$

Here, $K_{t}$ and $l_{t}$ are the unweighted integral of all labor and capital in the economy:

$$
K_{t}=\int_{0}^{1} K_{j t} d j, l_{t}=\int_{0}^{1} h_{j t} d j .
$$

The endogenous variable, $\nu_{t}$, represents the fraction of aggregate labor and capital services used in the goods-producing sector. The objects, $W_{t}^{*}$ and $W_{t}$, represent differently weighted integrals of $W_{j t}$ over all $j$, and similarly for $P_{t}^{*}$ and $P_{t}$. The scalars, $w_{t}^{*}$ and $p_{t}^{*}$, capture the loss of final output that occurs when resources are not evenly distributed across sectors, as efficiency requires. There is no efficiency loss when all wages and intermediate-goods prices are equal, so that $p_{t}^{*}=w_{t}^{*}=1$. The price and wage frictions that we assume imply that $p_{t}^{*}=w_{t}^{*}=1$ only holds in a nonstochastic steady state. The reasoning in Yun (1996) can be used to show that in the type of linear approximation about steady state that we study here, we can set $p_{t}^{*}=w_{t}^{*}=1$. We do this from here on.

To complete our discussion, final goods are allocated to monitoring for banks, utilization costs of capital, government consumption, household consumption, and investment:

$$
\begin{aligned}
& \mu \int_{0}^{\bar{\omega}_{t}} \omega d F_{t-1}(\omega)\left(1+R_{t}^{k}\right) Q_{\bar{K}^{\prime}, t-1} \bar{K}_{t}+a\left(u_{t}\right) \bar{K}_{t}+G_{t}+C_{t}+I_{t} \\
\leq & {\left[z_{t}^{1-\alpha} \epsilon_{t}\left(\nu_{t} K_{t}\right)^{\alpha}\left(\nu_{t} l_{t}\right)^{1-\alpha}-z_{t} \phi\right], }
\end{aligned}
$$

Here, government consumption is modeled as follows:

$$
G_{t}=z_{t} g
$$

where $g$ is a constant. 


\subsection{Exogenous Shocks}

There are eight exogenous shocks in the model. These are the monopoly power parameter, $\lambda_{f, t}$, corresponding to intermediate-goods firms; the parameter controlling bank demand for excess reserves, $\xi_{t}$; the parameter controlling household preferences for currency versus demand deposits, $\theta_{t}$; the monopoly power parameter for household labor supply, $\zeta_{t}$; the parameter governing household preference for liquidity, $v_{t}$; the productivity shock to intermediate-goods firms, $\epsilon_{t}$; the shock to the riskiness of entrepreneurs, $\sigma_{t}$; and the parameter governing the survival probability of entrepreneurs, $\gamma_{t}$.

Three of our variables, $\gamma_{t}, \xi_{t}$, and $\theta_{t}$, must lie inside the unit interval. Let $y_{t}$ denote one of these variables. We ensure that $y_{t}$ lies inside the unit interval by assuming that it is generated by a stochastic process, $x_{t}$, via the following transformation:

$$
y_{t}=\frac{1}{1+\exp \left(-x_{t}\right)} .
$$

Note that $x_{t} \in(-\infty, \infty)$ maps $y_{t}$ into the unit interval. If we let $d x_{t}$ denote a small perturbation of $x_{t}$ about its nonstochastic steady state value, and let $\hat{y}_{t}=d y_{t} / y$, where $y$ is the nonstochastic steady state of $y_{t}$, then

$$
d y_{t}=y(1-y) d x_{t}
$$

For the cases in which $y_{t}$ is $\gamma_{t}, \xi_{t}$ or $\theta_{t}$, we allow $d x_{t}$ to have a first-order autoregressive, moving average $(\operatorname{ARMA}(1,1))$ representation. We allow $\hat{\lambda}_{f, t}, \hat{v}_{t}, \hat{\zeta}_{t}$, and $\hat{\epsilon}_{t}$ to have $\operatorname{ARMA}(1,1)$ representations. Consider, for example, $\hat{\lambda}_{f, t}$. The joint evolution of this variable and its monetary response, $x_{f, t}$, are given by:

$$
\left(\begin{array}{c}
\hat{\lambda}_{f, t} \\
\hat{\varphi}_{f t} \\
x_{f, t}
\end{array}\right)=\left[\begin{array}{ccc}
\rho_{f} & \eta_{f} & 0 \\
0 & 0 & 0 \\
0 & \theta_{f}^{1} & \theta_{f}^{2}
\end{array}\right]\left(\begin{array}{c}
\hat{\lambda}_{f, t-1} \\
\hat{\varphi}_{f, t-1} \\
x_{f, t-1}
\end{array}\right)+\left(\begin{array}{c}
\hat{\varphi}_{f t} \\
\hat{\varphi}_{f t} \\
\theta_{f}^{0} \hat{\varphi}_{f t}
\end{array}\right) .
$$

Because at time- $t, \hat{\sigma}_{t-1}$ enters the model [see (5)], and because of the nature of the computational methods we use to solve the model, we find it convenient to handle $\hat{\sigma}_{t}$ somewhat differently. In particular,

$$
\left(\begin{array}{c}
\hat{\sigma}_{t} \\
\hat{\sigma}_{t-1} \\
x_{\sigma, t}
\end{array}\right)=\left[\begin{array}{ccc}
\rho_{\sigma} & 0 & 0 \\
1 & 0 & 0 \\
0 & 0 & \theta_{\sigma}^{2}
\end{array}\right]\left(\begin{array}{c}
\hat{\sigma}_{t-1} \\
\hat{\sigma}_{t-2} \\
x_{\sigma, t-1}
\end{array}\right)+\left(\begin{array}{c}
\hat{\varphi}_{\sigma, t} \\
0 \\
\theta_{\sigma}^{0} \hat{\varphi}_{\sigma, t}
\end{array}\right) .
$$

We stack all our random variables into the 24 by 1 vector, $\Psi_{t}$, which evolves as follows:

$$
\Psi_{t}=\rho \Psi_{t-1}+D \varphi_{t}
$$

where $\rho$ is 24 by 24 and $D$ is 24 by 8 . 


\subsection{Monetary Policy}

The ability of the monetary authority to affect the economy stems from its control over the monetary base, which has the following law of motion:

$$
M_{t+1}^{b}=M_{t}^{b}\left(1+x_{t}\right) .
$$

Here, $x_{t}$ is the net growth rate of the monetary base. In the literature, monetary policy is modeled in a variety of ways. For example, policy is often represented as an interest rate target that varies with economic conditions in a particular way. The notion is that the monetary authority manipulates the monetary base to ensure that the target is achieved. Specification of the target is often controversial. For example, "economic conditions" may be represented by deviations from a long-term trend, or by deviations from some flexible price level of output. Moreover, in models like ours with endogenous state variables, the "flexible level of output" is itself controversial. ${ }^{33}$ For the purpose of estimating our model, we do not need to take a stand on what the target of monetary policy is, or how that target varies with the state of the economy. We pursue the insight that whatever rule the monetary authority follows, it corresponds to a particular reduced-form feedback function from the shocks in the economy to the monetary base. It implies such a representation even if the monetary authority does not actually see the shocks.

Let $\hat{x}_{t}$ denote the percent deviation of $x_{t}$ from its mean value of $x$, so that $\hat{x}_{t}=\left(x_{t}-x\right) / x$. Our reduced form representation of monetary policy has the following form:

$$
\hat{x}_{t}=\sum_{i=0}^{p} x_{i t}
$$

where $x_{i t}$ is the component of money growth reflecting the $i^{\text {th }}$ element in $\varphi_{t}$ and:

$$
x_{i t}=\theta_{i}^{2} x_{i, t-1}+\theta_{i}^{0} \varphi_{i, t}
$$

for $i=0,1, \ldots, p$, with $\theta_{0}^{0} \equiv 1$. In our analysis, $p=8$, and we suppose that for $i=0, x_{0, t}$ represents an exogenous component to monetary policy. Although we set this to zero in the estimation of our model, a simulation of the response of our model to monetary policy shocks will nevertheless be useful for interpreting the results of our counterfactual analysis.

It is also useful to spell out in more detail the response of the monetary base to a shock. Iterating on the law of motion for the monetary base:

$$
\log \left(\frac{M_{t+1}^{b}}{M_{1}^{b}}\right)=\sum_{j=1}^{t} \log \left(1+x_{j}\right) \approx \sum_{j=1}^{t} x_{j}=x \sum_{j=1}^{t}\left(\hat{x}_{j}+1\right) .
$$

\footnotetext{
${ }^{33}$ See Woodford (2003, Chapter 5) for additional discussion.
} 
Suppose there is a perturbation in the $i^{\text {th }}$ economic shock only, so that $\hat{x}_{j}=x_{i, j}$ and:

$$
\log \left(\frac{M_{t+1}^{b}}{M_{1}^{b}}\right)=x \sum_{j=1}^{t}\left(x_{i, j}+1\right) .
$$

Let $\bar{M}_{t+1}^{b}$ denote the value of the monetary base in the event that there is no shock, with $M_{1}^{b}=\bar{M}_{1}^{b}$. Straightforward algebra implies:

$$
\log \left(\frac{M_{t+1}^{b}}{\bar{M}_{t+1}^{b}}\right)=x \sum_{j=1}^{t} x_{i, j} .
$$

Making use of (18), we conclude that if there is a one-standard-deviation perturbation, $\sigma_{i}$, in $\varphi_{i, 1}$ in period 1 , the impact on the time- $t+1$ money stock is:

$$
\log \left(\frac{M_{t+1}^{b}}{\bar{M}_{t+1}^{b}}\right)=\frac{1-\left(\theta_{i}^{2}\right)^{t}}{1-\theta_{i}^{2}} x \theta_{i}^{0} \sigma_{i}=\left\{\begin{array}{cc}
\frac{x \theta_{i}^{0}}{1-\theta_{i}^{2}} \sigma_{i} & t \rightarrow \infty \\
x \theta_{i}^{0} \sigma_{i} & t=1
\end{array} .\right.
$$

\subsection{Equilibrium and Model Solution}

We adopt a standard sequence-of-markets equilibrium concept, and we use the method in Christiano (2002), described in the appendix, to develop a linear approximation to the equilibrium quantities and prices. The solution is a set of matrices, $A, B$ and a core set of 23 endogenous variables contained in the vector, $\tilde{z}_{t}$, satisfying

$$
\tilde{z}_{t}=A \tilde{z}_{t-1}+B \Psi_{t}
$$

Here, $A$ is 23 by 23 and $B$ is 23 by 24 for $i=1,2$. The vector, $\tilde{z}_{t}$, is defined in the appendix. Each element in $\tilde{z}_{t}$ is expressed as a percent deviation from a steady state value, so that, in nonstochastic steady state, $\tilde{z}_{t}=0$. From the variables in $\tilde{z}_{t}$ and the various equilibrium relationships in the model, it is possible to compute any desired equilibrium variable. Suppose these are contained in the vector, $X_{t}$. After linearization, let the relationship of $X_{t}$ to $\tilde{z}_{t}$ and $\Psi_{t}$ be expressed as follows:

$$
X_{t}=\alpha+\tau z_{t}+\bar{\tau} z_{t-1}+\tau^{s} \Psi_{t}
$$


where $\alpha, \tau, \bar{\tau}$, and $\tau^{s}$ are functions of the model parameter values and its steady state. The set of variables of interest in our analysis is:

$$
X_{t}=\left(\begin{array}{c}
\log \left(\frac{N_{t+1}}{P_{t} Y_{t}}\right) \\
\log \left(\pi_{t}\right) \\
\log \left(l_{t}\right) \\
R_{t}^{b} \\
\Delta \log \left(Y_{t}\right) \\
\log \left(\frac{W_{t}}{P_{t} Y_{t}}\right) \\
\log \left(\frac{I_{t}}{Y_{t}}\right) \\
\log \left(V_{t}^{1}\right) \\
\log \left(\frac{C_{t}}{Y_{t}}\right) \\
P_{t}^{e} \\
\log \left(d_{t}^{c}\right) \\
\log \left(V_{t}^{b}\right) \\
\log \left(d_{t}^{r}\right)
\end{array}\right) .
$$

Here, $V_{t}^{1}$ and $V_{t}^{b}$ are the time- $t$ velocity of $\mathrm{M} 1$ and the monetary base, respectively. Also, $d_{t}^{c}$ and $d_{t}^{r}$ represent the currency to demand deposit ratio and the bank reserves to demand deposit ratio, respectively. As noted in section 3.4, $R_{t}^{b}$ is the interest rate on interbank loans. It is determined by an arbitrage condition. ${ }^{34}$ Finally, $P_{t}^{e}$ is the external finance premium, which was discussed at the end of section 3.3.

In our analysis we use the value of equity as measured by the real value of the DOW, as an indicator of $N_{t+1} / P_{t}$. This deserves comment because our model of entrepreneurs does not allow any role for equity finance. The entrepreneurs in our model resemble small shopkeepers and farmers, who do not issue equity and who must finance their ownership of capital with a combination of their own net worth and bank loans. Although it is probably true that most capital was owned by small proprietors like this in the 1920s and 1930s, we believe it is hard to obtain good, direct estimates of their net worth. Our analysis in effect assumes that the DOW constitutes a useful, albeit indirect, measure.

\section{Model Estimation and Fit}

Our aim in choosing parameter values is to produce a quantitative model that resembles key aspects of the U.S. economy in the 1920s and 1930s. This is what we need in order to have a credible laboratory for evaluating the consequences of alternative, counterfactual, monetary policies. The model parameters are divided into two sets: (i) those that govern the evolution

\footnotetext{
${ }^{34}$ The arbitrage condition is:
}

$$
R_{t}^{b}=\frac{R_{t} h_{e^{r}, t}}{\tau h_{e^{r}, t}+1},
$$

where $h_{e^{r}, t}$ denotes the derivative of the right side of (6) with respect to real excess reserves, $e_{t}^{r}=E_{t}^{r} / P_{t}$. 
of the exogenous shocks and the monetary response to them, and (ii) the rest. We begin with the latter. We then estimate the stochastic parameters in (i) by a maximum likelihood procedure. Ideally, we would have estimated all parameters simultaneously. However, computational challenges make this strategy less than straightforward, and we leave such an exercise for future work. After discussing the model parameter estimates, we discuss the quality of model fit.

\subsection{Parameters of the Nonstochastic Part of the Model}

The nonstochastic model parameters are listed in Table 2, and various properties of the model's steady state are reported in Tables 3-4. In many cases, the corresponding sample averages for U.S. data from both the 1920s and the postwar period are also reported. Our procedure for computing the steady state is discussed in the Appendix.

To compute the steady state, we found it convenient to proceed by specifying some of the economically endogenous variables to be exogenous. In particular, we assigned values to the steady state ratio of currency-to-monetary base, $m$, the steady state rental rate of capital, $r^{k}$, the steady state share of capital and labor in goods production, $\nu$, and the steady state share of government consumption of goods, $G / Y$. These were set to $m=0.70, r^{k}=0.043$, $\nu=0.99$, and $G / Y=0.07$. The currency-to-base ratio is a little high relative to the data from the 1920s. The value of $r^{k}$ may also be a little high because the model implies a value of the capital output ratio that is a little low, compared with our data on the 1920s (see Table 3). To make these four variables exogenous for purposes of computing the steady state required making four model parameters endogenous. For this purpose, we chose $\psi_{L}, x^{b}, \xi$, and $g$.

The model parameters in Table 2 are organized by sector. Turning to the household sector, values for $\beta, \lambda_{w}, \xi_{w}, \sigma_{L}$, and $b$ were taken from Altig et al. (2003). The parameters, $\theta, v$, and $\sigma_{q}$ were set exogenously. Regarding the goods-producing sector, all but one of the parameters were taken from Altig et al. (2003). The exception is $\psi_{k}$, which does not appear in Altig et al. (2003). We set this exogenously.

The Calvo price and wage stickiness parameters, $\xi_{p}$ and $\xi_{w}$, imply that the amount of time between reoptimization of prices and wages is $1 / 2$ year and 1 year, respectively. As noted in Altig et al. (2003), these values are consistent with recent survey evidence on price frictions.

Our selection of parameter values for the entrepreneurial sector is based on the calibration discussion in BGG. Following them, we assume that the idiosyncratic shock to entrepreneurs, $\omega$, has a lognormal distribution. We impose on our calibration the condition that the number of bankruptcies in steady state corresponds roughly to the number reported by BGG for the post- World War II period. In particular, we set $F(\bar{\omega})$ to 0.008 , so that, on average, 0.8 
percent of firms fail to meet their debt obligations in a given quarter. To understand how we were able to specify $F(\bar{\omega})$ exogenously, recall that the lognormal distribution has two parameters - the mean and variance of $\log \omega$. We set the mean of $\omega$ to unity. We are left with one degree of freedom, the variance of $\log \omega$. Conditional on the other parameters of the model, this can be set to ensure the exogenously set value of $F(\bar{\omega})$. The value of this variance is reported in Table 2. Finally, as noted above, the two parameters of the banking sector are an output of the steady state calculations.

The steady state implications of the model can be compared with the corresponding empirical quantities in Tables 3 - 5. There are five things worth emphasizing about Table 3. First, as noted above, the capital-to-output ratio in the model is a little low. Corresponding to this, the investment-to-output ratio is low and the consumption-to-output ratio is high. Second, note that $N /(\bar{K}-N)$ is roughly unity. This corresponds well with the data if the equity to debt ratio of publicly owned firms corresponds well to the net worth to bank loans ratio of small, wholly owned proprietorships, such as gasoline stations and restaurants. As discussed above, the latter are the empirical counterparts of the entrepreneurs in our model. Third, the relative size of the banking sector in the model, which is quite small, conforms roughly with the size of the actual banking sector in the 1920s. Fourth, although we have not obtained data on the fraction of GDP used up in bankruptcy costs, we suspect that the relatively low number of 0.84 percent is not be far from the mark. Finally, note that while inflation in the model is low by postwar standards, it is somewhat higher than what it was in the 1920s.

Table 4 reports the consolidated asset and liability accounts for the banks in the model. Several things are worth noting here. First, in the model most demand deposits are created in the process of extending working-capital loans. These deposits are what we call "firm demand deposits," and they are roughly 7 times as large as the quantity of demand deposits created when households deposit their financial assets with banks (i.e., "household demand deposits"). We are not aware of data that would allow us to evaluate this implication of the model. Second, the results in the table indicate that the amount of bank reserves in the model matches reasonably well with the corresponding quantity in the data. For example, in the model excess reserves are 2.2 percent of the sum of bank reserves and working-capital loans. We estimate that the analogous number for the U.S. economy in the 1920s is only slightly larger, around 3.4 percent.

Table 5 reports various monetary and interest rate statistics. The left set of columns shows that the basic orders of magnitude are on track: Base velocity and M1 velocity in the model match up reasonably well with the data. The ratio of currency to demand deposits is also reasonable. However, the fraction of currency in the monetary base is high, as noted above. The interest rate implications of the model accord reasonably well with the data. 
However, the interbank loan rate is a little high.

Taken together, these results suggest to us that the steady state implications of the model correspond reasonably well with the data.

\subsection{Parameters of Exogenous Stochastic Processes}

We estimate the stochastic parameters of the model using quarterly observations covering the period 1923I-1939IV on the data in (21). We adopt a standard state-observer setup in supposing that the measured data corresponds to $X_{t}$ plus an error that is independently distributed over time and across variables. We follow convention in referring to this error as "measurement error," although we actually think of it as some combination of literal measurement error and model-specification error. We then estimate the unknown parameters using a standard maximum-likelihood procedure. This part of our estimation procedure focuses only on fluctuations. We abstract from means at both the parameter estimation and model diagnostic stages. At the estimation stage we do so by subtracting the sample means from the data and setting the model mean to zero. When we simulate the model to determine how well it matches the data, we impose the condition that the mean in the model coincides with the mean in the data.

\subsubsection{Methodology}

For convenience, we describe our system using the notation in Hamilton (1994, chapter 13). Let the state vector, $\xi_{t}$, be:

$$
\xi_{t}=\left(\begin{array}{c}
\tilde{z}_{t} \\
\tilde{z}_{t-1} \\
\Psi_{t}
\end{array}\right)
$$

Then, the state equation, which summarizes (17) and (19), is

$$
\left(\begin{array}{c}
\tilde{z}_{t+1} \\
\tilde{z}_{t} \\
\Psi_{t+1}
\end{array}\right)=\left[\begin{array}{ccc}
A & 0 & B \rho \\
I & 0 & 0 \\
0 & 0 & \rho
\end{array}\right]\left(\begin{array}{c}
\tilde{z}_{t} \\
\tilde{z}_{t-1} \\
\Psi_{t}
\end{array}\right)+\left(\begin{array}{c}
B_{1} D \\
0 \\
D
\end{array}\right) \varphi_{t+1}
$$

or, in obvious, compact notation:

$$
\xi_{t+1}=F \xi_{t}+v_{t+1} .
$$

Here

$$
v_{t+1}=\left(\begin{array}{c}
B_{1} D \\
0 \\
D
\end{array}\right) \varphi_{t+1}
$$

The observation equation is

$$
y_{t}=H \xi_{t}+w_{t},
$$


where $w_{t}$ is a vector of measurement errors and

$$
H=\left[\begin{array}{lll}
\tau & \bar{\tau} & \hat{\tau}^{s}
\end{array}\right]
$$

Note from (20) that $H \xi_{t}=X_{t}$, apart from the constant vector, $\alpha$. We interpret the 13 variables on which we have observations as $y_{t}$ in (24).

To complete the description of the state space system, we must also specify the variance covariance matrix of $v_{t}$ and of the measurement error, $w_{t}$. We suppose that both these objects are $i i d$ and diagonal. In addition, we suppose that $w_{t}$ is orthogonal to $y_{t}$ and $\xi_{t}$ at all leads and lags. ${ }^{35}$ The variance covariance matrix of $w_{t}$ is $R$. The variance covariance matrix of $v_{t}$ has some structure in our setting:

$$
E v_{t} v_{t}^{\prime}=E\left(\begin{array}{c}
B_{1} D \hat{\varphi}_{t+1} \\
0 \\
D \hat{\varphi}_{t+1}
\end{array}\right)\left(\begin{array}{lll}
\hat{\varphi}_{t+1}^{\prime} D^{\prime} B_{1}^{\prime} & 0 & \hat{\varphi}_{t+1}^{\prime} D^{\prime}
\end{array}\right)=\left[\begin{array}{ccc}
B_{1} D V_{\varphi} D^{\prime} B_{1}^{\prime} & 0 & B_{1} D V_{\varphi} D^{\prime} \\
0 & 0 & 0 \\
D V_{\varphi} D^{\prime} B_{1}^{\prime} & 0 & D V_{\varphi} D^{\prime}
\end{array}\right] .
$$

Our system is completely characterized by $\left(F, H, R, V_{\varphi}\right)$. For our purposes here, the free parameters are the diagonal elements of $V_{\varphi}$ and $R$, as well as the parameters of the timeseries representations of the exogenous shocks, which are contained in $\rho$ and $D$. There are four parameters per shock: an autoregressive and variance term for the time-series representation of the shock, as well as two parameters governing the monetary policy response to each shock (we model the shocks and monetary responses as first-order autoregressions). In addition, for each of the 13 variables in $y_{t}$ there is one measurement error variance. Since there are 8 shocks, there is a total of 37 free parameters for the estimation. Denote these by the vector, $\Upsilon$. Given the values assigned to the other parameters of the model, $\left(F, H, R, V_{\varphi}\right)$ can be constructed once values are assigned to $\Upsilon$. We choose these values to maximize the Gaussian density function, as discussed in Hamilton (1994, section 13.4). In this analysis we ignore the levels of variables by removing the sample mean from the data and replacing the constant term in (20) by a vector of zeros (this was done implicitly in the definition of $y_{t}$ in (24).

\subsubsection{Results}

Tables 6 and 7 report our estimation results. Table 6 displays the estimates of the time-series representations of the exogenous shocks and the associated monetary policy responses. Table 7 presents the estimated standard-deviation of the measurement errors, $w_{t}$. We now discuss these in turn.

\section{Exogenous Shocks and Monetary Policy Response}

\footnotetext{
${ }^{35}$ These assumptions make it hard to interpret the shock, $w_{t}$, literally as measurement error. For data such as aggregate output it seems likely that statistical agencies apply some optimal smoothing before release, and this has the consequence that measurement error in the published data are correlated with true values.
} 
There are three things worth noting in Table 6. First, in several cases, the autoregressive root of a shock was driven very nearly to unity (numbers in the table are rounded). This is how the model captures the substantial, trend-like persistence in the data. Second, to understand the magnitude of the innovation standard-deviations, it is useful to express them in terms of their impact on the level of the shock itself. ${ }^{36}$ Thus, Table 6 displays the steady state value of each shock, as well as its position after a positive one-standard-deviation innovation. For example, the steady state value of the firm markup, $\lambda_{f}$, is 1.20 , and its value after a one-standard-deviation innovation is 1.21. In almost all cases, the displacement is relatively small. An exception is the shock to $\gamma_{t}$, where a positive one-standard-deviation positive innovation drives it a little above its upper limit of unity. (The fact that it exceeds its upper bound reflects a breakdown in the accuracy of (16) as an approximation to (15).) Overall, we were frankly somewhat surprised that these innovations seem to be of reasonable magnitude, despite the enormous variation in the data of the 1930s. Third, the response of monetary policy to the various shocks is relatively weak. The strongest response appears to be to the technology shock. And, as we show below, this response is not very strong either.

Because there is a large literature focused on the estimation and analysis of aggregate technology shocks, it is of interest to discuss the parameters pertaining to the technology shock, $\epsilon_{t}$, in greater detail. For comparability with other studies, it is useful to consider the impact of $\epsilon_{t}$ on GNP in a steady state, holding fixed the utilization of capital and labor resources, and holding fixed the amount of resources absorbed by bankruptcy. After scaling by $z_{t}$, GNP is:

$$
Y_{t}^{z}=\epsilon_{t} F\left(u_{t}, \bar{k}_{t}, \nu_{t}^{k}, l_{t}\right)-\phi-d_{t}-a\left(u_{t}\right) \frac{1}{\mu_{z}} \bar{k}_{t},
$$

where $d_{t}$ is the resources used up in bankruptcy (see the Appendix for an explicit representation of $d_{t}$ ). Here, the function $F$ is the production function of the typical intermediate-goods producer, (2), after scaling. The fact that aggregate output is a function of aggregate quantities alone reflects that in a steady state, the nature of our price and wage updating rules leads to symmetric behavior across all households and intermediate-goods firms. Totally differentiating the above expression with respect to $Y_{t}^{z}$ and $\epsilon_{t}$ and holding all other variables fixed at their steady state values, we obtain $Y^{z} \hat{Y}_{t}^{z}=\hat{\epsilon}_{t} F$, where $\hat{Y}_{t}^{z} \equiv d Y_{t}^{z} / Y^{z}$ and $\hat{\epsilon}_{t}=d \epsilon_{t}$ (recall, $\epsilon=1$ ). We obtain a simple expression for $F / Y^{z}$ by noting, first, that $Y^{z}=F-\phi-d$. Second, our assumption that intermediate-goods profits are zero in steady state implies that firm revenues equal firm costs, so that $F-\phi=F / \lambda_{f}$, where $\lambda_{f}$ is the reciprocal of real marginal cost (i.e., it is the markup). Combining the previous two expressions we obtain

\footnotetext{
${ }^{36}$ Suppose the shock of interest is $y_{t}$. In the case of shocks with hats, a one-standard-deviation innovation represents a perturbation to $\hat{y}_{t}=\left(y_{t}-y\right) / y$, which translates into a $\sigma \times y$ shock to $y_{t}$. So, for a variable with a hat, Table 6 displays $(y, y+\sigma y)$. For a variable with a $d$, a one-standard-deviation innovation represents a $y(1-y) \sigma$ shock to $y_{t}$. So, for a variable with a $d$, Table 6 displays $(y, y(1-y) \sigma)$.
} 
$Y^{z}=F / \lambda_{f}-d$, so that:

$$
\hat{Y}_{t}^{z}=\frac{F}{Y^{z}} \hat{\epsilon}_{t}=\frac{\lambda_{f}\left(Y^{z}+d\right)}{Y^{z}} \hat{\epsilon}_{t} \approx \lambda_{f} \hat{\epsilon}_{t}
$$

since $d / Y^{z}$ is small (see Table 3 ). So, a one percent change in $\epsilon_{t}$ results, approximately, in a 1.2 percent change in gross national product (recall, from Table $2, \lambda_{f}=1.2$ ). According to Table 6 , an innovation in $\epsilon_{t}$ has a standard-deviation of 0.0031 , which translates into an innovation in GNP of 0.0037. This is about one-half of Prescott's (1986) estimate of 0.00763 for the standard-deviation of the innovation to the aggregate technology shock. That Prescott's estimate should be larger than ours is perhaps not surprising, since he attributes the entire Solow residual to exogenous technology, whereas our Solow residual includes sources of endogenous variation, in part because we include variable capital utilization in our model. Our estimate of the autocorrelation of the technology resembles Prescott's in that both are high.

Turning to the monetary response to shocks, note from Table 6 that this is quite small in most cases. We briefly discuss the policy response to an innovation in technology, because that has been the subject of a literature. Table 6 indicates that a one-standard-deviation innovation in $\epsilon_{t}$ produces an immediate increase of 0.13 percent in the monetary base. Thereafter, the monetary base continues to rise until eventually it is roughly 0.96 percent higher than it would have been in the absence of a shock. That monetary policy accommodates aggregate technology is consistent with the findings for the postwar period in Altig et al. (2003) and Gali, Lopez-Sadilo and Valles (2003). However, our estimated response is very weak. In particular, the dynamic response of aggregate variables such as output, consumption, employment, capital utilization, and investment are roughly the same, whether monetary policy responds or not. Either way, all these variables respond positively, in a hump-shaped pattern to a shock. In the absence of monetary accommodation, the response is slightly weaker, and in the period of the shock the responses of capital utilization and employment are actually slightly negative.

\section{Measurement Error}

To understand the estimates in Table 7, it is useful to also consider the results in Figure 4. The thirteen panels in that figure display the raw data, $y_{t}, t=1, \ldots, T$, where $t=1$ corresponds to 1924QI and $t=T$ corresponds to 1939 QIV. The relatively smooth line in the figures displays the projection of $X_{t}$, for each $t$, on the entire data set, $\Omega=y_{1}, \ldots, y_{T}$. To compute this projection, $E\left(\xi_{t} \mid \Omega\right)$, we used the two-sided Kalman smoothing algorithm (see, e.g., Hamilton 1994.) We then formed $E\left(X_{t} \mid \Omega\right)=H \times E\left(\xi_{t} \mid \Omega\right)$. Prior to graphing the model's simulated data, we adjusted the data so that the sample mean in the simulated data coincides with the sample mean of the actual data. This is consistent with our overall 
strategy for estimating the stochastic part of the model, which ignores the difference between the mean in the data and in the model.

In addition to the projection interpretation, there is another interpretation of $E\left(X_{t} \mid \Omega\right)$ that is more convenient for our purposes. To see this, note first that one can obtain an estimate of the economic shocks, $E\left(\varphi_{t} \mid \Omega\right)$, by projecting both sides of (22) onto $\Omega$ :

$$
E\left(v_{t} \mid \Omega\right)=E\left(\xi_{t} \mid \Omega\right)-F \times E\left(\xi_{t-1} \mid \Omega\right)
$$

and making use of (23). ${ }^{37}$ The smooth data in Figure 4 can also be interpreted as the dynamic response of our model economy to the time-series of estimated shocks, $E\left(\varphi_{t} \mid \Omega\right)$, $t=1, \ldots, T$. This is the interpretation that we adopt in the remainder of this paper.

The vertical distance between the line depicting the raw data and the model simulation represents an estimate of the measurement error, $w_{t}$, in the state-observer system in section 4.2.1. The size of the measurement error varies substantially across variables. For example, in three cases $-\log \left(N_{t+1} /\left(P_{t} Y_{t}\right)\right), \log \left(l_{t}\right)$, and $R_{t}^{b}-w_{t}$ is so small that the two lines in the graph essentially coincide. According to Table 7, the maximum-likelihood estimate of the standard-deviation of the measurement error in these variables is $0.017,0.00014$, and 0.0000034, respectively. (The actual standard errors of the vertical distances in Figure 4 are displayed in parentheses in Table 7, and these correspond roughly to the maximum-likelihood estimates.) At the other extreme lie the variables from the national income and product accounts: the growth rate of GNP, the investment-to-output ratio and the consumptionto-output ratio. Measurement error is estimated to account for 73, 15, and 46 percent of the variance in these variables, respectively. To the extent that we interpret these errors as model-specification error, they may at first seem large enough to be a source of concern about the quality of model fit. We discuss model fit in the next subsection.

\subsection{General Observations about Model Fit}

To assess model fit, we converted the variables that appear as ratios and growth rates in Figure 4 into levels. The results are shown in Figure 5, where the variables in Figure 4 that were not transformed are reproduced for convenience. Note how the basic simulation results resemble the actual data remarkably closely. The failures of the model captured by the large measurement errors in Table 7 appear to be concentrated in the high-frequency components of the data.

There are some weaknesses in the model. For example, consumption does not fall enough. In addition, the fall in output and investment are also not quite large enough. Interestingly,

\footnotetext{
${ }^{37}$ Note from (23) that there is considerable structure on $v_{t}$. The Kalman filter algorithm produces $E\left(v_{t} \mid \Omega\right)$ that respects this structure. Thus, although there are many ways to recover $E\left(\varphi_{t} \mid \Omega\right)$ from $E\left(v_{t} \mid \Omega\right)$, they all produce the same result.
} 
the model's real wage exhibits excessive growth during the contraction phase of the Great Depression. Although the degree of wage rigidity in the model is by some measures quite modest, this evidence suggests the model might perform better with somewhat less rigidity.

\section{The U.S. Great Depression from the Perspective of the Model}

This section studies the estimated economic shocks and considers their role in the dynamics of the Great Depression. The time-series of the eight shocks are displayed in Figure 6. In discussing these shocks, it is useful to organize them into three groups: real shocks, financial shocks, and monetary shocks.

The real shocks include the technology shock and the variables that control firm and household market power, $\lambda_{f, t}$ and $\zeta_{t}$. Of these, only $\zeta_{t}$ plays an important role. Its persistent rise helps the model account for the weakness in employment during the recovery phase of the Great Depression. Our analysis is consistent with the conclusion of Prescott (1999) and Cole and Ohanian $(1999,2003)$ that the failure of hours worked to rise in the late 1930s reflected changes in the institutions of labor markets which had the effect of increasing the market power of workers. At the same time, $\zeta_{t}$ seems to have had little to do the with contraction phase of the Great Depression. This is true also for our two financial market shocks, $\sigma_{t}$ and $\gamma_{t}$.

Finally, we consider three monetary shocks: bank demand for reserves, $\xi_{t}$, household money demand, $\theta_{t}$, and the household liquidity preference shock, $v_{t}$. The last shock stands out above all our other shocks in terms of its role in accounting for the contraction phase of the Great Depression. We provide a detailed analysis of the transmission of this shock.

A crude summary of our model's account of the Great Depression is as follows. Much of the contraction phase is due to a rise in the liquidity preference shock, $v_{t}$. A notable feature of the expansion phase is the absence of a substantial recovery in employment. According to the model, this is due to a persistent increase in the labor market power of households. We find both of these implications reasonable, and they build confidence that this is a useful model for analysis of counterfactual monetary policy.

\subsection{Real Shocks}

Our analysis indicates that the role of fluctuations in technology in the Great Depression is very small. The technology shock, $\epsilon_{t}$, drops only about 1 percent from 1929 to 1933 . The third row of graphs in Figure 7 displays the dynamic behavior of output, employment, the price level, and investment when the only shock is our estimated technology shock. The 
figures show that the technology shock contributes almost nothing to variation about trend in output, the price level, and investment. ${ }^{38}$

Consider firm market power next. Our estimated $\lambda_{f, t}$ is high before 1929 and then drops roughly four percent to a lower level, where it is also more volatile (see Figure 6). In results not shown here, we found that our estimated $\lambda_{f, t}$ 's play only a minor role in the dynamics of the Great Depression. Although a drop in this variable helps somewhat towards explaining the drop in the price level, the implied increase in competition has the counterfactual implication that output and employment are strong. We presume this is the reason our econometric procedure chose to assign a small role to $\lambda_{f, t}$.

According to Figure 6, our estimate of households' labor market power, $\zeta_{t}$, increased sharply by 50-60 percent in the period 1929 to 1933. After this, the estimated $\zeta_{t}$ stabilizes. It is a challenge to find an economically interesting interpretation of the rise in $\zeta_{t}$ from 1929 to 1933. Recall that we have described two interpretations of $\zeta_{t}$. Under one, $\zeta_{t}$ is a measure of the market power of workers. But to interpret the low level of employment in the early 1930s, for the given real wage, as reflecting increased market power of workers seems implausible. For example, Goldin (2000, Figure 9) shows that union membership remained stable from the mid-1920s until well into the 1930s. As noted above, $\zeta_{t}$ can alternatively be interpreted as reflecting an increased aversion in utility for work. At best, this interpretation needs greater elaboration than is provided in our model. Although the rise in $\zeta_{t}$ during the period 1929 to 1933 is hard to interpret, the fact that it is high in the late 1930s is easy to interpret. This is the time when the New Deal legislation was passed to give greater bargaining power to workers (Kennedy 1999.)

It is easy to verify that the 60 percent rise in $\zeta_{t}$ and the 4 percent drop in $\lambda_{f, t}$ can roughly account for the persistent 20 percent drop in employment in a model like ours. For example, consider the version of our model with no fixed costs, money, variable capital utilization, investment-adjustment costs, working-capital, agency costs, growth, or banking system. The resource constraint and utility function for this model are:

$$
\begin{aligned}
c_{t}+k_{t+1}-(1-\delta) k_{t} & =k_{t}^{\alpha} l_{t}^{1-\alpha} \\
u(c, l) & =\log \left(c-b c_{-1}\right)-\zeta l^{2} / 2 .
\end{aligned}
$$

It is easy to verify that, in steady state:

$$
\begin{aligned}
\frac{d \log l}{d \log \zeta} & =-\frac{1}{2} \\
\frac{d \log l}{d \log \lambda_{f}} & =\frac{\lambda_{f}}{2 \alpha \delta}\left[\frac{1}{\beta}-1+\delta\right] \approx 2.3 .
\end{aligned}
$$

\footnotetext{
${ }^{38}$ The analysis of TFP in a previous section suggests that if TFP had been included in the data used for estimation, the role assigned to technology might have been greater.
} 
The second relationship uses $\beta=1.03^{-.25}, \lambda_{f}=1.2, \alpha=1 / 3$, and $\delta=0.10 / 4$. Evidently, a one percent change in $\lambda_{f}$ has a four times larger impact on employment than a one percent change in $\zeta$. Still, the magnitude of the change in $\zeta$ is so much greater that it dominates. In particular, the above expression suggests that the 60 percent rise in $\zeta$ alone drives down employment by 30 percent, while the 4 percent fall in $\lambda_{f}$ stimulates employment by about 8 percent. The net effect, 22 percent, corresponds well with the observation that employment in 1939 was about 20 percent lower than it was in 1929.

Figure 7 displays the behavior of our model in response to the $\zeta_{t}$ shock. The first row of figures displays the dynamic simulation of output, employment, investment, and the price level in response to our estimated time-series of $\zeta_{t}$. (The dotted line reports the model's simulation in response to all shocks, for convenient comparison.) Note that $\zeta_{t}$ is the only shock that can account for the fact that employment is substantially lower in 1939 than in 1929 (see the solid line). According to the figures, the $\zeta_{t}$ shock is not particularly useful for explaining the contraction phase of the Great Depression. For example, it fails to explain the fall in the price level. Somewhat surprisingly, it also fails to account for the fall in investment. Analysis of the model's impulse response function (not displayed) reveals that investment rises in response to a positive shock to $\zeta_{t}$. The rise lasts for a number of periods, after which it eventually falls as a steady state analysis suggests. We found that this initial increase in investment is partly a function of the high estimated autocorrelation of $\zeta_{t}$. When we replace the estimated autocorrelation of nearly unity with 0.90 , then investment falls immediately in response to a positive shock to $\zeta_{t}$. We suspect that the explanation for the transient rise in investment has to do with our entrepreneurial sector. However, this is something that is still under investigation. For our present purposes, the message is that the $\zeta_{t}$ shock is not an important shock for understanding the contraction phase of the Great Depression.

\subsection{Financial Market Shocks}

We have two financial market shocks. The first, $\gamma_{t}$, measures variations in the rate of destruction of financial wealth. The second, $\sigma_{t}$, measures the riskiness of entrepreneurs. Figure 7 displays the dynamic response of output, employment, investment, and the price level to these two shocks.

Consider the shock, $\gamma_{t}$. In results not displayed, we found that this shock helps the model account well for the fluctuations in the value of the stock market. It also has a noticeable effect on the risk premium and, according to row 2 of Figure 7, on investment. Still, according to the results in Figure 7 this shock plays essentially no role in explaining the fluctuations in output and employment. We suspect that the small role accorded to this shock by the estimation strategy reflects that a drop in $\gamma_{t}$ has a tendency to generate counterfactually strong consumption. This is a consequence of the fact that in our model, when an entrepreneur 
dies, his net worth is transferred to households, who proceed to consume a large part of it. Indeed, we suspect that this shock is responsible for the counterfactual jump in consumption evident in Figure 5. A possible improvement to the model that would allow $\gamma_{t}$ to play a greater role is if some fraction of the entrepreneur's physical stock of capital is destroyed when the entrepreneur dies.

Turning to $\sigma_{t}$, we found that this shock has a substantial impact on the risk premium and on investment. According to the fourth row of Figure 7, this shock also has a quantitatively noticeable impact on output and employment. However, the model-simulated movements in these variables are not well correlated with the corresponding U.S. data. Finally, a difficulty that the $\sigma_{t}$ shock shares with $\gamma_{t}$ is that by reducing the flow of resources into investment, it stimulates consumption. ${ }^{39}$ Presumably, this is why it did not have a larger role assigned to it.

\subsection{Monetary Shocks}

Consider the shock to bank reserve demand, $\xi_{t}$. According to Figure 6 , this variable displays a trend fall beginning in 1930. In results not displayed here, we found that the primary effect of this fall is to enable the model to explain the trend rise in the reserves-to-deposit ratio (see Figure 5). According to the model, this is not a key shock underlying the Great Depression. The same is true for $\theta_{t}$.

Consider now the liquidity preference shock, $v_{t}$. Figure 6 shows that this shock rises rapidly beginning in 1929. After 1933 its growth rate falls, though the shock continues to rise for the rest of the decade. Figure 8 displays the result of simulating our model in response to the estimated time-series of $v_{t}$ shocks alone. For comparison, the dotted lines display the actual data, reproduced from the solid line in Figure 5.

The key thing to notice in Figure 8 is that the $v_{t}$ shock accounts for several key features of the Great Depression. Notice in particular, that it explains part of the loss of value of the stock market, the fall in the price level, the fall in employment, and part of the fall in output and investment. It captures part of the rise in the premium and a major part of the fall in M1. Since this shock appears to be particularly important in our model's account of the Great Depression, we now explore the economics of how a rise in $v_{t}$ initially affects financial markets, and then how it is transmitted to the rest of the economy.

To understand the chain of events that an innovation in $v_{t}$ initiates, it is useful to understand how the household reacts to a tightening in its liquidity constraint, (9). Let $\mu_{t}$ denote the multiplier on (9). Recall that the household starts the period in possession of the economy's stock of base money, $M_{t}^{b}$, and allocates this between currency, $M_{t}$, and deposits, $A_{t}$. So, $\mu_{t}$ represents the marginal value to the household of additional beginning-of-time- $t$ base

\footnotetext{
${ }^{39}$ This mechanism has also been emphasized in Romer (1990).
} 
money. Let $\lambda_{t}$ denote the multiplier on the household's asset accumulation equation, (11). This multiplier represents the marginal value of end-of-time- $t$ base money. The first-order condition associated with $M_{t+1}^{b}$ in the Lagrangian representation of the household's problem implies $\lambda_{t}=\beta \mu_{t+1}$. (We ignore uncertainty in this discussion.) That is, the shadow value of end-of-period base money is equal to the discounted shadow of base money at the beginning of the next period.

Using these multipliers, we can write out the first-order conditions associated with the household's currency and deposit decisions:

$$
\begin{aligned}
u_{M, t}+\beta \mu_{t+1} & =\mu_{t} \\
u_{D^{h}, t}+\left(1+R_{a t}\right) \beta \mu_{t+1} & =\mu_{t} .
\end{aligned}
$$

Here, $u_{M, t}$ and $u_{D^{h}, t}$ denote the time- $t$ marginal utility of currency and household deposits, respectively. In (25) and (26), the left side measures the benefit of the given liquid asset, and the right side, the cost. In the case of currency, the benefit of an additional unit of currency is the marginal utility of that currency. There is also a pecuniary benefit, $\beta \mu_{t+1}$, because at the end of the time- $t$, currency held during time- $t$ adds to the household's beginning of time- $t+1$ holdings of base money. The right side of (25) has $\mu_{t}$, the shadow value of a unit of current-period base. This captures the fact that a marginal unit of currency requires giving up a unit of monetary base. Expression (26) is the analogous condition, applied to the household's deposit decision. The principal substantive difference between the two expressions is that the pecuniary benefit associated with deposits is greater, since they pay interest.

Since the marginal cost of an extra unit of deposits is the same as the marginal cost of an extra unit of currency, the marginal benefits of the two assets must be the same. Since deposits have a greater pecuniary payoff, their non-pecuniary payoff is necessarily smaller:

$$
u_{D^{h}, t}<u_{M, t} .
$$

Now, suppose something happens to raise the shadow value, $\mu_{t}$, of current-period base, while leaving $R_{a t}$ and $\mu_{t+1}$ unaffected. Then, the total marginal benefit of both assets must rise. Since the non-pecuniary part of the return to deposits is relatively small, it must be that $u_{D^{h}, t}$ rises by a greater percentage than $u_{M, t}$. Now, our functional-form assumptions imply

$$
\begin{aligned}
u_{M, t} & =v_{t} u_{L, t} \theta \frac{1}{M_{t}}, \\
u_{D^{h}, t} & =v_{t} u_{L, t}(1-\theta) \frac{1}{D_{t}^{h}},
\end{aligned}
$$

where

$$
u_{L, t}=\left[\frac{P_{t} C_{t}}{\left(M_{t}\right)^{\theta}\left(D_{t}^{h}\right)^{1-\theta}}\right]^{1-\sigma_{q}} .
$$


Then,

$$
\frac{u_{M, t}}{u_{D^{h}, t}}=\frac{\theta}{1-\theta} \frac{D_{t}^{h}}{M_{t}} .
$$

It follows that when the shadow value of current-period monetary base rises, then households allocate more base to currency.

With these considerations in mind, we can proceed to discuss the effects of a jump in $v_{t}$. According to our estimates (see Table 6), the monetary authority kept the monetary base roughly unchanged in response to a liquidity preference shock. At the same time, a jump in $v_{t}$ drives up the marginal utility of deposits and currency (see (27)-(28)). With the desire for liquidity up, and the total supply unchanged, the shadow value of liquidity, $\mu_{t}$, rises. By the argument in the previous paragraph, this induces households to reduce $D_{t}^{h} / M_{t}$. Since monetary policy keeps the sum of these two variables fixed, this requires reducing $D_{t}^{h}$ and raising $M_{t}$. Figure 9 displays the response of these variables, expressed as a ratio to their unshocked steady state growth paths, in response to a one-standard-deviation positive innovation in $v_{t}$ (for the magnitude of this shock, see Table 6 and the associated discussion.) Note how currency rises to a peak of about 1 percent above the steady state, while deposits fall by about 2 percent. In the quest for additional liquidity, households cut back on consumption and on the acquisition of time deposits. Figure 9 shows how these variables drop relative to their unshocked steady state growth paths. Time deposits eventually drop by 2 percent, and consumption eventually drops a little over 1 percent.

The reduced supply of reserves to banks leads to a drop in M1. These effects show up in interest rates. Figure 9 shows the interbank loan rate rises, at least initially.

Entrepreneurs feel the effects of these developments. The interest rate paid by nonbankrupt entrepreneurs rises, and this, together with the lost income due to the fall in capital rent in the slowing economy, drives up the bankruptcy rate (these are not shown). The latter rises to over one percent per quarter above the steady state value of 0.8 percent. Entrepreneurs cut back on purchases of new capital, and this leads capital producers to reduce investment. This leads to a fall in the price of capital, which exacerbates the fall in net worth. This fall further constrains the ability of entrepreneurs to purchase capital, leading to an additional fall in investment. In effect, the credit market restrictions have the effect of amplifying the negative output effects associated with the initial reductions in spending. Output ultimately falls over 1.5 percent in response to the one-standard-deviation jump in the liquidity preference shock. Investment falls over 4 percent.

Qualitatively, at least, all these effects resemble what actually happened to the economy after 1929. One exception is the interest rate, which rises initially. However, this effect is transient, and rates fall very soon after their initial rise. We suspect that this reflects the fall in money demand as the amount of economic activity declines. 


\section{Counterfactual Analysis}

We identify a monetary policy rule which, if implemented starting in 1929IV, would have resulted in a mild recession in the 1930s rather than the Great Depression. The rule feeds back on the monetary shocks only. ${ }^{40}$ The policy calls for a temporary increase in money growth in the periods after the shock. We pursue this type of policy in order to be consistent with the fact that there was essentially no scope for short-term interest rates to fall after 1932. We illustrate the importance of "backloading" the money response in this way by comparing it to a policy in which the full money base response is concentrated in the period of the shock ("frontloading"). This policy would have made the zero-bound restriction on the interest rate bind.

To describe the policy, it is convenient to reproduce the monetary policy rule in section 3.8:

$$
\log \left(\frac{M_{t+1}^{b}}{M_{t}^{b}}\right)=x \sum_{i}\left(x_{i, t}+1\right),
$$

where $x$ is the steady state net growth rate in the monetary base. Also, $x_{i, t}$ is the component of monetary policy that reacts to the $i^{\text {th }}$ shock:

$$
x_{i, t}=\theta_{i}^{0} \varphi_{i, t}+\theta_{i}^{1} \varphi_{i, t-1}+\theta_{i}^{2} x_{i, t-1} .
$$

When we backload policy, we set $\theta_{i}^{0}=0$ and $\theta_{i}^{1} \neq 0$, indicating that the monetary policy response does not begin until the period after the shock. In addition, we set $\theta_{i}^{2}>0$, so that part of the policy response occurs more than one period after the shock. We considered only those $i$ 's corresponding to the monetary shocks, $\xi_{t}, \theta_{t}$, and $v_{t}$. The policy we computed is one of "leaning against the wind." That is, if, in the absence of a monetary response, an innovation would lead to a fall in output, then our counterfactual policy calls for an increase in the base. Otherwise, the policy calls for a decrease.

In the case of shocks, $\xi_{t}$, to the bank demand for excess reserves, $\theta_{i}^{1}=-7$ and $\theta_{i}^{2}=0.85$. With this parameterization, the monetary base falls 0.55 percent in the period after a onestandard-deviation innovation in $\xi_{t}$. Because $\theta_{i}^{1}>0$, the monetary base continues to fall in later periods and it eventually stabilizes at a level 3.7 percent below where it would have been in the absence of a shock. ${ }^{41}$ This is a policy of "leaning against the wind" because a rise

\footnotetext{
${ }^{40}$ In some models an appropriately designed feedback rule can exactly neutralize the impact of money demand shocks on the economy. In our model, this is not the case, even though we consider monetary base rules that react to individual shocks. This can be seen by studying the equations that characterize equilibrium in our model (these are listed in the appendix). A given money demand shock and the money base growth rate appear asymmetrically across more than one equation. As a result, it is not possible to set the monetary base to exactly extinguish a shock.

${ }^{41}$ The contemporaneous response to an innovation of $\sigma$ in a shock is computed as $\sigma \times x \times \theta_{i}^{1} \times 100$, where $\sigma$ is found in Table 6 . The eventual response is $\sigma \times x \times \theta_{i}^{1} \times 100 /\left(1-\theta_{i}^{2}\right)$.
} 
in $\xi_{t}$ signifies a fall in bank demand for excess reserves, which would lead to an expansion in output in the absence of a monetary response. The policy response is substantially greater than what we estimated actually occurred (see Table 6 ).

In the case of $\theta_{t}, \theta_{i}^{1}=-1$, and $\theta_{i}^{2}=0.85$. Thus, the drop in the monetary base in the period after a one-standard-deviation innovation in $\theta_{t}$ is 0.08 percent. Eventually, the base falls by 0.55 percent. In the absence of any monetary policy response, an innovation in $\theta_{t}$ has the effect of stimulating output in our model. ${ }^{42}$ The response of the counterfactual policy to $\theta_{t}$ is somewhat weaker than what we estimated to have occurred. Finally, in the case of $v_{t}, \theta_{i}^{1}=2$, and $\theta_{i}^{2}=0.6$. As a result, the monetary base rises by 0.29 percent in the period after a one-standard-deviation innovation in $v_{t}$. Eventually, the monetary base rises by 0.72 percent in response to such a shock.

The dotted line in Figure 10 displays the dynamic behavior of the variables in our model, in response to all the estimated shocks and the counterfactual policy rule for the period 1929-1939. The solid line indicates the behavior of the same variables under the estimated monetary policy rule and shocks. We refer to this as the "baseline simulation." With one caveat, it corresponds to the dotted line in Figure 5. The caveat reflects our estimation strategy, which focusses on model means at the calibration stage, but abstracts from these at the stage where we estimate the parameters of the stochastic processes. ${ }^{43}$ One difference between the dotted line in Figure 5 and the baseline simulation in Figure 10 (solid line) that deserves emphasis is that the short-term interest rate (the "policy rate") is nearly 4 percentage points higher in Figure 10 than in Figure 5. Because of this, the interest rate in our model has a longer way to fall before hitting zero than the interest rate in the U.S. economy in the 1930s did. To make sure that we do not give ourselves any flexibility that policymakers in the 1930s did not have, we only considered counterfactual policies in which the interest rate never falls below the lowest value taken on by the interest rate in the baseline simulation.

Note first the dynamic behavior of real output. The magnitude of the contraction in the period 1929-1933 is cut substantially under the counterfactual policy (see Table 8). In the baseline simulation output falls by 26 percent (i.e., 4 times the 6.4 percent annual rate), while it falls only 6 percent under the counterfactual policy rule. Over the whole decade,

\footnotetext{
${ }^{42}$ To see why, note from (8) that since the currency-to-household-deposit ratio exceeds unity, one of the effects of an increase in $\theta_{t}$ is to raise the marginal utility of consumption. See Table 5 for the currency-tohousehold deposit ratio. (Note that the currency-to-deposit ratio is well below unity.) Given our parameterization, this is the dominant effect of an increase in $\theta_{t}$, and this is why a positive innovation in this shock stimulates output.

${ }^{43}$ Recall that the estimation strategy chooses parameter values of the stochastic processes in order to make the actual and model data in Figure 4 as close as possible. We abstract from the model's mean implications by adjusting the model data by a constant to ensure that model and empirical sample averages coincide. The variables in Figure 5 are just the variables in Figure 4, transformed. The baseline simulation reported in Figure 10 corresponds to the dotted line in Figure 5, except that no constant adjustments were made.
} 
output rises 8 percent under the counterfactual rule, versus the 10 percent fall recorded in the baseline. Output growth over the entire decade of the 1930s is 0.8 percent per year, a little over one-half its trend value of 1.5 percent. Initially, the interest rate falls relative to the baseline, but in the later part of the 1930s, it is higher than the baseline.

Turning to the other variables in the counterfactual simulation, consider first the monetary base. The rise in this variable over the full decade is 12 percent per year. The rise in the price level is roughly 3.2 percent per year. The counterfactual policy has a very substantial effect on asset values, driving up the real value of net worth by as much as 40 percent more after 1932. The impact on asset values before this is smaller, and perhaps this is the reason that the counterfactual policy does not have a large impact on investment until later. The counterfactual policy introduces some negatively correlated volatility in consumption and investment, which appears to cancel in output. We do not, as yet, understand the reason for this volatility.

It is interesting that the counterfactual policy has such a substantial stimulative impact on output without driving the interest rate down unduly. The reason for this is that the monetary policy response to shocks occurs primarily in the periods after the shock. As a result, the policy injects a substantial anticipated inflation effect into the interest rate. To illustrate this, we considered a monetary policy in which $\theta_{i}^{0}$ is replaced with $\theta_{i}^{0}=\theta_{i}^{1} /(1-$ $\theta_{i}^{2}$ ) and $\theta_{i}^{1}, \theta_{i}^{2}$ are both set to zero. With this policy the response of money to a shock is completely frontloaded. This reduces by a substantial amount the magnitude of the anticipated inflation effect on the interest rate. In addition, because the monetary response is completely unanticipated when it occurs, it has a relatively large impact on real allocations. To make the policy comparable to our counterfactual, we scaled the money responses to a shock by 0.69 so that the growth rate of output is 0.8 percent per year over the $1930 \mathrm{~s}$, as in the counterfactual policy in Table $8 .{ }^{44}$ Not surprisingly, with this alternative counterfactual, the rise in the price level is much less, only 0.8 percent per year in the 1930 s, versus 3.2 percent per year in the counterfactual (see Table 8 for the latter). In addition, M1 rises by less as well. The other variables in Table 8 are roughly unchanged. However, the interest rate response, displayed in Figure 11, is quite different. Under the alternative counterfactual, the interest rate drops substantially below the baseline simulation results. Such a large reduction in the interest rate could not have been implemented in the 1930s because it would have violated the zero lower bound constraint.

It is worth emphasizing that if the policy reaction function were stronger than it is in the counterfactual, then the output response would have been stronger as well. However, this would have come at the cost of substantially higher inflation. For example, when we set $\theta_{i}^{1}$ to 7 , rather than its value of 2 in the counterfactual, we found that average output growth

\footnotetext{
${ }^{44}$ Thus, we replaced $\theta_{i}^{0}$ with $\theta_{i}^{0}=0.69 \times \theta_{i}^{1} /\left(1-\theta_{i}^{2}\right)$.
} 
in the 1930 s is close to trend, 1.6 percent. However, this comes at the cost of substantially higher inflation. The annual inflation over the period 1929-1939 is 7.3 percent, and over the period $1933-1939$ it is 12.5 percent.

It is worth noting that the effectiveness of monetary policy in reducing the severity of the Great Depression depends very much on the state-contingent nature of the policy. To establish this, we considered a second alternative counterfactual experiment in which we instead adopted a completely deterministic monetary policy in 1929IV. In this policy, the money growth rate is roughly equal to the realized money growth in our counterfactual experiment. The impact on real variables of this policy was minor. This reflects that in the long run, monetary policy is roughly neutral in our model. Unexpected monetary policy, whether driven by exogenous random shocks or disturbances to the economy's fundamentals, do have a substantial effect. To document this, we simulated a version of our model in which the only shock driving the monetary base is an iid monetary policy shock. We picked the sequence of shocks to force the monetary base to grow as in our counterfactual experiment. We found that the impact on output and employment of this policy was roughly comparable to what we obtained in the counterfactual experiment.

We conclude this section by briefly indicating in what sense we confirm the hypothesis of Friedman and Schwartz (1963). Note that in our conterfactual experiment there is considerable growth in M1. In fact, we found that when monetary policy is designed to simply

prevent the decline in M1, this is not enough to substantially modify the course of the Great Depression in our model. In this sense we do not confirm Friedman and Schwartz, who argue that the 1930s would have been substantially improved if only the Fed had not permitted the drop in M1. We do confirm Friedman and Schwartz, however, in the sense that we identify a monetary policy that would have substantially reduced the severity of the Great Depression.

\section{Conclusion}

We have constructed a model of the U.S. economy in the 1920s and 1930s. The model deserves to be taken seriously as a laboratory for monetary policy because it reproduces key features of the data. According to the model, a liquidity preference shock played an important role in the contraction phase of the Great Depression. Increased market power of workers accounts for the persistently low level of employment and high real wages during the expansion phase of the Great Depression. The model indicates that a monetary policy which reacts to the innovations in the liquidity preference shock and other monetary shocks would have substantially reduced the magnitude of the Great Depression. This is consistent with the Friedman-Schwartz hypothesis.

The analysis of this paper suggests several avenues for future research. First, it would 
be of interest to see whether the liquidity preference shock plays an important role in other times and places, such as the postwar U.S., Japanese or Euro-area economies. In addition, it would be of interest to explore, at a more foundational level, the nature and sources of our liquidity preference shock. Second, our model incorporates various features: a banking sector, financing frictions, etc. Isolating the contribution of each of these features to the transmission of shocks is beyond the scope of this paper. However, doing so would provide crucial information for future model development. Third, in our analysis we have identified a particular feedback rule that relates the monetary base to the exogenous shocks, which would have mitigated the severity of the Great Depression. Discussions about monetary policy often focus on rules that relate variables such as the interest rate or the monetary base to endogenous variables such as inflation and the output gap. We conjecture that there are monetary policy rules like this that would, in practice, work like the one that we study, and it would be of interest to explore this further. Fourth, we have based our analysis on a linear approximation to the equilibrium conditions of the model. Given the relatively large size of the shocks during the Great Depression, it would be of interest to explore the robustness of the results to higher order approximations. Fifth, it would be of interest to explore optimal monetary policy in our model. Presumably, this requires a solution method which can accommodate an occasionally binding zero lower bound constraint on the interest rate. We suspect that such rules would involve accommodating money demand shocks, as our counterfactual rule does. 


\section{A Appendix: Model Solution}

This appendix reports the details of how we solved our model. The solution strategy involves linearization about the model's nonstochastic steady state. After a brief overview, we discuss the computation of the steady state. We then present the linearized equations of the model. The model solution was described in section 3.9. It involves a set of core endogenous variables, $\tilde{z}_{t}$. The variables in this 23 by 1 vector are:

$$
\tilde{z}_{t}=\left(\begin{array}{c}
\hat{\pi}_{t} \\
\hat{s}_{t} \\
\hat{r}_{t}^{k} \\
\hat{\imath}_{t} \\
\hat{u}_{t} \\
\hat{\bar{\omega}}_{t} \\
\hat{R}_{t}^{k} \\
\hat{n}_{t+1} \\
\hat{q}_{t} \\
\hat{\nu}_{t} \\
\hat{e}_{\nu, t} \\
\hat{m}_{t}^{b} \\
\hat{R}_{t}^{b} \\
\hat{u}_{c, t}^{z} \\
\hat{\lambda}_{z, t} \\
\hat{m}_{t} \\
\hat{R}_{a, t} \\
\hat{c}_{t} \\
\hat{w}_{t} \\
\hat{l}_{t} \\
\hat{\bar{k}}_{t+1} \\
\hat{R}_{t+1}^{e} \\
\hat{x}_{t}
\end{array}\right)
$$

Here, and throughout this paper, a hat $\left({ }^{\wedge}\right)$ over a variable indicates percent deviation from its nonstochatic steady state. That is, if $x$ is the steady state value of $x_{t}$, then $\hat{x}_{t}=\left(x_{t}-x\right) / x$. Most of the variables in $\tilde{z}_{t}$ have been defined before. One exception is real marginal cost for intermediate-good producers:

$$
s_{t}=\left(\frac{1}{1-\alpha}\right)^{1-\alpha}\left(\frac{1}{\alpha}\right)^{\alpha} \frac{\left(r_{t}^{k}\left[1+\psi_{k} R_{t}\right]\right)^{\alpha}\left(w_{t}\left[1+\psi_{l} R_{t}\right]\right)^{1-\alpha}}{\epsilon_{t}} .
$$

In addition, we adopt the following scaling of variables:

$$
\begin{aligned}
& w_{t}=\frac{W_{t}}{z_{t} P_{t}}, q_{t}=\frac{Q_{\bar{K}^{\prime}, t}}{P_{t}}, n_{t+1}=\frac{N_{t+1}}{P_{t} z_{t}}, \bar{k}_{t+1}=\frac{\bar{K}_{t+1}}{z_{t}}, m_{t}^{b}=\frac{M_{t}^{b}}{P_{t} z_{t}}, \\
& m_{t}=\frac{M_{t}}{M_{t}^{b}}, \quad c_{t}=\frac{C_{t}}{z_{t}}, i_{t}=\frac{I_{t}}{z_{t}}
\end{aligned}
$$


Finally, $e_{v, t}$ is the ratio of real excess reserves to value-added in the banking sector:

$$
e_{v, t}=\frac{\frac{A_{t}+X_{t}-\tau\left(A_{t}+X_{t}+S_{t}^{w}\right)}{P_{t}}}{\left(z_{t}\left(1-\nu_{t}\right) u_{t} \bar{k}_{t} / \mu_{z}\right)^{\alpha}\left(z_{t}\left(1-\nu_{t}\right) l_{t}\right)^{1-\alpha}}
$$

To solve for the 23 variables in $\tilde{z}_{t}$, we linearize 23 equations of our model. We express these in matrix form as follows:

$$
E_{t}\left[\alpha_{0} \tilde{z}_{t+1}+\alpha_{1} \tilde{z}_{t}+\alpha_{2} \tilde{z}_{t-1}+\beta_{0} \Psi_{t+1}+\beta_{1} \Psi_{t}\right]=0
$$

We seek a solution of the form, (19), which ensures that (30) is satisfied for all possible $\tilde{z}_{t-1}$ and $\Psi_{t}$, and which is covariance stationary. This requires an $A$ and $B$ that satisfy:

$$
\begin{aligned}
\alpha_{0} A^{2}+\alpha_{1} A+\alpha_{2} I & =0 \\
\alpha_{0}(A B+B \rho)+\alpha_{1} B+\beta_{0} \rho+\beta_{1} & =0 .
\end{aligned}
$$

We found that there is a unique $A$ with eigenvalues inside the unit circle that satisfies the first equation. Conditional on this value of $A$, the second set of equations is linear in $B$.

To complete our discussion of the solution method requires explaining how $\alpha_{0}, \alpha_{1}, \alpha_{2}$, $\beta_{0}$, and $\beta_{1}$ were computed. This requires a discussion of the steady state of the model and of the actual equations in (30).

\section{A.1 Model Steady State}

This section describes our strategy for computing the steady state for our model. In many models, solving for the steady state is straightforward, because one can find a recursive ordering among the equations. We were not able to do so for our model, and so the computation of the steady state represents a considerable challenge. We developed two strategies. In the first one we set some of the endogenous variables of the model to values that seem reasonable based on empirical evidence, making these variables exogenous in the steady state calculations. We moved an equal number of the model's exogenous variables into the list of variables that were endogenous in the steady state calculations. This approach allowed us to reduce the problem of computing the steady state to the relatively manageable one of solving a single equation in a single unknown. This approach works well for solving our baseline model. However, it is impractical when we considered a counterfactual experiment in which it was desired to change the value of one (and only one) exogenous variable. ${ }^{45} \mathrm{~A}$ second strategy was developed for this. We now describe the two strategies. Our description refers to the steady state formulas which are derived subsequently.

\footnotetext{
${ }^{45}$ In the main text, we discuss the results of this experiment, where we change the value of the money growth rate, $\mu$.
} 
For the first strategy, the set of exogenously set variables are:

$$
\begin{aligned}
& \tau^{l}, \beta, F(\bar{\omega}), \mu, x, \mu_{z}, \lambda_{f}, \lambda_{w}, \alpha, \psi_{k}, \psi_{l}, \delta, v \\
& \tau^{k}, \gamma, \tau, \sigma_{L}, \zeta, \sigma_{q}, \theta, v, w^{e}, \nu^{l}, \nu^{k}, m, \eta_{g}, r^{k} .
\end{aligned}
$$

The variables to be solved for are:

$$
\begin{aligned}
& q, \pi, R^{e}, R_{a}, h_{e^{r}}, R, R^{k}, \bar{\omega}, k, n, i, w, l, c, u_{c}^{z}, m^{b}, \\
& \lambda_{z}, \psi_{L}, e_{z}^{r}, e_{v}, x^{b}, \xi, h_{K^{b}}, y, g, \sigma .
\end{aligned}
$$

The equations available for solving for these unknowns are summarized below. The first three variables are trivial functions of the structural parameters, and from here on we treat them as known. In addition, $R_{a}$ can be solved using equation (51) below. There remain 22 unknowns. Below, we have 22 equations that can be used to solve for them.

The algorithm involves finding a value of $R$ that solves (40). To evaluate (40) requires first solving for the other 'endogenous' variables. For a given $R$, we proceed as follows. Solve for $h_{e^{r}}$ using (46). Solve for $R^{k}$ using (36); solve for $\bar{\omega}$ using (37); solve for $\sigma$ using the given values of $F(\bar{\omega})$ and $\bar{\omega}$, as well as the condition, $E \omega=1$; solve for $k$ and $n$ using (38) and (39); solve for $i$ using (35); solve for $w$ using (31); solve for $l$ using (33); solve for $c$ using (55); solve (56) and (54) for $g$ and $y$; solve for $u_{c}^{z}$ using (52); solve for $m^{b}$ and $\lambda_{z}$ using (49) and (50); solve (53) for $\psi_{L}$; solve for $e_{z}^{r}$ using (48); solve $\xi$ from (47); solve $e_{v}$ from (43); solve $x^{b}$ from (42); $h_{K^{b}}$ from (41). Vary $R$ until (40) is satisfied. In these calculations, all variables must be positive, and:

$$
0 \leq m \leq 1+x, 0 \leq \xi \leq 1, \lambda_{z}>0, k>n>0
$$

Our second strategy solves the steady state when the 'exogenous variables' are the economically exogenous ones, and the 'endogenous variables' are the economically endogenous ones. In particular, consider the situation in which the exogenous variables are:

$$
\begin{aligned}
& \tau^{l}, \beta, \mu, x, \mu_{z}, \lambda_{f}, \lambda_{w}, \alpha, \psi_{k}, \psi_{l}, \delta, v, x^{b}, \xi, \sigma \\
& \tau^{k}, \gamma, \tau, \sigma_{L}, \zeta, \sigma_{q}, \theta, v, w^{e}, \nu^{l}, \eta_{g}, \psi_{L} .
\end{aligned}
$$

and the variables to be solved for are:

$$
\begin{aligned}
& q, \pi, R^{e}, R_{a}, h_{e^{r}}, r^{k}, R^{k}, \bar{\omega}, F(\bar{\omega}), k, n, i, w, l, c, u_{c}^{z} \\
& m^{b}, R, \lambda_{z}, e_{z}^{r}, e_{v}, h_{K^{b}}, y, g, \nu^{k}, m .
\end{aligned}
$$

We solve for the 26 variables above as follows. The first three are solved in the same way as before. The remainder are solved by solving three equations, (40), (42), and (46), in the 
three unknowns, $r^{k}, \nu^{k}$, and $R$. Ideally, we start in a neighborhood of the solution obtained in the previous calculations. Fix a set of values for $r^{k}, \nu^{k}$, and $R$. The basic sequence of calculations is the same as above. Solve for $R^{k}$ using $(36)$, and then $\bar{\omega}, F(\bar{\omega})$ using $(37)$ and the value of $\sigma$. Then, solve for $k, n$, and $i$ using (38), (39), and (35), in that order. Next, we obtain $w$ from (31) and $l$ from (33). The resource constraint, (55), can be used to obtain $c$; and (56) and (54) can be used to compute $y, g$. Then, obtain $\lambda_{z}$ and $u_{c}^{z}$ from (52) and (53). Solve (49), (50) and (51) for $R_{a}, m$, and $m^{b}$. This can be made into a one-dimensional search in $m$. In particular, for a given $m$, solve for $R_{a}$ from (51) and for $m^{b}$ from (49). Vary $m$ until (50) is satisfied. In this search, the lower bound on $m$ is zero, while the upper bound is $\theta(1+x)$, and is dictated by $R_{a} \geq 0$. Compute $h_{e^{r}}, h_{K^{b}}, e_{\nu}$, and $e_{z}^{r}$, using (41), (43), (47), and (48). We can now evaluate (40), (42), and (46). Vary $r^{k}, \nu^{k}$, and $R$ until these equations are satisfied.

The equations that $r^{k}, \nu^{k}$ and $R$ solve are not well behaved. They are not well defined for all possible values of $r^{k}, \nu^{k}$ and $R$. Typically, this happens because there is no $m$ that satisfies (50). We found that if the equations are defined for a particular set of values of $r^{k}, \nu^{k}$, and $R$, then they are not defined for what seems like a tiny perturbation. Equations of this type are hard to solve with standard Gauss-Newton algorithm, unless one has an extremely good idea of the exact solution. To find such a solution, we applied a random search method. We made a guess of the true solution, and then constructed an interval about that solution. We drew randomly from that interval, and recorded the parameter constellation which produced the outcome closest to zero for the equations of interest. After the algorithm ran for 5 minutes or so, it had found a solution close enough that a Gauss-Newton method could take over and productively drive into the exact solution for $r^{k}, \nu^{k}$, and $R$.

We now describe the equations of the steady state.

\section{A.1.1 Firms}

From the equations that characterize the firm sector and the assumption that there are no price distortions in a steady state, we have

$$
s=\frac{1}{\lambda_{f}}
$$

Also, evaluating (29) in steady state:

$$
\frac{1}{\lambda_{f}}=\left(\frac{1}{1-\alpha}\right)^{1-\alpha}\left(\frac{1}{\alpha}\right)^{\alpha}\left(r^{k}\left[1+\psi_{k} R\right]\right)^{\alpha}\left(w\left[1+\psi_{l} R\right]\right)^{1-\alpha} .
$$

In addition to (29), real marginal cost is also equated to the ratio of the real marginal cost of renting capital to its marginal product:

$$
s_{t}=\frac{r_{t}^{k}\left[1+\psi_{k, t} R_{t}\right]}{\alpha \epsilon_{t}\left(\frac{\mu_{z, t} l_{t}}{k_{t}}\right)^{1-\alpha}}
$$


Combining (29) with (32) in steady state:

$$
\frac{r^{k}\left[1+\psi_{k} R\right]}{w\left[1+\psi_{l} R\right]}=\frac{\alpha}{1-\alpha} \frac{\mu_{z} l}{\bar{k}}
$$

\section{A.1.2 Capital Producers}

The first-order necessary condition for maximization of $I_{t}$ for the capital producers is

$$
E_{t}\left[\lambda_{t} P_{t} q_{t} F_{1, t}-\lambda_{t} P_{t}+\beta \lambda_{t+1} P_{t+1} q_{t+1} F_{2, t+1}\right]=0 .
$$

Here, $F_{1 t}$ and $F_{2 t}$ denote the derivatives of the adjustment cost function with respect to its first and second arguments. Multiplying the first-order condition by $z_{t} / P_{t}$ we obtain, in steady state:

$$
\lambda_{z} q F_{1}-\lambda_{z}+\frac{\beta}{\mu_{z}} \lambda_{z} q F_{2} \pi=0 .
$$

Since $F_{1}=1$, and $F_{2}=0$,

$$
q=1
$$

Also,

$$
\bar{k}_{t+1}=(1-\delta) \frac{1}{\mu_{z, t}} \bar{k}_{t}+\left[1-S\left(\frac{i_{t} \mu_{z, t}}{i_{t-1}}\right)\right] i_{t},
$$

so that in steady state, when $S=0$,

$$
\frac{i}{\bar{k}}=1-\frac{1-\delta}{\mu_{z}}
$$

\section{A.1.3 Entrepreneurs}

From the entrepreneurs:

$$
r^{k}=a^{\prime}
$$

Also,

$$
u=1 \text {. }
$$

The after-tax rate of return on capital, in steady state, is:

$$
R^{k}=\left[\left(1-\tau^{k}\right) r^{k}+(1-\delta)\right] \pi+\tau^{k} \delta-1
$$

Conditional on a value for $R^{k}, R^{e}$, the steady state value for $\bar{\omega}$ may be found using the following equation:

$$
[1-\Gamma(\bar{\omega})] \frac{1+R^{k}}{1+R^{e}}+\frac{1}{1-\mu \bar{\omega} h(\bar{\omega})}\left[\frac{1+R^{k}}{1+R^{e}}(\Gamma(\bar{\omega})-\mu G(\bar{\omega}))-1\right]=0
$$


where the hazard rate, $h$, is defined as follows:

$$
h(\omega)=\frac{F^{\prime}(\omega)}{1-F(\omega)} .
$$

This equation has two additional parameters, the two parameters of the lognormal distribution, $F$. These two parameters, however, are pinned down by the assumption $E \omega=1$ and the fact that we specify $F(\bar{\omega})$ exogenously. With these conditions, (37) forms a basis for computing $\bar{\omega}$. Note here that when $\mu=0$, (37) reduces to $R^{k}=R^{e}$. Then, combining (36) with the first-order condition for time deposits, we end up with the conclusion that $r^{k}$ is determined as it is in the neoclassical growth model.

From the single first-order condition for $k$ in the costly-state-verification problem, and conditional on $F(\bar{\omega})$ and $\bar{\omega}$, we may solve for $k$, thus obtaining: ${ }^{46}$

$$
\frac{\bar{k}}{n}=\frac{1}{1-\frac{1+R^{k}}{1+R^{e}}(\Gamma(\bar{\omega})-\mu G(\bar{\omega}))} .
$$

The law of motion for net worth implies the following relation in steady state:

$$
n=\frac{\frac{\gamma}{\pi \mu_{z}}\left[R^{k}-R^{e}-\mu G(\bar{\omega})\left(1+R^{k}\right)\right] \bar{k}+w^{e}}{1-\gamma\left(\frac{1+R^{e}}{\pi}\right) \frac{1}{\mu_{z}}} .
$$

\section{A.1.4 Banks}

The first-order condition associated with the bank's capital decision is:

$$
\left(1+\psi_{k} R\right) r^{k}=\frac{R h_{K^{b}}}{1+\tau h_{e^{r}}}
$$

The first-order condition for labor is redundant given (31), (33), and (40), and so we do not list it here. In (40),

$$
\begin{gathered}
h_{K^{b}}=\alpha \xi x^{b}\left(e_{v}\right)^{1-\xi}\left(\frac{\mu_{z} l}{k}\right)^{1-\alpha}, \\
h_{e^{r}}=(1-\xi) x^{b}\left(e_{v}\right)^{-\xi},
\end{gathered}
$$

and

$$
e_{v}=\frac{(1-\tau) m^{b}(1-m+x)-\tau\left(\psi_{l} w l+\frac{1}{\mu_{z}} \psi_{k} r^{k} \bar{k}\right)}{\left(\frac{1}{\mu_{z}}\left(1-\nu^{k}\right) \bar{k}\right)^{\alpha}\left(\left(1-\nu^{l}\right) l\right)^{1-\alpha}}
$$

The first-order conditions associated with the bank's supply of deposits to households, $A_{t}$, and working-capital loans, $S_{t}^{w}$, are, respectively,

$$
-R_{a t}+\lambda_{t}^{b} \frac{1}{P_{t}}\left[\left(1-\tau_{t}\right) h_{e^{r}, t}-1\right]=0
$$

\footnotetext{
${ }^{46}$ See BGG for details.
} 


$$
R_{t}-\lambda_{t}^{b} \frac{1}{P_{t}}\left[\tau h_{e^{r}, t}+1\right]=0
$$

where $\lambda_{t}^{b}$ is the multiplier on the technology associated with the provision of bank deposits. Hence, another efficiency condition for the banks can be obtained by taking the ratio of (45) to (44). Rewriting that ratio, we obtain:

$$
1+\frac{R}{R_{a}}=h_{e^{r}}\left[(1-\tau) \frac{R}{R_{a}}-\tau\right]
$$

Substituting out for $a^{b} x^{b}\left(e_{v}\right)^{-\xi}$ from (42) into the scaled production function, we obtain:

$$
\frac{h_{e^{r}}}{(1-\xi)} e_{z}^{r}=m^{b}(1-m+x)+\psi_{l} w l+\psi_{k} r^{k} \frac{\bar{k}}{\mu_{z}},
$$

where

$$
e_{z}^{r}=(1-\tau) m^{b}(1-m+x)-\tau\left(\psi_{l} w l+\psi_{k} r^{k} \frac{\bar{k}}{\mu_{z}}\right)
$$

\section{A.1.5 Households}

The first-order condition for $T$ is

$$
1+R^{e}=\frac{\mu_{z} \pi}{\beta}
$$

The first-order condition for $M$ :

$$
\begin{array}{r}
v\left[c\left(\frac{1}{m}\right)^{\theta}\left(\frac{1}{1-m+x}\right)^{1-\theta}\right]^{1-\sigma_{q}}\left[\frac{\theta}{m}-\frac{1-\theta}{1-m+x}\right]\left(m^{b}\right)^{\sigma_{q}-2} \\
-\lambda_{z} R_{a}=0 .
\end{array}
$$

The first-order condition for $M^{b}$

$$
\begin{array}{r}
v(1-\theta)\left[c\left(\frac{1}{m}\right)^{\theta}\left(\frac{1}{1-m+x}\right)^{1-\theta}\right]^{1-\sigma_{q}} \\
\left(\frac{1}{m^{b}}\right)^{2-\sigma_{q}}\left(\frac{1}{1-m+x}\right) \\
=\pi \lambda_{z}\left\{\frac{\mu_{z}}{\beta}-\frac{\left(1+R_{a}\right)}{\pi}\right\} .
\end{array}
$$

The first-order condition for consumption corresponds to:

$$
u_{c}^{z}-\lambda_{z}=v c^{-1}\left(m^{b}\right)^{\sigma_{q}-1}\left[c\left(\frac{1}{m}\right)^{\theta}\left(\frac{1}{1-m+x}\right)^{1-\theta}\right]^{1-\sigma_{q}} .
$$

Taking the ratio of (49) and the first-order conditions for $m^{b}$, and rearranging, we obtain:

$$
\begin{aligned}
R_{a} & =\frac{\frac{(1-m+x)}{m} \theta-(1-\theta)}{\frac{(1-m+x)}{m} \theta}\left(\frac{\pi \mu_{z}}{\beta}-1\right) \\
& =\left[1-\frac{m}{1-m+x} \frac{(1-\theta)}{\theta}\right] R^{e}
\end{aligned}
$$


Note that non-negativity of $R_{a}$ requires $m \leq \theta(1+x)$. The marginal utility of consumption is:

$$
c u_{c}^{z}=\frac{\mu_{z,}}{\mu_{z}-b}-b \beta \frac{1}{\mu_{z}-b}=\frac{\mu_{z}-b \beta}{\mu_{z}-b} .
$$

The first-order condition for households setting wages is:

$$
w \frac{\lambda_{z}\left(1-\tau^{l}\right)}{\lambda_{w}}=\zeta \psi_{L} l^{\sigma_{L}}
$$

\section{A.1.6 Monetary Authority}

$$
\pi=\frac{(1+x)}{\mu_{z}}
$$

\section{A.1.7 Resource Constraint and Zero Profits}

After substituting out for the fixed cost in the resource constraint using the restriction that firm profits are zero in steady state and using

$$
g=\eta_{g} y
$$

we obtain:

$$
c=\left(1-\eta_{g}\right)\left[\frac{1}{\lambda_{f}}\left(\frac{1}{\mu_{z}} \nu^{k} k\right)^{\alpha}\left(\nu^{l} l\right)^{1-\alpha}-\mu G(\bar{\omega})\left(1+R^{k}\right) \frac{k}{\mu_{z} \pi}\right]-i .
$$

The object in square brackets is gross national product, $y$, so that (55) corresponds to $c+i+g=y$. To see that the object in square brackets indeed is $y$, consider:

$$
y=\left(\frac{1}{\mu_{z}} \nu^{k} k\right)^{\alpha}\left(\nu^{l} l\right)^{1-\alpha}-\phi-\mu G(\bar{\omega})\left(1+R^{k}\right) \frac{k}{\mu_{z} \pi},
$$

Write the first two expressions after the equality as $F-\phi$. These are the revenues, in units of goods, paid to the typical intermediate-goods producer. The total cost of producing these goods is $s F$, where $s$ denotes marginal cost. In steady state, $s=1 / \lambda_{f}$. Zero profits requires that revenues equal costs, so that $F / \lambda_{f}=F-\phi$, or, $\phi=F\left(1-1 / \lambda_{f}\right)$, or

$$
\phi=\left(\frac{\nu^{k} k}{\mu_{z}}\right)^{\alpha}\left(\nu^{l} l\right)^{1-\alpha}\left(1-\frac{1}{\lambda_{f}}\right) .
$$

We obtain the expression for gross national product in the square brackets in (55) by substituting out for $\phi$ in (56) from (57).

\section{A.2 Linearizing the Model Economy}

This section describes the 23 equations that characterize the equilibrium for our model economy. In each case, we present the log-linear expansion of the equation about the nonstochastic steady state. With a few exceptions, we also present the non-linear representation of the equation. 


\section{A.2.1 Firms}

The log-linearized expression for inflation in our model is taken directly from Christiano, Eichenbaum, and Evans (2003):

$$
E_{t}\left[\hat{\pi}_{t}-\frac{1}{1+\beta} \hat{\pi}_{t-1}-\frac{\beta}{1+\beta} \hat{\pi}_{t+1}-\frac{\left(1-\beta \xi_{p}\right)\left(1-\xi_{p}\right)}{(1+\beta) \xi_{p}}\left(\hat{s}_{t}+\hat{\lambda}_{f, t}\right)\right]=0 .
$$

Linearizing the expression for the real marginal cost for a firm producing intermediate goods, (29), we obtain:

$$
\alpha \hat{r}_{t}^{k}+(1-\alpha) \hat{w}_{t}+\left[\frac{\alpha \psi_{k} R}{1+\psi_{k} R}+\frac{(1-\alpha) \psi_{l} R}{1+\psi_{l} R}\right] \hat{R}_{t}-\hat{\epsilon}_{t}-\hat{s}_{t}=0
$$

Linearizing (32),

$$
\hat{r}_{t}^{k}+\frac{\psi_{k} R}{1+\psi_{k} R} \hat{R}_{t}-\hat{\epsilon}_{t}-(1-\alpha)\left(\hat{l}_{t}-\left[\widehat{\bar{k}}_{t}+\hat{u}_{t}\right]\right)-\hat{s}_{t}=0
$$

\section{A.2.2 Capital Producers}

Following Christiano, Eichenbaum, and Evans (2003), we suppose that $F\left(I_{t}, I_{t-1}\right)$ has the following form:

$$
F\left(I_{t}, I_{t-1}\right)=\left[1-S\left(I_{t} / I_{t-1}\right)\right] I_{t}
$$

where $S^{\prime \prime}$ denotes the second derivative of $S$, evaluated at the steady state value of $I_{t} / I_{t-1}$. In addition, we suppose that $S=S^{\prime}=0$ in steady state. Recalling that the the first-order necessary condition for maximization of $I_{t}$ for the capital producers can be written:

$$
E_{t}\left[\lambda_{z t} q_{t} F_{1, t}-\lambda_{z, t}+\frac{\beta}{\mu_{z, t+1}} \lambda_{z, t+1} q_{t+1} F_{2, t+1} \pi_{t+1}\right]=0,
$$

we linearize this expression as,

$$
E_{t}\left[\hat{q}_{t}-S^{\prime \prime} \mu_{z}^{2}(1+\pi \beta) \hat{\imath}_{t}+S^{\prime \prime} \mu_{z}^{2} \hat{\imath}_{t-1}+\beta S^{\prime \prime} \pi \mu_{z}^{2} \hat{\imath}_{t+1}\right]=0
$$

\section{A.2.3 Entrepreneurs}

There are five equations pertaining to entrepreneurs. The first is the optimality condition associated with the entrepreneur's capital utilization decision:

$$
r_{t}^{k}-a^{\prime}\left(u_{t}\right)=0
$$

After linearization, this reduces to:

$$
E \hat{r}_{t}^{k}-\sigma_{a} \hat{u}_{t}=0
$$


where $\sigma_{a}=a^{\prime \prime} / a^{\prime}$ and $a^{\prime \prime}, a^{\prime}$ denote the second and first derivatives of $a$, respectively, evaluated in steady state.

Of the other four equations corresponding to the entrepreneurial sector, two characterize the loan contracts received from banks. The third defines the law of motion of entrepreneurial net worth. The fourth defines the rate of return on capital earned by entrepreneurs.

The necessary condition associated with optimality of the loan contract received by entrepreneurs from banks is:

$E_{t}\left\{\left[1-\Gamma_{t}\left(\bar{\omega}_{t+1}\right)\right] \frac{1+R_{t+1}^{k}}{1+R_{t+1}^{e}}+\frac{\Gamma_{t}^{\prime}\left(\bar{\omega}_{t+1}\right)}{\Gamma_{t}^{\prime}\left(\bar{\omega}_{t+1}\right)-\mu G_{t}^{\prime}\left(\bar{\omega}_{t+1}\right)}\left[\frac{1+R_{t+1}^{k}}{1+R_{t+1}^{e}}\left(\Gamma_{t}\left(\bar{\omega}_{t+1}\right)-\mu G_{t}\left(\bar{\omega}_{t+1}\right)\right)-1\right]\right\}=0$.

Here, $R_{t+1}^{e}$ is the rate of return received by households, which is constrained not to be a function of the realization of date $t+1$ random variables. The functions $G_{t}$ and $\Gamma_{t}$ are defined as follows:

$$
\begin{aligned}
G_{t}\left(\bar{\omega}_{t+1}\right) & =\int_{0}^{\bar{\omega}_{t+1}} \omega d F_{t}(\omega) . \\
\Gamma_{t}\left(\bar{\omega}_{t+1}\right) & =\bar{\omega}_{t+1}\left[1-F_{t}\left(\bar{\omega}_{t+1}\right)\right]+G_{t}\left(\bar{\omega}_{t+1}\right),
\end{aligned}
$$

where $F_{t}$ denotes the cumulative distribution function for $\omega_{t+1}$. Here, a prime indicates derivative with respect to $\bar{\omega}_{t+1}$. We assume that $F_{t}$ corresponds to a lognormal distribution with a mean of zero and a standard-deviation, $\sigma_{t}$. The second equation that characterizes the optimal contract corresponds to the condition that bank profits are zero in each state of nature:

$$
\frac{Q_{\bar{K}^{\prime}, t} \bar{K}_{t+1}}{N_{t+1}} \frac{1+R_{t+1}^{k}}{1+R_{t+1}^{e}}\left(\Gamma_{t}\left(\bar{\omega}_{t+1}\right)-\mu G_{t}\left(\bar{\omega}_{t+1}\right)\right)-\frac{Q_{\bar{K}^{\prime}, t} \bar{K}_{t+1}}{N_{t+1}}+1=0 .
$$

After scaling, this reduces to:

$$
\frac{q_{t} \bar{k}_{t+1}}{n_{t+1}} \frac{1+R_{t+1}^{k}}{1+R_{t+1}^{e}}\left(\Gamma_{t}\left(\bar{\omega}_{t+1}^{N}\right)-\mu G_{t}\left(\bar{\omega}_{t+1}^{N}\right)\right)-\frac{q_{t} \bar{k}_{t+1}}{n_{t+1}}+1=0 .
$$

For a detailed discussion of the two equations that characterize the optimal contract, see Bernanke, Gertler and Gilchrist (1999).

Linearizing the efficiency condition associated with the optimal contract, we obtain:

$$
\begin{array}{r}
E_{t}\left\{\lambda\left(\frac{R^{k} \hat{R}_{t+1}^{k}}{1+R^{k}}-\frac{R^{e} \hat{R}_{t+1}^{e}}{1+R^{e}}\right)\right. \\
-[1-\Gamma] \frac{1+R^{k}}{1+R^{e}}\left[\frac{\Gamma_{\omega \omega} \bar{\omega}}{\Gamma_{\omega}}-\frac{\lambda\left[\Gamma_{\omega \omega}-\mu G_{\omega \omega}\right] \bar{\omega}}{\Gamma_{\omega}}\right] \widehat{\bar{\omega}}_{t+1} \\
\left.+\frac{1+R^{k}}{1+R^{e}}\left(\sigma\left[-\Gamma_{\sigma}+\lambda\left(\Gamma_{\sigma}-\mu G_{\sigma}\right)\right]-[1-\Gamma]\left[\frac{\Gamma_{\omega \sigma} \sigma}{\Gamma_{\omega}}-\frac{\lambda\left[\Gamma_{\omega \sigma}-\mu G_{\omega \sigma}\right] \sigma}{\Gamma_{\omega}}\right]\right) \hat{\sigma}_{t}\right\}=0 .
\end{array}
$$


Here, $\Gamma_{\omega \omega}$ and $G_{\omega \omega}$ denote the second derivatives of $\Gamma$ and $G$ with respect to $\bar{\omega}$, evaluated in steady state. Also, $\Gamma_{\sigma}$ and $G_{\sigma}$ denote the derivatives with respect to $\sigma$ in steady state, and $\Gamma_{\omega \sigma}$ and $G_{\omega \sigma}$ represent the corresponding cross derivatives. Finally, $\lambda$ denotes the steady state value of the multiplier on the bank zero-profit condition in the Lagrangian representation of the problem solved by the optimal contract. It is:

$$
\lambda=\frac{\Gamma_{\omega}}{\Gamma_{\omega}-\mu G_{\omega}}
$$

The linearized zero-profit condition is:

$$
\begin{aligned}
&\left(\frac{\bar{k}}{n}-1\right) \frac{R^{k}}{1+R^{k}} \hat{R}_{t}^{k}-\left(\frac{\bar{k}}{n}-1\right) \frac{R^{e}}{1+R^{e}} \hat{R}_{t}^{e}+\left(\frac{\bar{k}}{n}-1\right) \frac{\left(\Gamma_{\omega}-\mu G_{\omega}\right)}{(\Gamma-\mu G)} \bar{\omega}_{\bar{\omega}_{t}} \\
&+\left(\frac{\bar{k}}{n}-1\right) \frac{\left(\Gamma_{\sigma}-\mu G_{\sigma}\right)}{(\Gamma-\mu G)} \sigma \hat{\sigma}_{t-1}-\left(\hat{q}_{t-1}+\widehat{\bar{k}}_{t}-\hat{n}_{t}\right)=0 .
\end{aligned}
$$

The law of motion governing the evolution of aggregate net worth is, after scaling:

$$
n_{t+1}=\frac{\gamma_{t}}{\pi_{t} \mu_{z}}\left\{R_{t}^{k}-R_{t}^{e}-\mu\left[\int_{0}^{\bar{\omega}_{t}} \omega d F_{t-1}(\omega)\right]\left(1+R_{t}^{k}\right)\right\} \bar{k}_{t} q_{t-1}+w_{t}^{e}+\gamma_{t}\left(\frac{1+R_{t}^{e}}{\pi_{t}}\right) \frac{1}{\mu_{z}} n_{t} .
$$

Here, $\gamma_{t}$ is the probability that an entrepreneur survives from time- $t$ to time- $t+1$. Also, $w_{t}^{e}=W_{t}^{e} /\left(z_{t} P_{t}\right)$ and $W_{t}^{e}$ is a transfer made to each entrepreneur in existence in time- $t+1$. This includes the $\gamma_{t}$ who were alive in time- $t$ and survive into time- $t+1$, as well as the $1-\gamma_{t}$ new entrepreneurs born in time- $t$. The linearized law of motion for scaled net worth is:

$$
\begin{aligned}
& -\hat{n}_{t+1}+a_{0} \hat{R}_{t}^{k}+a_{1} \hat{R}_{t}^{e}+a_{2}\left(\hat{\bar{k}}_{t}+\hat{q}_{t-1}\right)+a_{4}\left(\hat{\gamma}_{t}-\hat{\pi}_{t}\right) \\
& +a_{8} \widehat{\bar{\omega}}_{t}+a_{9} \hat{n}_{t}+a_{10} \hat{\sigma}_{t-1}=0 .
\end{aligned}
$$

where

$$
\begin{aligned}
& a_{0}=\frac{\gamma}{\pi \mu_{z}}(1-\mu G) \frac{\bar{k} q}{n} R^{k} \\
& a_{1}=\left(1-\frac{\bar{k} q}{n}\right) \frac{\gamma R^{e}}{\pi \mu_{z}} \\
& a_{2}=\frac{\gamma}{\pi \mu_{z}}\left\{R^{k}-R^{e}-\mu G\left(1+R^{k}\right)\right\} \frac{\bar{k} q}{n} \\
& a_{4}=a_{2}+\frac{\gamma\left(1+R^{e}\right)}{\mu_{z} \pi} \\
& a_{8}=-\frac{\gamma}{\pi \mu_{z}} \mu G_{\omega}\left(1+R^{k}\right) \frac{\bar{k} q}{n} \bar{\omega} \\
& a_{9}=\gamma\left(\frac{1+R^{e}}{\pi}\right) \frac{1}{\mu_{z}} \\
& a_{10}=-\frac{\gamma}{\pi \mu_{z}} \mu G_{\sigma}\left(1+R^{k}\right) \frac{\bar{k} q}{n} \sigma
\end{aligned}
$$


We define the rate of return on capital as follows:

$$
R_{t+1}^{k}=\frac{\left(1-\tau^{k}\right)\left[u_{t+1} r_{t+1}^{k}-a\left(u_{t+1}\right)\right]+(1-\delta) q_{t+1}}{q_{t}} \pi_{t+1}+\tau^{k} \delta-1
$$

where $\tau^{k}$ is the tax rate on capital. Linearizing this expression, we obtain:

$$
\hat{R}_{t+1}^{k}-\frac{\left(1-\tau^{k}\right) r^{k}+(1-\delta) q}{R^{k} q} \pi\left[\frac{\left(1-\tau^{k}\right) r^{k} \hat{r}_{t+1}^{k}+(1-\delta) q \hat{q}_{t+1}}{\left(1-\tau^{k}\right) r^{k}+(1-\delta) q}+\hat{\pi}_{t+1}-\hat{q}_{t}\right]
$$

\section{A.2.4 Banks}

Following is a discussion of the four equations corresponding to the banking sector. For a detailed discussion of these equations, see Chari, Christiano, and Eichenbaum (1995). It is useful to begin by developing an expression for the ratio of excess reserves to value added, $\left(K_{t}^{b}\right)^{\alpha}\left(z_{t} l_{t}^{b}\right)^{1-\alpha}$. After imposing the definition of working-capital loans, $S_{t}^{w}$, and imposing our scaling convention, (32) reduces to:

$$
e_{v, t}=\frac{(1-\tau) m_{t}^{b}\left(1-m_{t}+x_{t}\right)-\tau\left(\psi_{l} w_{t} l_{t}+\frac{1}{\mu_{z}} \psi_{k} r_{t}^{k} k_{t}\right)}{\left(\frac{1}{\mu_{z}}\left(1-\nu_{t}^{k}\right) k_{t}\right)^{\alpha}\left(\left(1-\nu_{t}^{l}\right) l_{t}\right)^{1-\alpha}}
$$

Linearizing this expression about the steady state:

$$
\begin{aligned}
& -\hat{e}_{v, t}+n_{m^{b}} \hat{m}_{t}^{b}+n_{m} \hat{m}_{t}+n_{x} \hat{x}_{t} \\
& +\left(n_{k}-d_{k}\right)\left[\hat{\bar{k}}_{t}+\hat{u}_{t}\right]+n_{r^{k}} \hat{r}_{t}^{k}+n_{w} \hat{w}_{t} \\
& +\left(n_{l}-d_{l}\right) \hat{l}_{t}-d_{\nu^{k}} \hat{\nu}_{t}^{k}-d_{\nu l} \hat{\nu}_{t}^{l}=0 .
\end{aligned}
$$

Here, we have used the condition $k_{t}=\bar{k}_{t} u_{t}$. Also,

$$
\begin{aligned}
n_{m^{b}} & =(1-\tau) m^{b}(1-m+x) / \bar{n} \\
n_{m} & =-(1-\tau) m^{b} m / \bar{n} \\
n_{x} & =(1-\tau) m^{b} x / \bar{n} \\
n_{w} & =n_{l}=-\tau \psi_{l} w l / \bar{n} \\
n_{r^{k}} & =n_{k}=-\tau \frac{1}{\mu_{z}} \psi_{k} r^{k} k / \bar{n} \\
n_{\mu_{z}} & =\tau \frac{1}{\mu_{z}} \psi_{k} r^{k} k / \bar{n},
\end{aligned}
$$

where

$$
\bar{n}=(1-\tau) m^{b}(1-m+x)-\tau\left(\psi_{l} w l+\frac{1}{\mu_{z}} \psi_{k} r^{k} k\right)
$$


Also,

$$
\begin{aligned}
d_{\mu_{z}} & =\frac{-\alpha\left(\frac{1}{\mu_{z}}\left(1-\nu^{k}\right) k\right)^{\alpha}\left(\left(1-\nu^{l}\right) l\right)^{1-\alpha}}{\left(\frac{1}{\mu_{z}}\left(1-\nu^{k}\right) k\right)^{\alpha}\left(\left(1-\nu^{l}\right) l\right)^{1-\alpha}}=-\alpha \\
d_{k} & =\alpha \\
d_{\nu^{k}} & =-\alpha \frac{\nu^{k}}{1-\nu^{k}} \\
d_{l} & =1-\alpha \\
d_{\nu^{l}} & =-(1-\alpha) \frac{\nu^{l}}{1-\nu^{l}},
\end{aligned}
$$

where

$$
d=\left(\frac{1}{\mu_{z}}\left(1-\nu^{k}\right) k\right)^{\alpha}\left(\left(1-\nu^{l}\right) l\right)^{1-\alpha} .
$$

The technology associated with the provision of bank deposits is:

$$
x^{b}\left(e_{v, t}\right)^{-\xi_{t}} e_{t}^{r}=\frac{M_{t}^{b}-M_{t}+X_{t}+S_{t}^{w}}{P_{t}},
$$

where the term on the right corresponds to the real value of deposits, and $e_{t}^{r}$ represents the real value of excess reserves. It is useful to develop expressions for the partial derivative of the function on the left of the equality, which we denote by $h$, with respect to real excess reserves and labor. The derivative of $h$ with respect to real excess reserves is:

$$
h_{e^{r}, t}=\left(1-\xi_{t}\right) x^{b}\left(e_{v, t}\right)^{-\xi_{t}}
$$

which, in linearized form, is:

$$
\hat{h}_{e^{r}, t}=-\left[\frac{1}{1-\xi}+\log \left(e_{v}\right)\right] \xi \hat{\xi}_{t}-\xi \hat{e}_{v, t} .
$$

The derivative of $h$ with respect to labor is:

$$
h_{l^{b}, t}=(1-\alpha) \xi_{t} x^{b}\left(e_{v, t}\right)^{1-\xi_{t}}\left(\frac{\mu_{z}\left(1-\nu_{t}^{l}\right) l_{t}}{\left(1-\nu_{t}^{k}\right) k_{t}}\right)^{-\alpha} z_{t} .
$$

Defining $h_{z, l^{b}, t}=h_{l^{b}, t} / z_{t}$ and linearizing $h_{z, l^{b}, t}$ :

$$
\hat{h}_{z, l^{b}, t}=\left[1-\log \left(e_{v}\right) \xi\right] \hat{\xi}_{t}+(1-\xi) \hat{e}_{v, t}-\alpha\left[-\frac{\nu^{l} \hat{\nu}_{t}^{l}}{1-\nu^{l}}+\hat{l}_{t}+\frac{\nu^{k} \hat{\nu}_{t}^{k}}{1-\nu^{k}}-\hat{k}_{t}\right] .
$$

The first-order conditions in the Lagrangian representation of the bank problem associated with $A_{t}$ and $S_{t}^{w}$ are given in (44) from (45) above. The first-order condition for $l_{t}^{b}$ is:

$$
-\left(1+\psi_{l, t} R_{t}\right) W_{t}+\lambda_{t}^{b} h_{l^{b}, t}=0 .
$$


Substituting for $\lambda_{t}^{b}$ in (68) from (45), and taking into account our scaling convention, we obtain:

$$
0=\frac{R_{t} h_{z, l^{b}, t}}{1+\tau h_{e^{r}, t}}-\left(1+\psi_{l} R_{t}\right) w_{t} .
$$

Linearizing this, and taking into account the expressions for $\hat{h}_{e^{r}, t}$ and $\hat{h}_{z, l^{b}, t}$, we obtain:

$$
\begin{aligned}
0= & l_{R} \hat{R}_{t}+l_{\xi} \hat{\xi}_{t}-\hat{w}_{t}+l_{e} \hat{e}_{v, t} \\
& +l_{\nu^{l}} \hat{\nu}_{t}^{l}+l_{\nu^{k}} \hat{\nu}_{t}^{k}+l_{l} \hat{l}_{t}+l_{k} \hat{k}_{t},
\end{aligned}
$$

where

$$
\begin{aligned}
l_{i} & =k_{i} \text { for all } i, \text { except } \\
l_{R} & =\left[1-\frac{\psi_{l} R}{1+\psi_{l} R}\right], l_{\psi l}=-\frac{\psi_{l} R}{1+\psi_{l} R} \\
l_{\mu} & =k_{\mu}-1, l_{\nu^{l}}=k_{\nu^{l}}+\frac{\nu^{l}}{1-\nu^{l}}, l_{l}=k_{l}-1, \\
l_{\nu^{k}} & =k_{\nu^{k}}-\frac{\nu^{k}}{1-\nu^{k}}, l_{k}=k_{k}+1
\end{aligned}
$$

and

$$
\begin{aligned}
k_{R} & =\left[1-\frac{\psi_{k} R}{1+\psi_{k} R}\right], k_{\xi}=1-\log \left(e_{v}\right) \xi+\frac{\tau h_{e^{r}}\left[\frac{1}{1-\xi}+\log \left(e_{v}\right)\right] \xi}{1+\tau h_{e^{r}}} \\
k_{e} & =1-\xi+\frac{\tau h_{e^{r}} \xi}{1+\tau h_{e^{r}}}, \\
k_{\nu^{l}} & =-(1-\alpha) \frac{\nu^{l}}{1-\nu^{l}}, k_{\nu^{k}}=(1-\alpha) \frac{\nu^{k}}{1-\nu^{k}}, k_{l}=(1-\alpha), k_{k}=-(1-\alpha) .
\end{aligned}
$$

Recalling that the ratio of (45) to (44) is:

$$
R_{a t}=\frac{(1-\tau) h_{e^{r}, t}-1}{\tau h_{e^{r}, t}+1} R_{t}
$$

we can linearize this expression. Taking into account the expressions for $\hat{h}_{e^{r}, t}$ and $\hat{h}_{z, l^{b}, t}$, we obtain:

$$
\begin{aligned}
& \hat{R}_{a t}-h_{e^{r}}\left[\frac{1-\tau}{(1-\tau) h_{e^{r}}-1}-\frac{\tau}{\tau h_{e^{r}}+1}\right]\left[-\left(\frac{1}{1-\xi}+\log \left(e_{v}\right)\right) \xi \hat{\xi}_{t}-\xi \hat{e}_{v, t}\right] \\
& -\hat{R}_{t}=0
\end{aligned}
$$

Then we scale the production function for real deposits:

$$
\begin{aligned}
x^{b}\left(e_{v, t}\right)^{-\xi_{t}} e_{z, t}^{r} & =\frac{M_{t}^{b}-M_{t}+X_{t}+\left(\psi_{l, t} W_{t} l_{t}+\psi_{k, t} P_{t} r_{t}^{k} K_{t}\right)}{z_{t} P_{t}} \\
& =m_{1 t}+m_{2 t},
\end{aligned}
$$


where

$$
\begin{aligned}
m_{1 t} & =m_{t}^{b}\left(1-m_{t}+x_{t}\right) \\
m_{2 t} & =\psi_{l} w_{t} l_{t}+\psi_{k} r_{t}^{k} k_{t} / \mu_{z} \\
e_{z, t}^{r} & =\frac{e_{t}^{r}}{z_{t}}
\end{aligned}
$$

Linearizing this, we obtain:

$$
\begin{aligned}
& 0=\xi \hat{e}_{v, t}+\log \left(e_{v}\right) \xi \hat{\xi}_{t} \\
& +\left[\frac{m_{1}}{m_{1}+m_{2}}-\frac{(1-\tau) m_{1}}{(1-\tau) m_{1}-\tau m_{2}}\right]\left[\hat{m}_{t}^{b}+\frac{-m \hat{m}_{t}}{1-m+x}\right] \\
& +\left[\frac{m_{2}}{m_{1}+m_{2}}+\frac{\tau m_{2}}{(1-\tau) m_{1}-\tau m_{2}}\right] \\
& \times\left[\frac{\psi_{l} w l}{\psi_{l} w l+\psi_{k} r^{k} k / \mu_{z}}\left(\hat{w}_{t}+\hat{l}_{t}\right)+\frac{\psi_{k} r^{k} k / \mu_{z}}{\psi_{l} w l+\psi_{k} r^{k} k / \mu_{z}}\left(\hat{r}_{t}^{k}+\hat{k}_{t}\right)\right] .
\end{aligned}
$$

It is of interest to note that monetary policy cannot exactly neutralize the $\hat{\xi}_{t}$ shock. From (66), we see that the impact of $\hat{x}_{t}$ on $\hat{e}_{v, t}$ is determined by $n_{x}$. So, according to (67), neutralizing the $\hat{\xi}_{t}$ shock requires setting the component in $\hat{x}_{t}$ pertaining to $\hat{\xi}_{t}, \hat{x}_{\hat{\xi}_{t}, t}$ as follows:

$$
\hat{x}_{\hat{\xi}_{t}, t}=-\frac{1}{n_{x}}\left(\frac{1}{1-\xi}+\log \left(e_{v}\right)\right) \hat{\xi}_{t} .
$$

The same reasoning applied to (71) implies:

$$
\hat{x}_{\hat{\xi}_{t}, t}=-\frac{1}{n_{x}} \log \left(e_{v}\right) \hat{\xi}_{t} .
$$

Evidently, the previous two equations cannot both be satisfied at the same time.

\section{A.2.5 Households}

We now turn to the equations associated with the household sector. It is useful to define $u_{c, t}$ as the derivative of the present discounted value of utility with respect to $C_{t}$ :

$$
E_{t}\left\{u_{c, t}-u^{\prime}\left(C_{t}-b C_{t-1}\right)+b \beta u^{\prime}\left(C_{t+1}-b C_{t}\right)\right\}=0 .
$$

Using the definition, $u_{c, t}^{z}=z_{t} u_{c, t}$, and our functional form assumption, this reduces to:

$$
E_{t}\left[u_{c, t}^{z}-\frac{\mu_{z}}{c_{t} \mu_{z}-b c_{t-1}}+b \beta \frac{1}{c_{t+1} \mu_{z}-b c_{t}}\right]=0
$$

Linearizing this expression:

$$
\begin{gathered}
E_{t}\left\{u_{c}^{z} \hat{u}_{c, t}^{z}+\frac{\mu_{z}^{2}+\beta b^{2}}{c^{2}\left(\mu_{z}-b\right)^{2}} c \hat{c}_{t}\right. \\
\left.-\frac{b \beta \mu_{z}}{c^{2}\left(\mu_{z}-b\right)^{2}} c \hat{c}_{t+1}-\frac{b \mu_{z}}{c^{2}\left(\mu_{z}-b\right)^{2}} c \hat{c}_{t-1}\right\}=0 .
\end{gathered}
$$


The household's first-order condition with respect to time deposits is:

$$
E_{t}\left\{-\lambda_{t}+\beta \lambda_{t+1}\left[1+R_{t+1}^{e}\right]\right\}=0
$$

To scale this, we multiply by $z_{t} P_{t}$ :

$$
E_{t}\left\{-\lambda_{z, t}+\frac{\beta}{\mu_{z} \pi_{t+1}} \lambda_{z, t+1}\left[1+R_{t+1}^{e}\right]\right\}=0,
$$

where $\lambda_{z, t}=\lambda_{t} z_{t} P_{t}$. Linearizing this expression:

$$
E\left\{-\hat{\lambda}_{z, t}+\hat{\lambda}_{z, t+1}-\hat{\pi}_{t+1}+\frac{R^{e}}{1+R^{e}} \hat{R}_{t+1}^{e}\right\}=0 .
$$

The household's first-order condition with respect to currency, $M_{t}$, is:

$$
\begin{aligned}
& E_{t}\left\{v_{t}\left[\left(\frac{P_{t} C_{t}}{M_{t}}\right)^{\theta_{t}}\left(\frac{P_{t} C_{t}}{M_{t}^{b}-M_{t}+X_{t}}\right)^{1-\theta_{t}}\right]^{1-\sigma_{q}}\left[\frac{\theta_{t}}{M_{t}}-\frac{\left(1-\theta_{t}\right)}{M_{t}^{b}-M_{t}+X_{t}}\right]\right. \\
& \left.-\lambda_{t} R_{a t}\right\}=0 \text {. }
\end{aligned}
$$

We scale this by multiplying both sides by $z_{t} P_{t}$ :

$$
\begin{array}{r}
v_{t}\left[c_{t}\left(\frac{1}{m_{t}}\right)^{\theta_{t}}\left(\frac{1}{1-m_{t}+x_{t}}\right)^{1-\theta_{t}}\right]^{1-\sigma_{q}}\left[\frac{\theta_{t}}{m_{t}}-\frac{1-\theta_{t}}{1-m_{t}+x_{t}}\right]\left(\frac{1}{m_{t}^{b}}\right)^{2-\sigma_{q}} \\
-\lambda_{z t} R_{a t}=0 .
\end{array}
$$

Linearizing this expression:

$$
\begin{aligned}
&\left\{\hat{v}_{t}+\left(1-\sigma_{q}\right) \hat{c}_{t}+\right. {\left[-\left(1-\sigma_{q}\right)\left(\theta-(1-\theta) \frac{m}{1-m+x}\right)-\frac{\frac{\theta}{m}+\frac{1-\theta}{(1-m+x)^{2}} m}{\frac{\theta}{m}-\frac{1-\theta}{1-m+x}}\right] \hat{m}_{t} } \\
&-\left[\frac{\left(1-\sigma_{q}\right)(1-\theta) x}{1-m+x}-\frac{\frac{1-\theta}{(1-m+x)^{2}} x}{\frac{\theta}{m}-\frac{1-\theta}{1-m+x}}\right] \hat{x}_{t} \\
&+ {\left[-\left(1-\sigma_{q}\right)(\log (m)-\log (1-m+x))+\frac{1+x}{\theta(1+x)-m}\right] \theta \hat{\theta}_{t} } \\
&\left.-\left(2-\sigma_{q}\right) \hat{m}_{t}^{b}-\left(\hat{\lambda}_{z, t}+\hat{R}_{a, t}\right)\right\}=0 .
\end{aligned}
$$

The first-order condition with respect to $M_{t+1}^{b}$ is:

$$
\begin{aligned}
& E_{t}\left\{\beta v_{t+1}\left(1-\theta_{t+1}\right)\left[P_{t+1} C_{t+1}\left(\frac{1}{M_{t+1}}\right)^{\theta_{t+1}}\left(\frac{1}{M_{t+1}^{b}-M_{t+1}+X_{t+1}}\right)^{\left(1-\theta_{t+1}\right)}\right]^{1-\sigma_{q}} \times\right. \\
& \left.\times \frac{1}{M_{t+1}^{b}-M_{t+1}+X_{t+1}}+\beta \lambda_{t+1}\left[1+R_{a, t+1}\right]-\lambda_{t}\right\} \\
& =0 .
\end{aligned}
$$


Scaling this by multiplying by $P_{t} z_{t}$ :

$$
\begin{array}{r}
E_{t}\left\{\beta v_{t+1}\left(1-\theta_{t+1}\right)\left[c_{t+1}\left(\frac{1}{m_{t+1}}\right)^{\theta_{t+1}}\left(\frac{1}{1-m_{t+1}+x_{t+1}}\right)^{\left(1-\theta_{t+1}\right)}\right]^{1-\sigma_{q}}\right. \\
\times\left(\frac{1}{m_{t+1}^{b}}\right)^{2-\sigma_{q}} \frac{1}{\pi_{t+1} \mu_{z}} \frac{1}{1-m_{t+1}+x_{t+1}} \\
\left.+\beta \frac{1}{\pi_{t+1} \mu_{z}} \lambda_{z, t+1}\left[1+R_{a, t+1}\right]-\lambda_{z, t}\right\}=0 .
\end{array} .
$$

Linearizing:

$$
\begin{aligned}
& E_{t}\left\{\frac{\beta}{\pi \mu_{z}} v(1-\theta)\left[c\left(\frac{1}{m}\right)^{\theta}\right]^{1-\sigma_{q}}\left(\frac{1}{1-m+x}\right)^{(1-\theta)\left(1-\sigma_{q}\right)+1}\left(\frac{1}{m^{b}}\right)^{2-\sigma_{q}}\right. \\
& \times\left\{\hat{v}_{t+1}-\frac{\theta \hat{\theta}_{t+1}}{1-\theta}+\left(1-\sigma_{q}\right) \hat{c}_{t+1}-\left(1-\sigma_{q}\right) \log (m) \theta \hat{\theta}_{t+1}-\theta\left(1-\sigma_{q}\right) \hat{m}_{t+1}\right. \\
& -\left[(1-\theta)\left(1-\sigma_{q}\right)+1\right]\left(\frac{1}{1-m+x}\right)\left[x \hat{x}_{t+1}-m \hat{m}_{t+1}\right] \\
& \left.+\left(1-\sigma_{q}\right) \log (1-m+x) \theta \hat{\theta}_{t+1}-\left(2-\sigma_{q}\right) \hat{m}_{t+1}^{b}\right\} \\
& +\frac{\beta}{\pi \mu_{z}} \lambda_{z}\left[1+R_{a}\right] \hat{\lambda}_{z, t+1} \\
& \left.+\frac{\beta}{\pi \mu_{z}} \lambda_{z} R_{a} \hat{R}_{a, t+1}-\lambda_{z}\left[\hat{\lambda}_{z t}+\hat{\pi}_{t+1}\right]\right\}=0 .
\end{aligned}
$$

The household's first-order condition for consumption is:

$$
E_{t}\left\{u_{c, t}-v_{t} C_{t}^{-\sigma_{q}}\left[\left(\frac{P_{t}}{M_{t}}\right)^{\theta_{t}}\left(\frac{P_{t}}{M_{t}^{b}-M_{t}+X_{t}}\right)^{1-\theta_{t}}\right]^{1-\sigma_{q}}-P_{t} \lambda_{t}\right\}=0 .
$$

Scaling this by multiplying by $z_{t}$, we obtain:

$$
E_{t}\left\{u_{c, t}^{z}-v_{t} c_{t}^{-\sigma_{q}}\left[\frac{1}{m_{t}^{b}}\left(\frac{1}{m_{t}}\right)^{\theta_{t}}\left(\frac{1}{1-m_{t}+x_{t}}\right)^{1-\theta_{t}}\right]^{1-\sigma_{q}}-\lambda_{z, t}\right\}=0 .
$$

Linearizing this expression,

$$
\begin{aligned}
& E_{t}\left\{u_{c}^{z} \hat{u}_{c, t}^{z}-v c^{-\sigma_{q}}\left[\frac{1}{m^{b}}\left(\frac{1}{m}\right)^{\theta}\left(\frac{1}{1-m+x}\right)^{1-\theta}\right]^{1-\sigma_{q}}\right. \\
& \times\left[\hat{v}_{t}-\sigma_{q} \hat{c}_{t}+\left(1-\sigma_{q}\right)\left(-\hat{m}_{t}^{b}-\theta_{t} \hat{m}_{t}-\left(1-\theta_{t}\right)\left(\frac{-m}{1-m+x} \hat{m}_{t}+\frac{x}{1-m+x} \hat{x}_{t}\right)\right)\right. \\
& \left.+\left(1-\sigma_{q}\right)\left[\log \left(\frac{1}{m}\right)-\log \left(\frac{1}{1-m+x}\right)\right] \theta \hat{\theta}_{t}\right] \\
& \left.-\lambda_{z} \hat{\lambda}_{z, t}\right\}=0 .
\end{aligned}
$$


The linearized expression for wages is taken directly from Christiano, Eichenbaum, and Evans (2003):

$$
E_{t}\left\{\eta_{0} \hat{w}_{t-1}+\eta_{1} \hat{w}_{t}+\eta_{2} \hat{w}_{t+1}+\eta_{\overline{3}} \hat{\pi}_{t-1}+\eta_{3} \hat{\pi}_{t}+\eta_{4} \hat{\pi}_{t+1}+\eta_{5} \hat{l}_{t}+\eta_{6} \hat{\lambda}_{z, t}+\eta_{7} \hat{\zeta}_{t}\right\}=0
$$

where

$$
\eta=\left(\begin{array}{c}
b_{w} \xi_{w} \\
-b_{w}\left(1+\beta \xi_{w}^{2}\right)+\sigma_{L} \lambda_{w} \\
\beta \xi_{w} b_{w} \\
b_{w} \xi_{w} \\
-\xi_{w} b_{w}(1+\beta) \\
b_{w} \beta \xi_{w} \\
-\sigma_{L}\left(1-\lambda_{w}\right) \\
1-\lambda_{w} \\
-\left(1-\lambda_{w}\right)
\end{array}\right)=\left(\begin{array}{c}
\eta_{0} \\
\eta_{1} \\
\eta_{2} \\
\eta_{\overline{3}} \\
\eta_{3} \\
\eta_{4} \\
\eta_{5} \\
\eta_{6} \\
\eta_{7}
\end{array}\right)
$$

\section{A.2.6 Monetary Policy}

The monetary base evolves as follows:

$$
M_{t+1}^{b}=M_{t}^{b}\left(1+x_{t}\right)
$$

where $x_{t}$ is the net growth rate of the monetary base. The law of motion of the scaled monetary base, $m_{t}^{b}=M_{t}^{b} /\left(P_{t} z_{t}\right)$, is:

$$
\frac{M_{t+1}^{b}}{P_{t+1} z_{t+1}}=\frac{P_{t} z_{t}}{P_{t+1} z_{t+1}} \frac{M_{t}^{b}}{P_{t} z_{t}}\left(1+x_{t}\right)
$$

or

$$
m_{t+1}^{b}=\frac{1}{\pi_{t+1} \mu_{z}} m_{t}^{b}\left(1+x_{t}\right)
$$

Linearizing this expression,

$$
\hat{m}_{t-1}^{b}+\frac{x}{1+x} \hat{x}_{t-1}-\hat{\pi}_{t}-\hat{m}_{t}^{b}=0
$$

Monetary policy has the following representation:

$$
\hat{x}_{t}=\sum_{i=1}^{p} x_{i t},
$$

where the $x_{i t}$ 's are functions of the underlying shocks, as discussed in section 3.7.

\section{A.2.7 Aggregate Restrictions}

The condition that the use of final goods equals the supply of final goods implies:

$\mu \int_{0}^{\bar{\omega}_{t}} \omega d F_{t-1}(\omega)\left(1+R_{t}^{k}\right) \frac{Q_{\bar{K}^{\prime}, t-1}}{P_{t}} \bar{K}_{t}+a\left(u_{t}\right) \bar{K}_{t}+G_{t}+C_{t}+I_{t} \leq z_{t}^{1-\alpha} \epsilon\left(\nu_{t}^{k} K_{t}\right)^{\alpha}\left(\nu_{t}^{l} L_{t}\right)^{1-\alpha}-z_{t} \phi$. 
Here we have ignored additional terms in the aggregate resource constraint which appear when labor and capital are misallocated across the intermediate goods firms. For a justification, see the argument in Christiano, Eichenbaum, and Evans (2003), which builds on the important work of Yun (1996). Scaling the goods constraint by $z_{t}$ :

$$
d_{t}+a\left(u_{t}\right) \frac{1}{\mu_{z, t}} \bar{k}_{t}+g_{t}+c_{t}+i_{t} \leq \epsilon_{t}\left(u_{t} \frac{1}{\mu_{z, t}} \nu_{t}^{k} \bar{k}_{t}\right)^{\alpha}\left(\nu_{t}^{l} L_{t}\right)^{1-\alpha}-\phi
$$

where

$$
d_{t}=\mu G\left(\bar{\omega}_{t}, \sigma_{t-1}\right)\left(1+R_{t}^{k}\right) q_{t-1} \frac{1}{\mu_{z, t}} \frac{1}{\pi_{t}} \bar{k}_{t} .
$$

Linearizing the goods constraint:

$$
\begin{aligned}
& 0=d_{y}\left[\frac{G_{\omega}}{G} \bar{\omega} \widehat{\bar{\omega}}_{t}+\frac{G_{\sigma}}{G} \sigma \hat{\sigma}_{t-1}+\frac{R^{k}}{1+R^{k}} \hat{R}_{t}^{k}+\hat{q}_{t-1}+\widehat{\bar{k}}_{t}-\hat{\pi}_{t}\right]+u_{y} \hat{u}_{t}+c_{y} \hat{c}_{t}+\bar{k}_{y} \frac{i}{\bar{k}} \hat{\imath}_{t}(79) \\
& -\alpha\left(\hat{u}_{t}+\widehat{\bar{k}}_{t}+\hat{\nu}_{t}^{k}\right)-(1-\alpha)\left(\hat{l}_{t}+\hat{\nu}_{t}^{l}\right)-\hat{\epsilon}_{t},
\end{aligned}
$$

where

$$
\begin{aligned}
c_{y} & =\frac{c}{y+\phi+d}, d_{y}=\frac{d}{y+\phi+d}, \\
v_{y} & =\frac{v}{y+\phi+d}, u_{y}=\frac{a^{\prime} \frac{1}{\mu_{z}} \bar{k}}{y+\phi+d}, \\
\bar{k}_{y} & =\frac{\bar{k}}{y+\phi+d} .
\end{aligned}
$$

The capital accumulation equation is:

$$
\bar{K}_{t+1}=(1-\delta) \bar{K}_{t}+F\left(I_{t}, I_{t-1}\right)
$$

Scaling, by dividing both sides by $z_{t}$ :

$$
\bar{k}_{t+1}=(1-\delta) \frac{1}{\mu_{z}} \bar{k}_{t}+\frac{F\left(I_{t}, I_{t-1}\right)}{z_{t}} .
$$

Linearizing and taking into account the restrictions on $F$ discussed above,

$$
\widehat{\bar{k}}_{t+1}-\frac{1-\delta}{\mu_{z}}\left(\widehat{\bar{k}}_{t}-\hat{\mu}_{z, t}\right)-\frac{i}{\bar{k}} \hat{\imath}_{t}=0
$$




\section{References}

[1] Altig, David, Lawrence J. Christiano, Martin Eichenbaum, and Jesper Linde, 2003, "Technology Shocks and Aggregate Fluctuations," unpublished manuscript.

[2] Balke, Nathan S. and Robert J. Gordon. (1986). "Appendix B, Historical Data." In The American Business Cycle: Continuity and Change," edited by Robert J. Gordon, pp. 781-850. Chicago: University of Chicago Press.

[3] Bernanke, Ben. (1983). "Nonmonetary Effects of the Financial Crisis in the Propagation of the Great Depression." American Economic Review 73, 257-76.

[4] Bernanke, Ben. (1995). "The Macroeconomics of the Great Depression: A Comparative Approach." Journal of Money, Credit, and Banking 27, 1-28.

[5] Bernanke, Ben. (2002). "On Milton Friedman's 90th Birthday," remarks at the conference in honor of Milton Friedman, University of Chicago, Chicago, Illinois, November 8.

[6] Bernanke, Ben, Mark Gertler and Simon Gilchrist. (1999). "The Financial Accelerator in a Quantitative Business Cycle Framework." Handbook of Macroeconomics, edited by John B. Taylor and Michael Woodford, pp. 1341-93. Amsterdam, New York and Oxford: Elsevier Science, North-Holland.

[7] Bernanke, Ben, and Kevin Carey. (1996). "Nominal Wage Stickiness and Aggregate Supply in the Great Depression." The Quarterly Journal of Economics 111, 853-883.

[8] Blanchard, Olivier and Nobuhiro Kiyotaki. (1987). "Monopolistic Competition and the Effects of Aggregate Demand." American Economic Review 77, 647-66.

[9] Bliss, Charles A. (1934). "Recent Changes in Production." National Bureau of Economic Research, Bulletin 51, June 28. May be found at http://www.nber.org/newsbulletin/newsbulletin/june28_1934.pdf.

[10] Board of Governors of the Federal Reserve System. (1943). Banking and Monetary Statistics, Washington, D.C.

[11] Board of Governors of the Federal Reserve System. "Flow of Funds Accounts, Flows and Outstandings, Z.1 Statistical Release." Washington, D.C.

[12] Boldrin, Michele, Lawrence J. Christiano and Jonas Fisher. (2001). "Asset Pricing Lessons for Modeling Business Cycles.” American Economic Review 91, 149-66. 
[13] Bordo, Michael D., Ehsan U. Choudhri and Anna J. Schwartz. (1995). "Could Stable Money Have Averted the Great Contraction?" Economic Inquiry 33, 484-505.

[14] Bordo, Michael D., Christopher Erceg and Charles Evans. (2000). "Money, Sticky Wages, and the Great Depression." American Economic Review 90, 1447-1463.

[15] Bordo, Michael D., Christopher Erceg and Charles Evans. (2001). "Comment on Cole and Ohanian." In NBER Macroeconomics Annual 2000, edited by Ben Bernanke and Kenneth Rogoff. Cambridge: MIT Press.

[16] Bresnahan, Timothy, and Daniel M. G. Raff. (1991). "Intra-Industry Heterogeneity and the Great Depression: The American Motor Vehicles Industry, 1929-1935." The Journal of Economic History 51, 317-331.

[17] Bureau of the Census. (2002). Quarterly Financial Report for Manufacturing, Mining, and Trade Corporations, Washington, D.C., April.

[18] Carlstrom, Chuck, and Timothy Fuerst. (1997). "Agency Costs, Net Worth and Business Fluctuations: A Computable General Equilibrium Analysis." American Economic Review 87, 893-910.

[19] Carlstrom, Chuck, and Timothy Fuerst. (2000). "Monetary Shocks, Agency Costs and Business Cycles." Federal Reserve Bank of Cleveland Working Paper 00-11.

[20] Calvo, Guillermo. (1983). "Staggered Prices and in a Utility-Maximizing Framework." Journal of Monetary Economics 12, 383-98.

[21] Cecchetti, Stephen. (1998). "Understanding the Great Depression: Lessons for Current Policy." In The Economics of the Great Depression, edited by M. Wheeler, pp. 171-194. Kalamazoo, Michigan: W.E. Upjohn Institute for Employment Research.,

[22] Chari, V.V., Lawrence J. Christiano, and Martin Eichenbaum. (1995). "Inside Money, Outside Money and Short Term Interest Rates." Journal of Money, Credit and Banking $27,1354-86$.

[23] Chari, V.V., Patrick Kehoe, and Ellen McGrattan. (2002). "Business Cycle Accounting." Federal Reserve Bank of Minneapolis Research Department Staff Report 350, April.

[24] Christiano, Lawrence J. (1999). "Discussion of Christopher Sims, 'The Role of Interest Rate Policy in the Generation and Propagation of Business Cycles: What Has Changed Since the 30s?" In Beyond Shocks: What Causes Business Cycles?, edited by Scott Shuh and Jeffrey Fuhrer, Federal Reserve Bank of Boston. 
[25] Christiano, Lawrence J. (2002). "Solving Dynamic Equilibrium Models by a Method of Undetermined Coefficients." Computational Economics 20, 21-55.

[26] Christiano, Lawrence J, Martin Eichenbaum, and Charles L. Evans. (2003). "Nominal Rigidities and the Dynamic Effects of a Shock to Monetary Policy" National Bureau of Economic Research Working paper, forthcoming in Journal of Political Economy.

[27] Christiano, Lawrence J., and Jonas Fisher. (2000). "Algorithms for Solving Models with Occasionally Binding Constraints." Journal of Economic Dynamics and Control 24, 1179-1232.

[28] Christiano, Lawrence J., and Terry Fitzgerald. (2000). "Understanding the Fiscal Theory of the Price Level." Federal Reserve Bank of Cleveland Economic Review 36, 2-37.

[29] Cole, Hal, and Lee Ohanian. (1999). "The Great Depression in the United States from a Neoclassical Perspective." Federal Reserve Bank of Minneapolis Quarterly Review 23, 2-24.

[30] Cole, Hal, and Lee Ohanian. (2001). "Re-examining the Contribution of Money and Banking Shocks to the U.S. Great Depression." In NBER Macroeconomics Annual 2000, edited by Ben Bernanke and Kenneth Rogoff, pp. 183-227. Cambridge: MIT Press.

[31] Cole, Hal, and Lee Ohanian. (2003). "New Deal Policies and the Persistence of the Great Depression: A General Equilibrium Analysis," manuscript, Department of Economics, UCLA.

[32] Cole, Hal, and Lee Ohanian. (2003a). "Deflation, Real Wages, and the International Great Depression: A Productivity Puzzle," manuscript, Department of Economics, UCLA.

[33] Dighe, Ranjit S. (1997). "Wage Rigidity in the Great Depression: Truth? Consequences?" Research in Economic History 17, 85-134.

[34] Eggertsson, Gauti B. (2003). "The Deflation Bias and Committing to Being Irresponsible," unpublished manuscript, International Monetary Fund, Washington, D.C.

[35] Eggertsson, Gauti B. and Michael Woodford. (2003). "The Zero Bound on Interest Rates and Optimal Monetary Policy" Brookings Papers on Economic Activity 1, 139-211.

[36] Eichengreen, Barry, and Jeffrey Sachs. (1985). "Exchange Rates and Economic Recovery in the 1930s." Journal of Economic History 45, 925-46. 
[37] Eichengreen, Barry and Peter Temin. (2000). "The Gold Standard and the Great Depression." Contemporary European History 9, 183-207.

[38] Erceg, Christopher, J., Dale W. Henderson, and Andrew T. Levin. (2000). "Optimal Monetary Policy with Staggered Wage and Price Contracts." Journal of Monetary Economics 46, 281-313.

[39] Field, Alexander, Jr. (1984). "A New Interpretation of the Onset of the Great Depression." Journal of Economic History 44, 489-498.

[40] Field, Alexander, Jr. (2001). "Sources of Productivity Advance in the Twentieth Century: An Historical Perspective," may be found at http://sts.scu.edu/nexus/Issue11/AJ_Field-Productivity.asp.

[41] Field, Alexander. (2003). "The Most Technologically Progressive Decade of the Century." American Economic Review 93, 1399-1413.

[42] Fisher, Irving. (1933). "The Debt-Deflation Theory of Great Depressions." Econometrica $1,337-357$.

[43] Friedman, Milton, and Anna Jacobson Schwartz. (1963). A Monetary History of the United States, 1867-1960. Princeton: Princeton University Press.

[44] Fuhrer, Jeffrey. (2000). "Habit Formation in Consumption and Its Implications for Monetary-Policy Models." American Economic Review 90, 367-90.

[45] Gale, Douglas, and Martin Hellwig. (1985). "Incentive-Compatible Debt Contracts I: The One-Period Problem." Review of Economic Studies 52, 647-64.

[46] Gali, Jordi, Mark Gertler and J. David Lopez-Salido. (2002). "Markups, Gaps and the Welfare Costs of Business Fluctuations." National Bureau of Economic Research Working Paper 8850.

[47] Gali, Jordi, David Lopez-Sadilo, and Javier Valles. (2003). "Technology Shocks and Monetary Policy: Assessing the Fed's Performance." Journal of Monetary Economics $50,723-43$.

[48] Gertler, Mark. (2001). "Comment on Cole and Ohanian." In NBER Macroeconomics Annual 2000, edited by Ben Bernanke and Kenneth Rogoff. Cambridge: MIT Press.

[49] Goldin, Claudia. (2000). "Labor Markets in the 20 ${ }^{\text {th }}$ Century." In The Cambridge Economic History of the United States, Vol. III, edited by Stanley Engerman and Robert Gallman, pp. 549-623. Cambridge: Cambridge University Press. 
[50] Hall, Robert E. (1997). "Macroeconomic Fluctuations and the Allocation of Time." Journal of Labor Economics 15, S223-50.

[51] Hamilton, James B. (1994). Time Series Analysis. Princeton: Princeton University Press.

[52] Hanes, Christopher (1996). "Changes in the cyclical behavior of real wage rates, 18701990." Journal of Economic History 56, 837-61.

[53] Harrison, Sharon and Mark Weder. (2003). "Did Sunspot Forces Cause the Great Depression?", manuscript, Barnard College, Columbia University.

[54] Ingram, Beth F., Narayana R. Kocherlakota, and N.E. Savin. (1997). "Using Theory for Measurement: An Analysis of the Cyclical Behavior of Home Production." Journal of Monetary Economics 40, 435-456.

[55] Kendrick, John W. (1961). Productivity Trends in the United States. Princeton: Princeton University Press (for NBER).

[56] Kennedy, David M. (1999). Freedom from Fear: The American People in Depression and War, 1929-1945. New York: Oxford University Press.

[57] Keynes, John Maynard. (1930). A Treatise on Money, vol. 2. London: Macmillan.

[58] Keynes, John Maynard. (1939). "Relative Movements of Real Wages and Output." Economic Journal 49, 34-51.

[59] Krugman, Paul. (1998). "It's Baaack! Japan's Slump and the Return of the Liquidity Trap." Brookings Papers on Economic Activity 0, 137-87.

[60] Kuznets, Simon. (1941). National Income. New York: National Bureau of Economic Research.

[61] Lebergott, Stanley. (1989). “Wage Rigidity' in the Depression: Concept or Phrase?" manuscript, Department of Economics, Wesleyan University, September.

[62] Leeper, Eric M., and Christopher A. Sims. (1994). "Toward a Modern Macroeconomic Model Usable for Policy Analysis." In NBER Macroeconomics Annual 1994, edited by Stanley Fischer and Julio Rotemberg, pp. 81-117, Cambridge and London: MIT Press.

[63] Leeper, Eric. (1991). "Equilibria Under 'Active' and 'Passive' Monetary and Fiscal Policies." Journal of Monetary Economics 27, 129-147. 
[64] Lucas, Robert E., Jr. and Rapping. (1972). "Unemployment in the Great Depression: Is there a Full Explanation?" Journal of Political Economy 80, 186-191.

[65] Margo, Robert A. (1993). "Employment and Unemployment in the 1930s'." The Journal of Economic Perspectives 7, 41-59.

[66] Masulis, Ronald. W. (1983). "The Impact of Capital Structure Change on Firm Value: Some Estimates." Journal of Finance 38, 107-26.

[67] McCallum, Bennett T. (1990). "Could a Monetary Base Rule Have Prevented the Great Depression?" Journal of Monetary Economics 26, 3-26.

[68] McCallum, Bennett T., and Edward Nelson. (1999). "Nominal Income Targeting in an Open-Economy Optimizing Model." Journal of Monetary Economics 43, 553-78.

[69] Mills, Frederick. (1934). "Changes in Prices, Manufacturing Costs and Industrial Productivity." National Bureau of Economic Research, Bulletin 53, December 22. This may be found at http://www.nber.org/newsbulletin/newsbulletin/dec22_1934.pdf.

[70] Mishkin, Frederic S. (1978). "The Household Balance Sheet and the Great Depression." The Journal of Economic History 38, 918-937.

[71] Mulligan, Casey. (2002). "A Dual Method of Empirically Evaluating Competitive Equilibrium Models with Market Distortions, Applied to the Great Depression." National Bureau of Economic Research Working Paper 8775.

[72] Orphanides, Athanasios. (2003). "Monetary Policy in Deflation: The Liquidity Trap in History and Practice," manuscript, Board of Governors of the Federal Reserve System, April.

[73] Parkin, Michael. (1988). "A Method for Determining Whether Parameters in Aggregative Models are Structural." In Money, Cycles and Exchange Rates: Essays in Honor of Allan Meltzer, edited by Karl Brunner and Bennett T. McCallum, Carnegie-Rochester Conference Series on Public Policy 29, 215-52.

[74] Prescott, Edward. (1986). "Theory Ahead of Business Cycle Measurement." Federal Reserve Bank of Minneapolis Quarterly Review 10, 9-22.

[75] Prescott, Edward C. (1999). "Some Observations on the Great Depression." Federal Reserve Bank of Minneapolis Quarterly Review 23, 25-31.

[76] Romer, Christina. (1990). "The Great Crash and the Onset of the Great Depression." The Quarterly Journal of Economics 105, 597-624. 
[77] Romer, Christina. (1993). "The Nation in Depression." The Journal of Economic Perspectives 7, 19-39.

[78] Sims, Christopher. (1994). "A Simple Model for Study of the Determination of the Price Level and the Interaction of Monetary and Fiscal Policy." Economic Theory 4, 381-399.

[79] Sims, Christopher. (1999). "The Role of Interest Rate Policy in the Generation and Propagation of Business Cycles: What Has Changed Since the 30s?" In Beyond Shocks: What Causes Business Cycles?, edited by Scott Shuh and Jeffrey Fuhrer, Federal Reserve Bank of Boston.

[80] Solow, Robert. (1957). "Technical Change and the Aggregate Production Function." The Review of Economics and Statistics 39, 312-320.

[81] Solon, Gary, Robert Barsky, and Jonathan A. Parker. (1994). "Measuring the Cylicality of Real Wages: How Important is Composition Bias." The Quarterly Journal of Economics 109, 1-25.

[82] Temin, Peter. (1976). Did Monetary Forces Cause the Great Depression? New York: W.W. Norton.

[83] Temin, Peter. (1989). Lessons from the Great Depression. Lionel Robbins Lectures. Cambridge, MA and London: MIT Press.

[84] Temin, Peter. (1990). "Socialism and Wages in the Recovery from the Great Depression in the United States and Germany." The Journal of Economic History 50, 297-307.

[85] Townsend, Robert. (1979). "Optimal Contracts and Competitive Markets with Costly State Verification." Journal of Economic Theory 21, 265-93.

[86] Williamson, Stephen. (1987). "Financial Intermediation, Business Failures and Real Business Cycles." Journal of Political Economy 95, 1196-1216.

[87] Woodford, Michael. (1994). "Monetary Policy and Price Level Determinacy in a CashIn-Advance Economy." Economic Theory 4, 345-389.

[88] Woodford, Michael. (1996). "Control of the Public Debt: A Requirement for Price Stability." National Bureau of Economic Research Working Paper 5684.

[89] Woodford, Michael. (2003). Interest and Prices: Foundations of a Theory of Monetary Policy. Princeton: Princeton University Press.

[90] Yun, Tack. (1996). "Nominal Price Rigidity, Money Supply Endogeneity, and Business Cycles." Journal of Monetary Economics 37, 345 - 370. 


\begin{tabular}{|c|c|c|}
\hline Peak to Trough & Peak $I / Y$ & Trough $I / Y$ \\
\hline 1929II-19331 & 0.25 & 0.06 \\
\hline $1948 \mathrm{IV}-1949 \mathrm{IV}$ & 0.26 & 0.23 \\
\hline 1953П-1954П & 0.24 & 0.22 \\
\hline 1957III-1958II & 0.24 & 0.21 \\
\hline 1960II-19611 & 0.23 & 0.21 \\
\hline $1969 \mathrm{IV}-1970 \mathrm{IV}$ & 0.24 & 0.22 \\
\hline $1973 \mathrm{IV}-1975 \mathrm{I}$ & 0.26 & 0.22 \\
\hline 1980I-1982IV & 0.27 & 0.22 \\
\hline 1990П1-19911 & 0.23 & 0.21 \\
\hline $20011-20011 \mathrm{~V}$ & 0.26 & 0.26 \\
\hline \multicolumn{3}{|c|}{$\begin{array}{l}\text { Notes: Source for postwar business cycle data: Bureau of } \\
\text { Economic Analysis' website. } I \text { - Nominal } \\
\text { household purchases of durable goods, plus gross } \\
\text { private domestic investment; } Y \text { - Nominal gross } \\
\text { domestic product }\end{array}$} \\
\hline
\end{tabular}




\begin{tabular}{|c|c|c|}
\hline \multicolumn{3}{|c|}{ Table 2: Model Parameters (Time unit of model: quarterly) } \\
\hline$\beta$ & Discount rate & $1.03^{-0.25}$ \\
\hline$\psi_{L}$ & Weight on disutility of labor & 145.32 \\
\hline$\sigma_{L}$ & Curvature on disutility of labor & 1.00 \\
\hline$v$ & Weight on utility of money & $2 \mathrm{e}-008$ \\
\hline$\sigma_{q}$ & Curvature on utility of money & -10.00 \\
\hline $\begin{array}{c}4 \\
\theta\end{array}$ & Power on currency in utility of money & 0.75 \\
\hline$b$ & Habit persistence parameter & 0.63 \\
\hline$\xi_{w}$ & Fraction of households that cannot reoptimize wage within a quarter & 0.70 \\
\hline$\lambda_{w}$ & Steady state markup, suppliers of labor & 1.05 \\
\hline \multicolumn{3}{|c|}{ Panel B: Goods-Producing Sector } \\
\hline$\mu_{z}$ & Growth rate of technology (APR) & 1.50 \\
\hline$S^{\prime \prime}$ & Curvature on investment adjustment cost & 7.69 \\
\hline$\sigma_{a}$ & Curvature on capital utilization cost function & 0.01 \\
\hline$\xi_{p}$ & Fraction of intermediate good firms that cannot reoptimize price within a quarter & 0.50 \\
\hline$\psi_{k}$ & Fraction of capital rental costs that must be financed & 0.70 \\
\hline$\psi_{l}$ & Fraction of wage bill that must be financed & 1.00 \\
\hline$\delta$ & Depreciation rate on capital. & 0.02 \\
\hline$\alpha$ & Power on capital in production function & 0.36 \\
\hline$\lambda_{f}$ & Steady state markup, intermediate good firms & 1.20 \\
\hline$\Phi$ & Fixed cost, intermediate goods & 0.036 \\
\hline \multicolumn{3}{|c|}{ Panel C: Entrepreneurs } \\
\hline$\gamma$ & Percent of entrepreneurs who survive from one quarter to the next & 97.00 \\
\hline$\mu$ & Fraction of realized profits lost in bankruptcy & 0.120 \\
\hline$F(\bar{\omega})$ & Percent of businesses that go into bankruptcy in a quarter & 0.80 \\
\hline $\operatorname{Var}(\log (\omega))$ & Variance of (Normally distributed) log of idiosyncratic productivity parameter & 0.07 \\
\hline \multicolumn{3}{|c|}{$\begin{array}{l}\text { Panel D: Banking Sector } \\
\end{array}$} \\
\hline$\xi$ & One minus power on excess reserves in deposit services technology & 0.9690 \\
\hline$x^{b}$ & Constant in front of deposit services technology & 82.1902 \\
\hline \multicolumn{3}{|c|}{ Panel E: Policy } \\
\hline$\tau$ & Bank reserve requirement & 0.100 \\
\hline$\tau^{k}$ & Tax rate on capital income & 0.29 \\
\hline$\tau^{l}$ & Tax rate on labor income & 0.04 \\
\hline$x$ & Growth rate of monetary base (APR) & 1.610 \\
\hline
\end{tabular}




\begin{tabular}{|l|l|l|l|}
\hline \multicolumn{5}{|c|}{ Table 3: Steady State Properties of the Model, versus U.S. Data } \\
\hline \multicolumn{1}{|c|}{ Variable } & Model & U.S. 1921-29 & U.S. 1964-2001 \\
\hline$\frac{k}{y}$ & 8.35 & $10.8^{1}$ & 9.79 \\
\hline$\frac{z}{y}$ & 0.20 & 0.24 & 0.25 \\
\hline$\frac{c}{y}$ & 0.73 & 0.67 & 0.57 \\
\hline$\frac{g}{y}$ & 0.07 & 0.07 & 0.19 \\
\hline$r^{k}$ & 0.043 & & \\
\hline$\frac{N}{K-N}$ ('Equity to Debt') & 0.999 & $1-1.25^{2}$ & $1-1.25^{2}$ \\
\hline$\frac{W^{c}}{p y}$ & 0.055 & & \\
\hline Percent of goods output lost to bankruptcy & $0.371 \%$ & & \\
\hline Percent of aggregate labor and capital in banking & $1.00 \%$ & $1 \%^{3}$ & $2.5 \%^{5}$ \\
\hline Inflation (APR) & $0.11 \%$ & $-0.6 \%^{4}$ & $4.27 \%^{6}$ \\
\hline
\end{tabular}

Note: ${ }^{1}$ End of 1929 stock of capital, divided by 1929 GNP, obtained from Chari, Kehoe, and McGrattan (2002).. ${ }^{2}$ Masulis (1983) reports that the debt-to-equity ratio for U.S. corporations averaged $0.5-0.75$ in the period 19371984. ${ }^{3}$ Share of value-added in the banking sector, according to Kuznets (1941), 1919-1938. ${ }^{4}$ Average annual inflation, measured using the GNP deflator, over the period 1922-1929. ${ }^{5}$ Based on analysis of data on the finance, insurance, and real estate sectors. ${ }^{6}$ Average annual inflation measured using GNP deflator. 


\begin{tabular}{|l|l|l|l|l|l|l|l|l|}
\hline \multicolumn{7}{|c|}{ Table 4: Consolidated Banking Sector Balance Sheet, Model versus U.S. Data } \\
\hline \multicolumn{1}{|c|}{ Variable } & Model & $1921-1929$ & $1995-2001$ & \multicolumn{2}{c|}{ Variable } & Model & $1921-1929$ & $1995-2001$ \\
\hline Assets (fraction of annual GNP) & 1.296 & 0.722 & 0.604 & Liabilities (fraction of annual GNP) & 1.296 & & 0.604 \\
\hline Total reserves & 0.122 & 0.152 & 0.081 & Total demand deposits & 1.000 & 1.0 \\
\hline ○ Required reserves & 0.100 & 0.118 & 0.052 & ○ Firm demand deposits & 0.878 & 1.0 \\
\hline 。 Excess reserves & 0.022 & 0.034 & 0.029 & $\circ$ Household demand deposits & 0.122 & & 0.523 \\
\hline Working-capital loans & 0.878 & 0.848 & 0.919 & & & & & \\
\hline ○ Capital rental expenses & 0.249 & & & & & & \\
\hline ○ Wage bill expenses & 0.629 & & & & & & \\
\hline Entrepreneurial loans & 0.803 & 0.525 & 0.828 & Time deposits & 0.803 & 0.525 & 0.828 \\
\hline
\end{tabular}

Notes on Table 4: Total assets consists of reserves, plus working-capital loans, plus loans to entrepreneurs. The first

line shows the ratio of these to annual goods output. With the exception of the bottom row of numbers, remaining entries in the table are expressed as a fraction of bank reserves plus working capital loans. The bottom row of numbers is expressed as a fraction of total assets.

Data for the period 1995-2001: We define working-capital loans as total demand deposits minus total reserves. This number is the same order of magnitude as the sum of short-term bank loans with maturity 24 months or less (taken from the Board of Governors' "Banking and Monetary Statistics", 1943) and commerical paper (Table L101 in Board of Governors' Flow of Funds Accounts). Long-term entrepreneurial loans are defined as the total liabilities of the nonfinancial business sector (nonfarm nonfinancial corporate business, plus nonfarm noncorporate business, plus farm business) net of municipal securities, trade payables, taxes payables, "miscellaneous liabilites," and the working-capital loans. Source: With exception of required and excess reserves, the source is the Federal Reserve's Flow of Funds data. Required and excess reserves are obtained from Federal Reserve Bank of St. Louis.

Data for the period 1921-1929: We define working-capital loans as total demand deposits minus total reserves for all banks. Entrepreneurial loans are constructed on the basis of all bank loans minus working capital loans plus outstanding bonds issued by all industries. Source: Banking and Monetary Statistics, Board of Governors, September 1943, and NBER historical database, available at www.nber.org. 


\begin{tabular}{|c|c|c|c|c|c|c|c|}
\hline \multicolumn{8}{|c|}{ Table 5: Money and Interest Rates, Model versus U.S. Data } \\
\hline Money & Model & $1921-1929$ & $1964-2002$ & Interest Rates (APR) & Model & $1921-1929$ & 1964-2002 \\
\hline Monetary base velocity & 9.77 & 12 & 16.6 & Demand deposits & 1.07 & & 3.21 \\
\hline M1 velocity & 3.92 & 3.5 & 6.5 & Time deposits & 4.66 & & 6.96 \\
\hline & & & & Rate of return on capital & 6.91 & & 17.33 \\
\hline Currency / Demand deposits & 0.28 & 0.2 & 0.3 & Entrepeneurial standard debt contract & 5.31 & 5.74 & 8.95 \\
\hline Currency / Monetary base & 0.70 & 0.55 & 0.73 & Interest rate on working capital loans & 4.76 & 4.72 & 7.10 \\
\hline Curr. / Household D. Deposit & 2.30 & & & Interbank loan rate & 5.87 & 3.90 & 6.86 \\
\hline
\end{tabular}

Notes to Table 5:

Data for 1921-1929: (1) "Federal funds rate" is the average rate on bankers' acceptances. (2) Interest rate on working-capital loans is the commerical paper rate. (3) Rate on loans to entrepreneurs is the average of returns on Aaa and Baa corporate bonds. (4) Rate on time deposits is available only from 1933 onwards. Reported data in Board of Governors (1943) only cite the administrative rate (maximum rate) set by the Fed. The average of this rate was $2.7 \%$ over the period 1933-41. (5) There are no data available on the rate paid on demand deposits (to our knowledge).

Data for 1964-2002: (1) The federal funds rate covers the period 1964III-2002III. Source: Board of Governors of the Federal Reserve. (2) The rate on demand deposits is the "Money Zero Maturity Own Rate" (1964III-2002III). Source: Federal Reserve Bank of Saint Louis. (3) The rate on loans to entrepreneurs is the average between Aaa and Baa corporate bonds (1964III-2002III). Source: Board of Governors. (4) The rate on time deposit is the rate on 3-month CDs (1964III-2002III). Source: Board of Governors. (5) The rate of return on capital is the rate of profit on stockholders' equity for the manufacturing sector (1980I-2001IV). Source: Bureau of the Census (2002, Table I). (6) The rate on working-capital loans is the rate on commercial paper (dealer-placed unsecured short-term negotiable promissory notes issued by companies with Aa bond ratings and sold to investors), averaged over 1971I-2002III. Source: Board of Governors. (7) The Currency to M1 ratio is an average over 1964III-2002III (currency includes dollars held abroad). Source: Federal Reserve Bank of Saint Louis. (8) The Currency to Monetary Base ratio is the average over 1964III-2002III (currency includes dollars held abroad). Source: Federal Reserve Bank of Saint Louis. (9) The Monetary Base and M1 velocities are averages over 1964III-2002III (currency includes dollars held abroad). Source: Federal Reserve Bank of Saint Louis. 
Table 6: Parameters of Exogenous Shocks and Monetary Policy Response

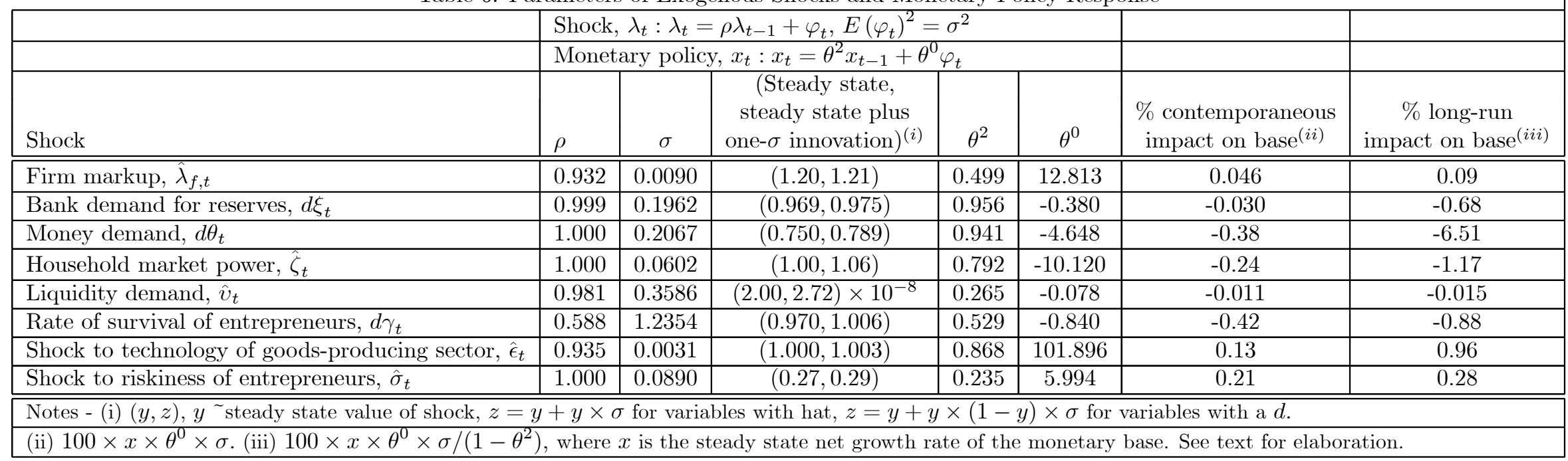


Table 8: Annualized Percent Growth Rates, Data Versus Alternative Models

\begin{tabular}{|l|l|l|l|l|l|l|l|l|l|l|l|l|}
\multicolumn{8}{|c}{ Table 8: Annualized Percent Growth Rates, Data Versus Alternative Models } \\
\hline & \multicolumn{3}{|c|}{$1929-1933$} & \multicolumn{3}{c|}{$1933-1939$} & \multicolumn{5}{c|}{$1929-1939$} \\
\hline & $(1)^{(i)}$ & $(2)$ & $(3)$ & $(4)^{(i i)}$ & $(1)$ & $(2)$ & $(3)$ & $(4)$ & $(1)$ & $(2)$ & $(3)$ & $(4)^{(i i)}$ \\
\hline \hline Output & -9.2 & -6.4 & -3.8 & -1.6 & 5.1 & 2.6 & 1.9 & 2.4 & -0.6 & -1.0 & -0.4 & 0.8 \\
\hline Investment & -35.3 & -28.5 & -17.3 & -15.7 & 16.9 & 13.2 & 4.1 & 13.8 & -4.0 & -3.5 & -4.5 & 2.0 \\
\hline Hours worked & -7.3 & -7.3 & -5.0 & -2.1 & 1.4 & 1.4 & 1.5 & 0.2 & -2.1 & -2.1 & -1.1 & -0.7 \\
\hline Price level & -7.6 & -9.2 & -7.8 & -6.5 & 1.7 & 2.1 & -1.6 & 9.7 & -2.0 & -2.4 & -4.1 & 3.2 \\
\hline M1 & -9.1 & -8.5 & -7.3 & -1.7 & 8.1 & 6.2 & 1.4 & 12.8 & 1.2 & 0.3 & -2.1 & 7.0 \\
\hline Real wage & 0.4 & 2.8 & 1.3 & 2.6 & 4.0 & 2.2 & 1.4 & 2.1 & 2.6 & 2.4 & 1.4 & 2.3 \\
\hline TFP & -2.3 & -1.1 & -0.4 & -0.8 & 3.2 & 1.8 & 1.2 & 1.6 & 1.0 & 0.6 & 0.6 & 0.6 \\
\hline Firm wedge & -9.0 & -7.3 & -0.5 & -8.3 & -2.0 & -6.1 & -5.6 & 0.5 & -11.1 & -13.3 & -6.1 & -7.8 \\
\hline Household wedge ${ }^{(i i i)}$ & 54.9 & 43.8 & 30.7 & $23.7^{(i v)}$ & 1.3 & 7.0 & -8.1 & 42.3 & 56.2 & 50.8 & 22.6 & $65.9^{(i v)}$ \\
\hline \hline
\end{tabular}

Note: Statistics denote $100 \times \log \left(x_{j} / x_{i}\right)$, where $x_{j}$ and $x_{i}$ denote average values of $x$ in the indicated years

(except where noted); except in the last two rows, numbers are converted to annualized, percent terms.

(i) (1) is U.S. data; (2) is estimated model with all shocks; (3) is estimated model with only $v_{t}$ shock;

(4) is results for counterfactual policy. (ii) results for 1929 correspond to 1929IV.

(iii) results for 1939 represent average over 1939I-1939III. (iv) results for 1929 are actually average for 1930. 
Figure 1: Key Macroeconomic Data for the 1920s and 1930s (fourth quarters after 1928 indicated by *)

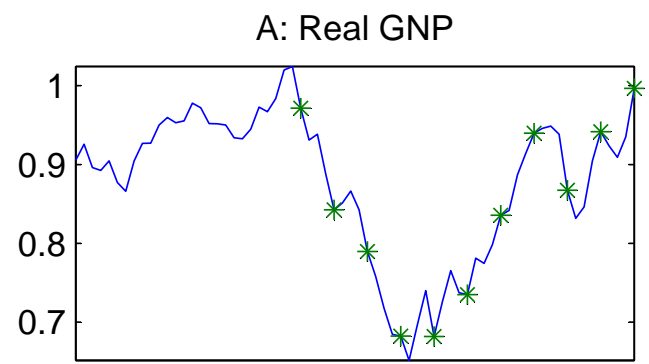

D: Total Manhours (incl. military)

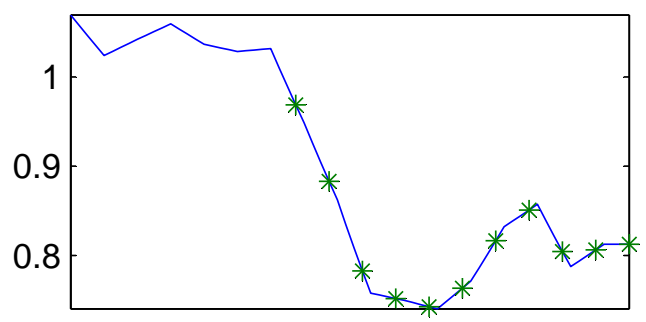

G: Short-term Rate

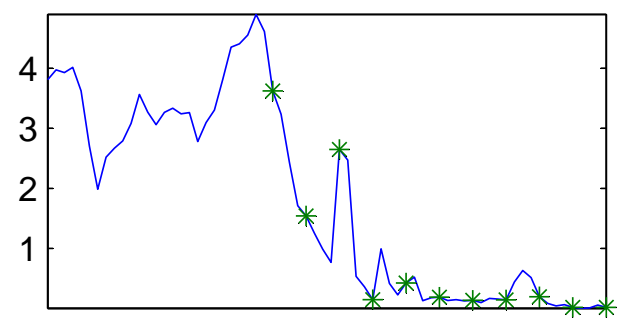

J: Reserve-to-Deposit Ratio

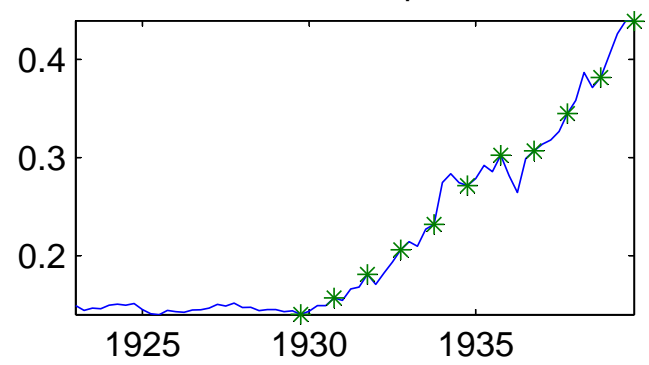

B: Investment

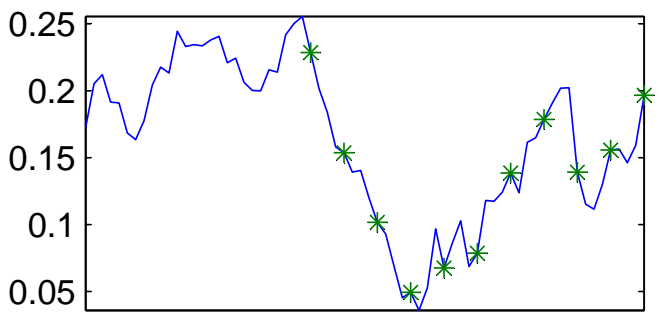

E: GNP Deflator

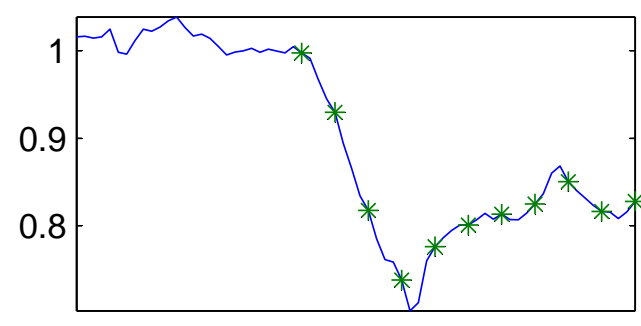

H: Real DOW

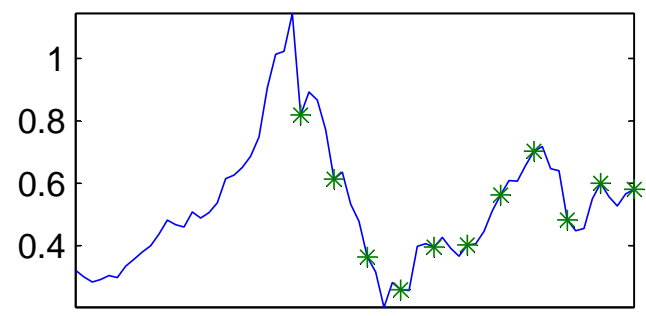

K: Spread, Baa and Aaa Bonds

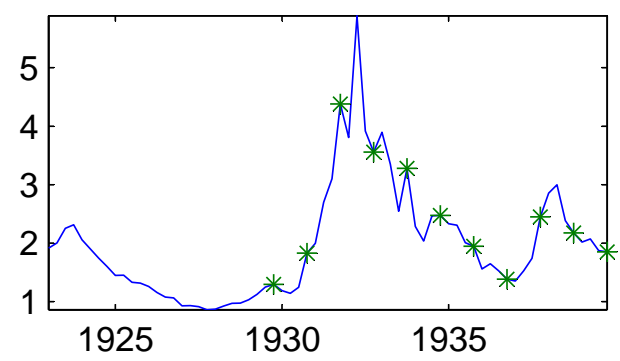

C: Consumption

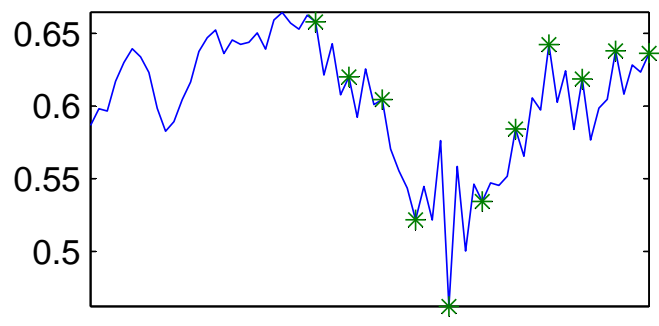

F: Real M1
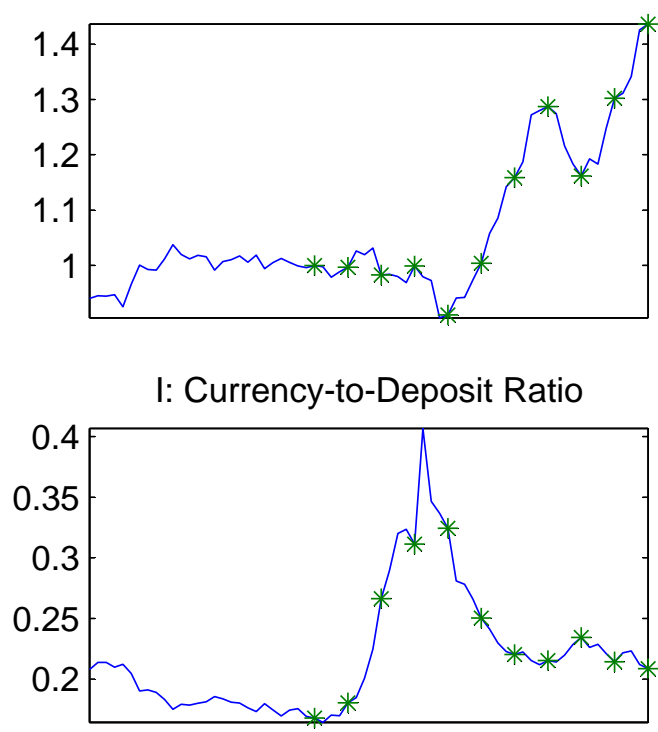

L: Economy-wide Real Wage

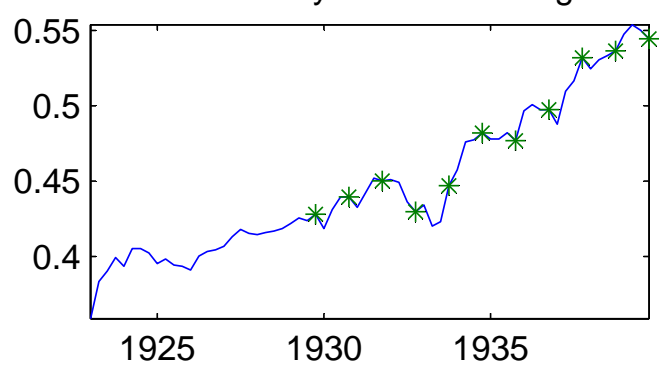


FIGURE 2: One Period in the Life of an Entrepreneur

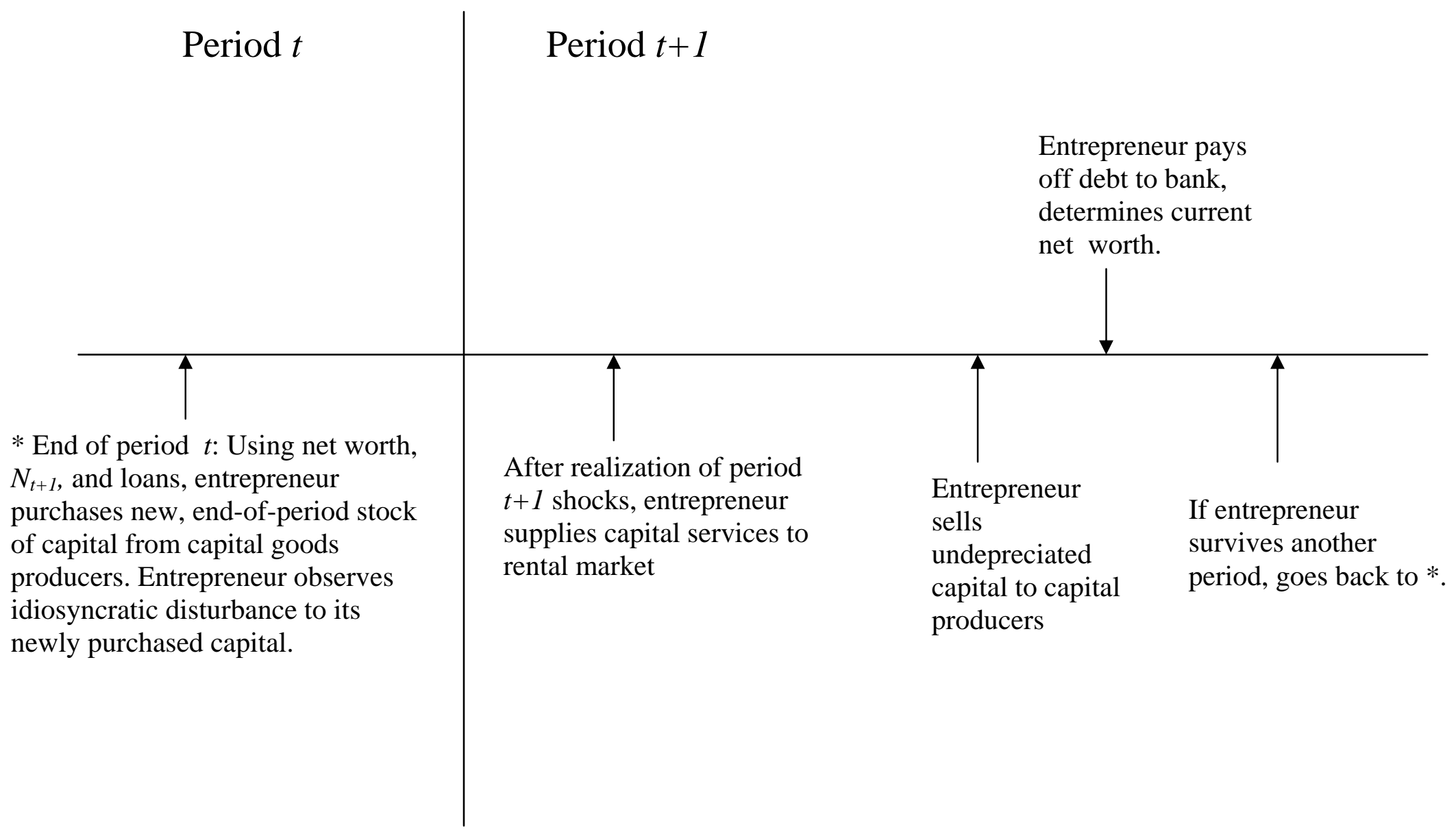




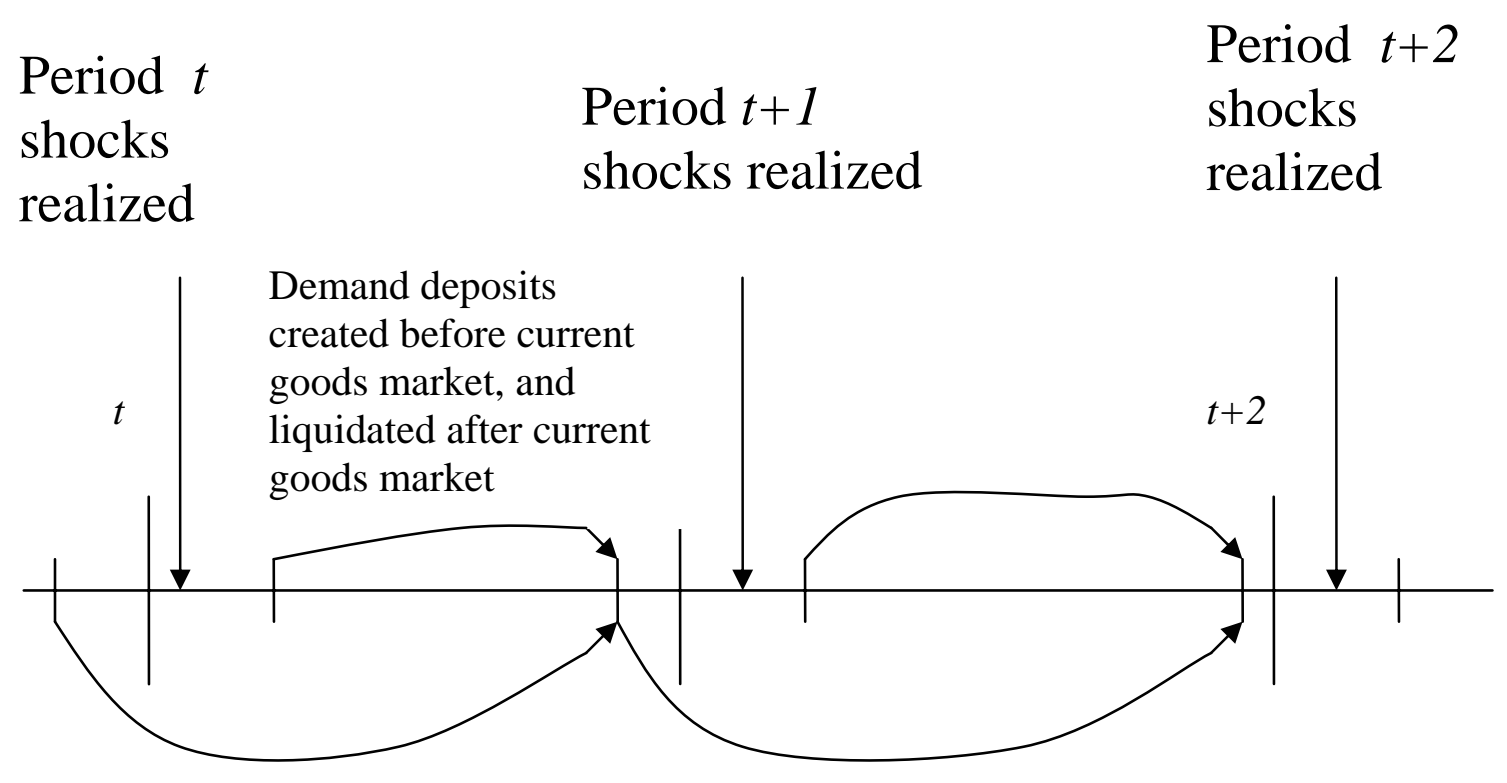

Time deposits created at end of current period goods market and liquidated at end of next period goods market.

\section{Figure 3: Maturity Structure of Time and Demand Deposits}


Figure 4: Actual and Fitted Data, Growth Rates and Ratios

Log, Net Worth/GDP

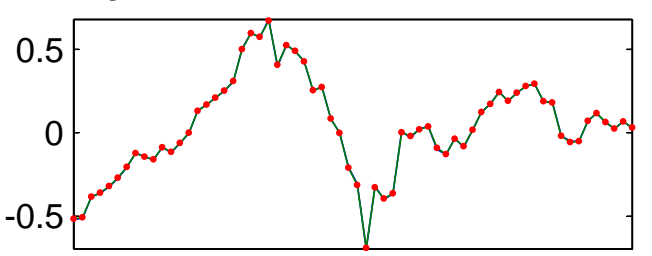

Policy Rate (APR)

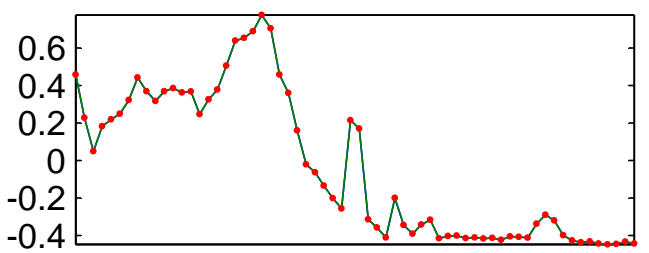

Log, Investment / GDP

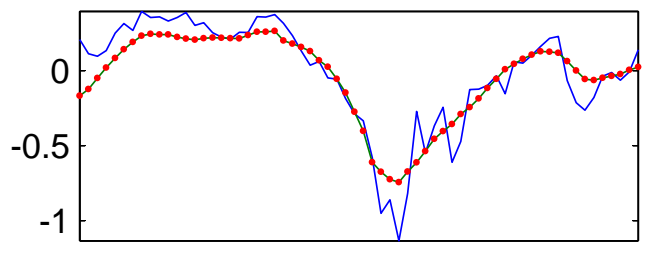

Spread, Abb over Aaa Corporate Bonds (APR)

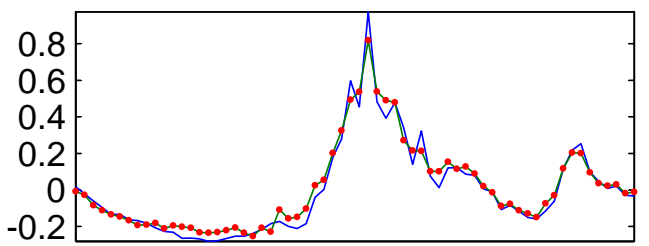

Log, Reserves-to-Deposit Ratio

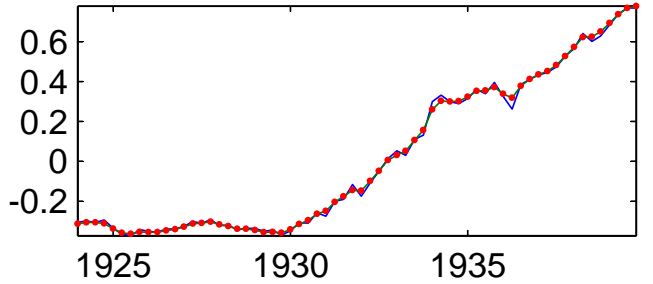

Inflation

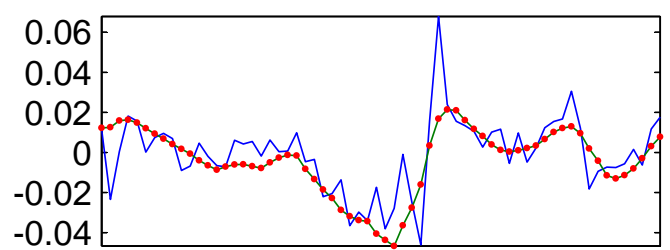

GDP Growth

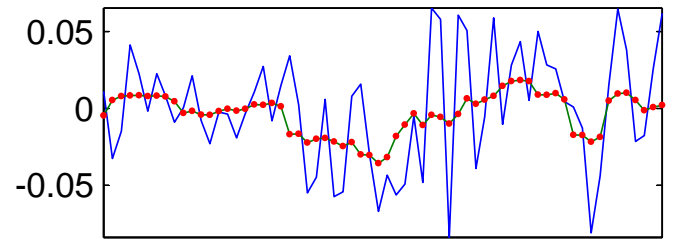

Log, $M_{1}$ Velocity

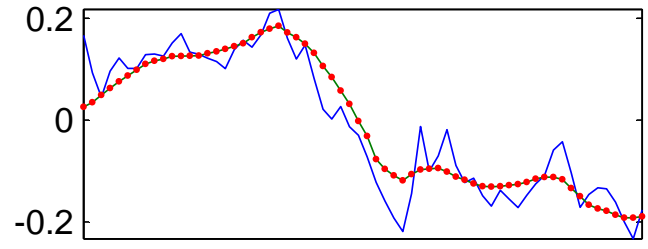

Log, Currency-to-Deposit Ratio

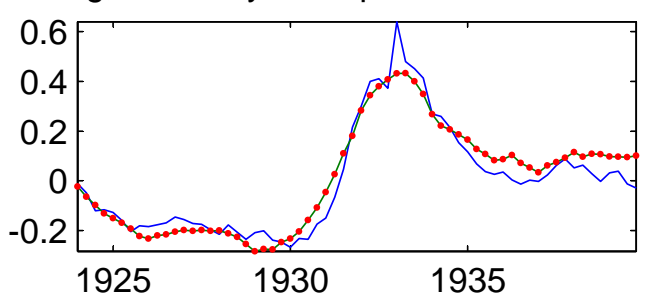

Log, Hours

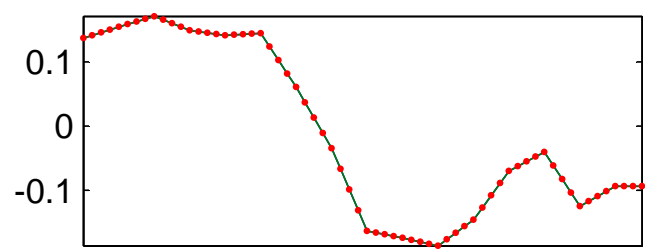

Log, Real Wage / GDP

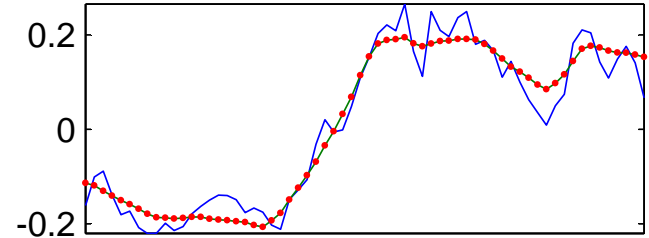

Log, Consumption / GDP

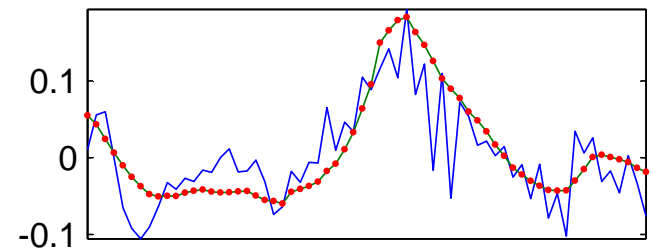

Log, Base Velocity

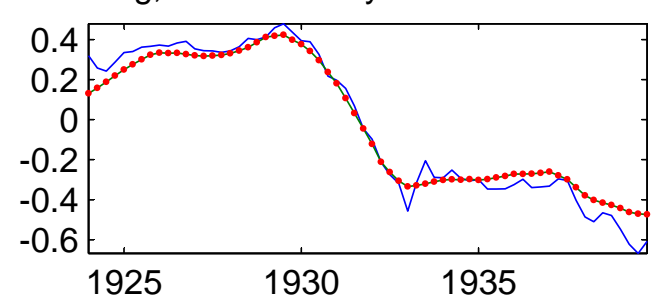

Notes:

(i) Dotted line - Model fitted values, produced by

two-sided Kalman smoothing.

(ii) Solid line - Actual data.

(iii) In several cases, actual and fitted coincide.

(iv) Fitted and actual data adjusted to have zero means. 
Figure 5: Actual and Fitted Data, Converted to Levels

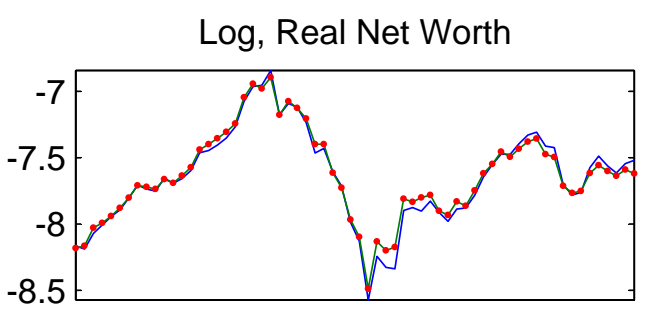

Policy Rate

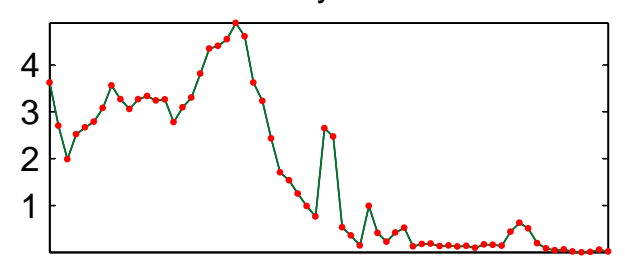

Log, Investment

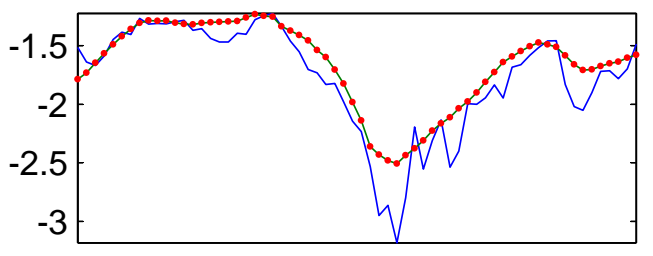

Premium (APR)

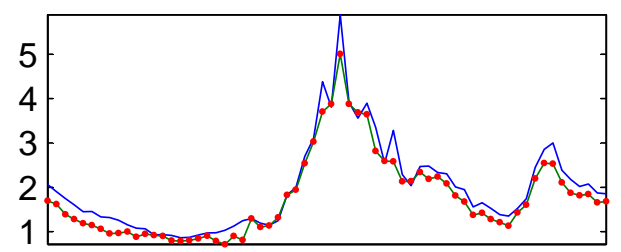

Log, Money Base

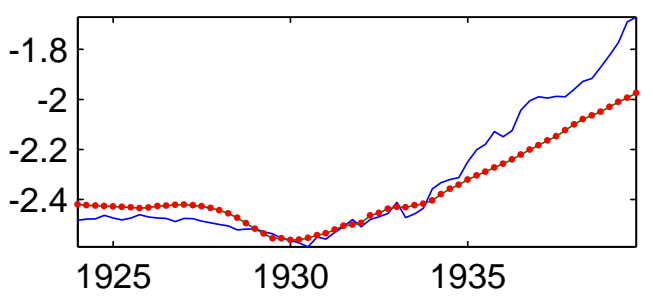

Log, Price Level

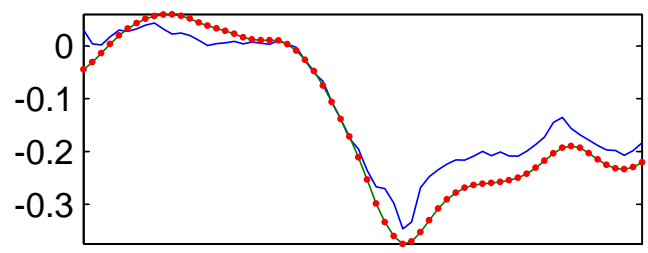

Log, Output

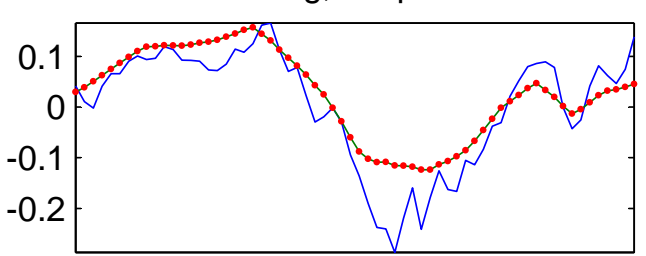

Log, M1

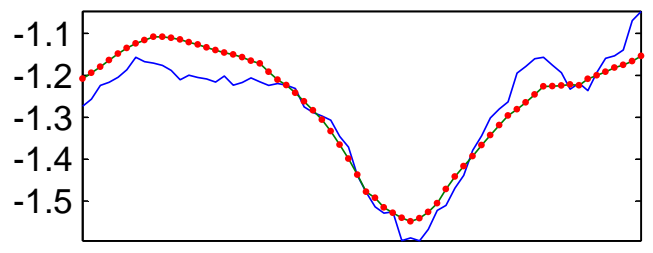

Log, Currency-to-Deposit Ratio

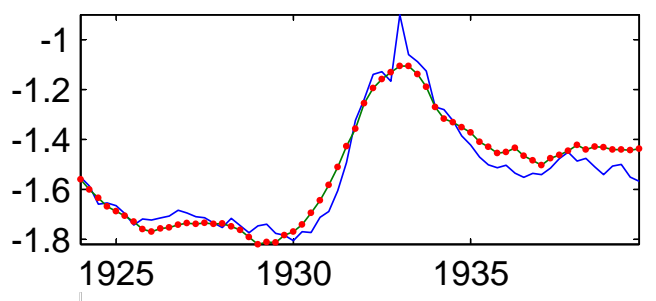

Notes:

(i) Dotted, solid line - Model, actual data.

(ii) Results obtained by first adding

actual data sample mean to results displayed

in Figure 4 and then aggregating to levels.

(iii) Currency-deposit, reserves-deposit ratio, premium reproduced from Figure 4.

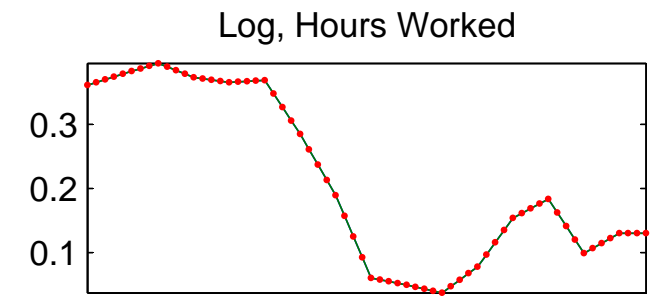

Log, Real Wage

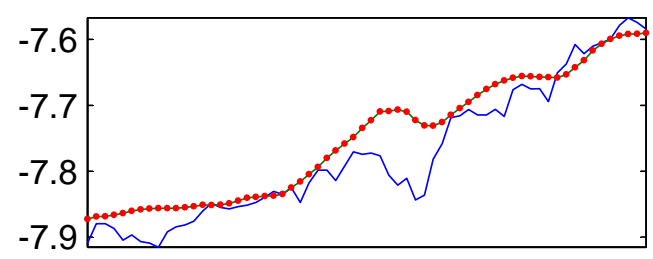

Log, Consumption

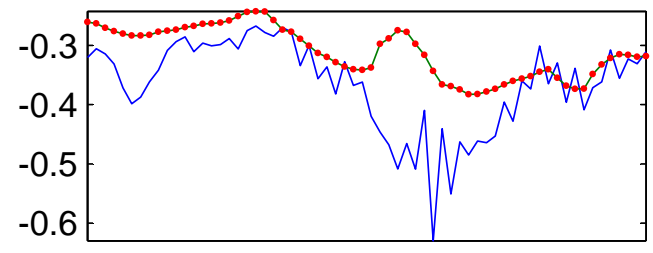

Log, Bank Reserve-to-Deposit Ratio

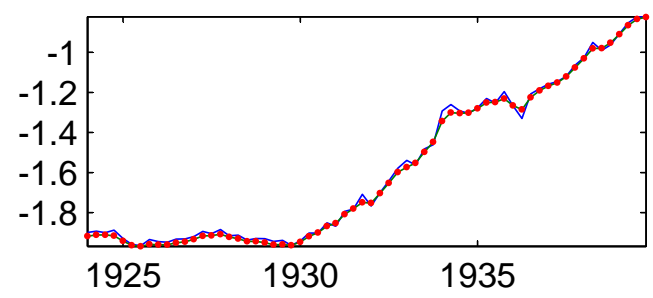


Figure 6: Estimated Economic Shocks
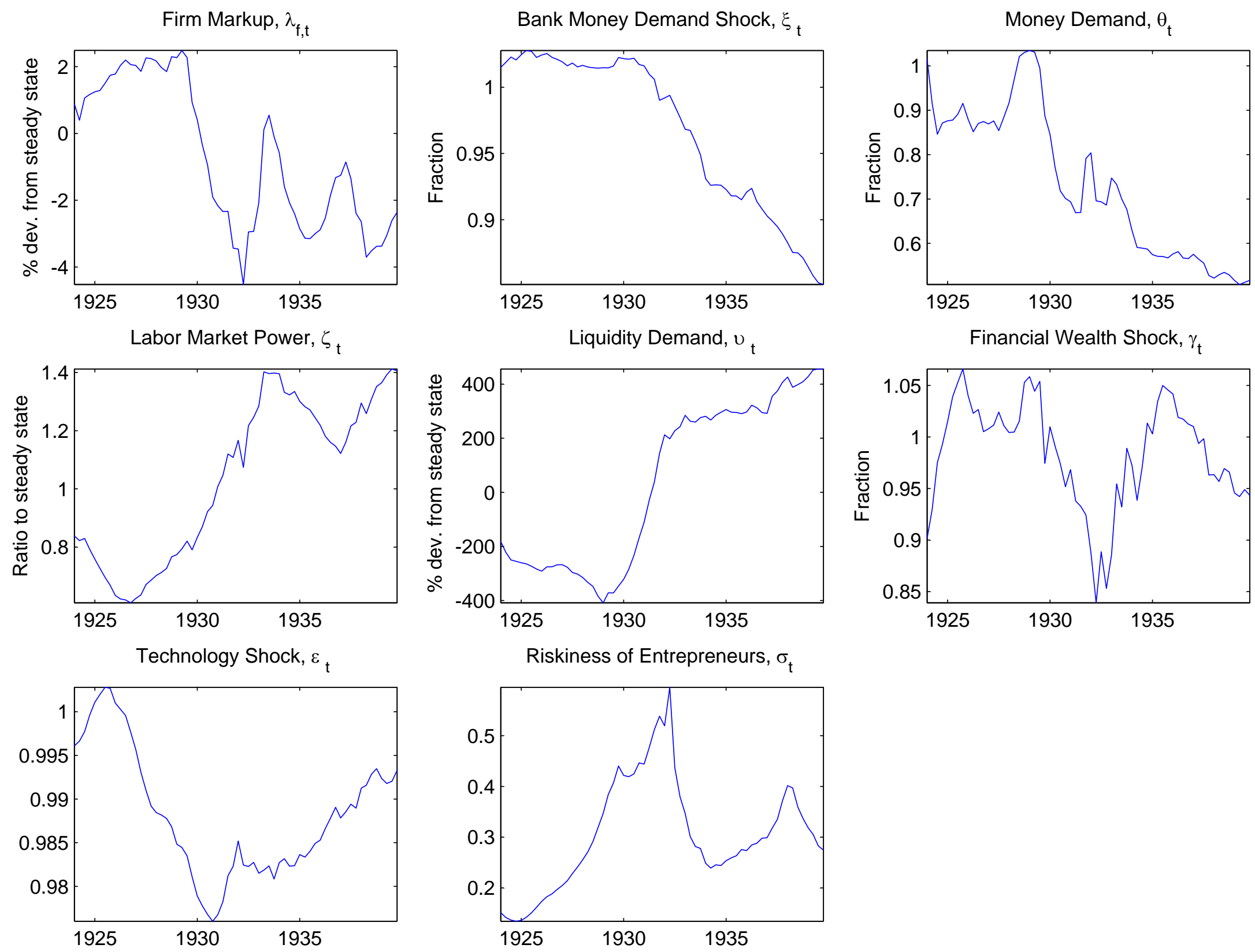
Figure 7: Output, Employment, Investment and Price Response to Indicated Single Shock, and all Shocks
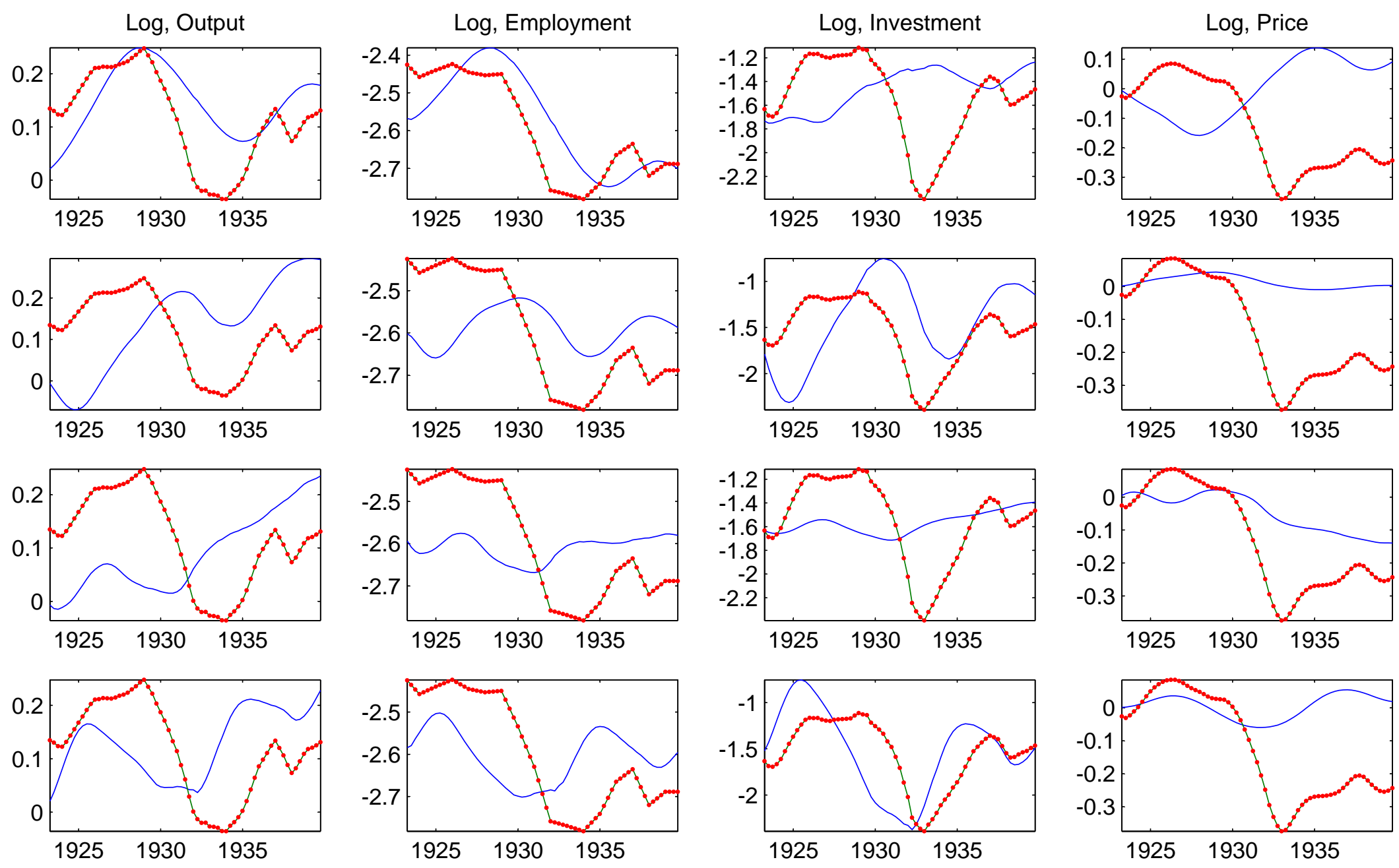

Notes:

(i) Dotted line: response of model to all estimated shocks.

(ii) Solid line: response of model to one of the estimated shocks.

(iii) All simulations assume economy is in nonstochastic steady state in 1923।

(Iv) Row 1: Labor market power, $\zeta_{\mathrm{t}}$, Row 2: Financial wealth shock, $\gamma_{\mathrm{t}}$, Row 3: Technology shock, $\varepsilon_{\mathrm{t}}$, Row 4: Riskiness of entrepreneurs, $\sigma_{\mathrm{t}}$. 
Figure 8: Model Response with Only v Shocks, and Data

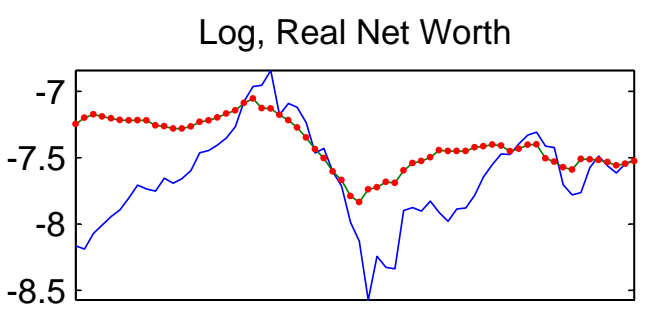

Policy Rate

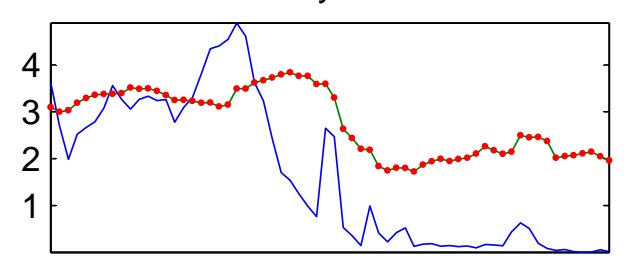

Log, Investment

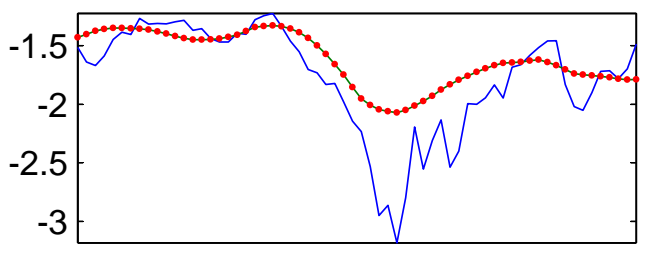

Premium (APR)

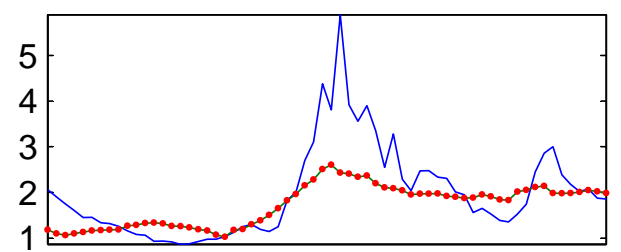

Log, Money Base

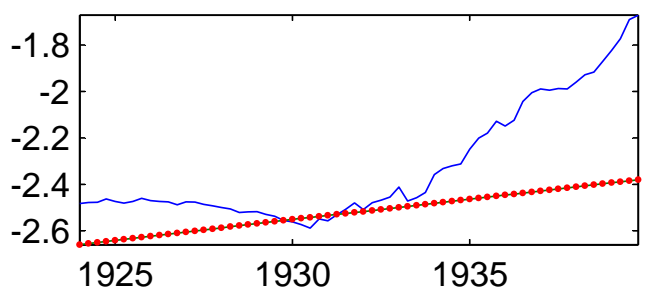

Log, Price Level

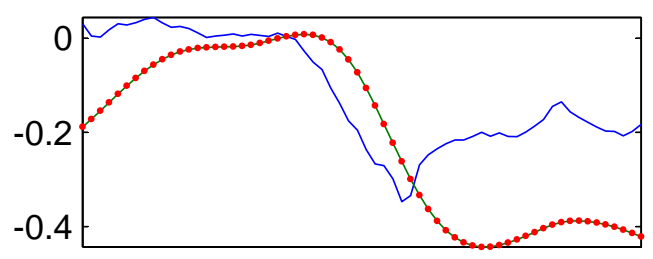

Log, Output

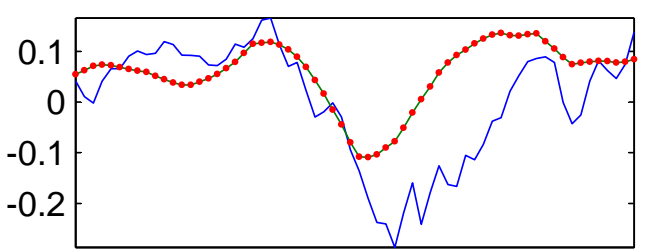

Log, M1

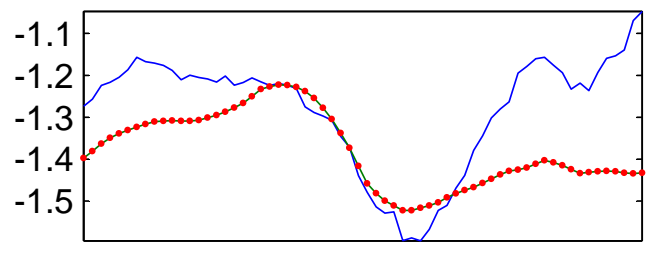

Log, Currency-to-Deposit Ratio

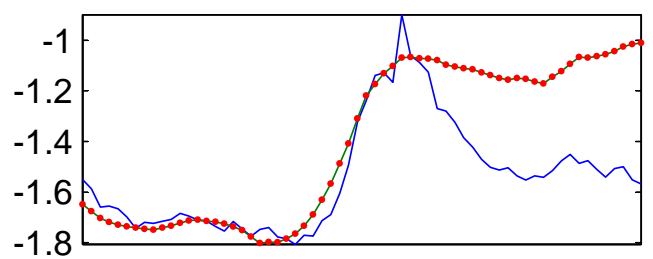

Notes:

Results correspond to those in Figure 5 , except model simulation only includes estimated $v_{t}$ shocks.

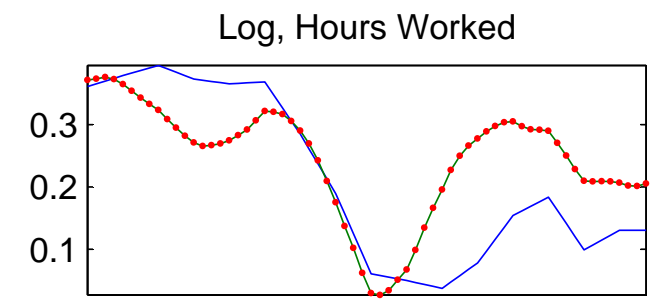

Log, Real Wage

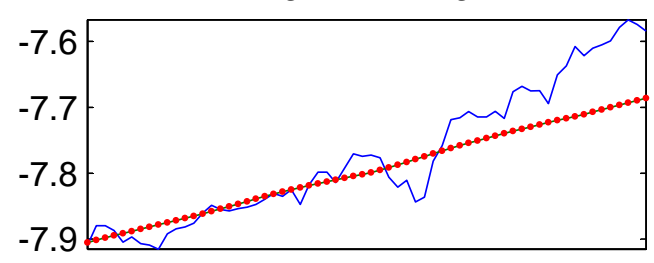

Log, Consumption

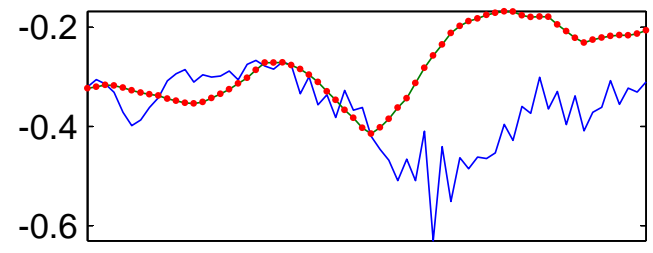

Log, Bank Reserve-to-Deposit Ratio

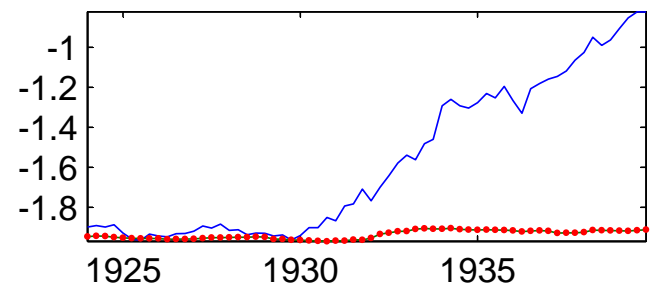


Figure 9: Response to One-Standard Deviation Innovation to Liquidity Preference, $v_{t}$
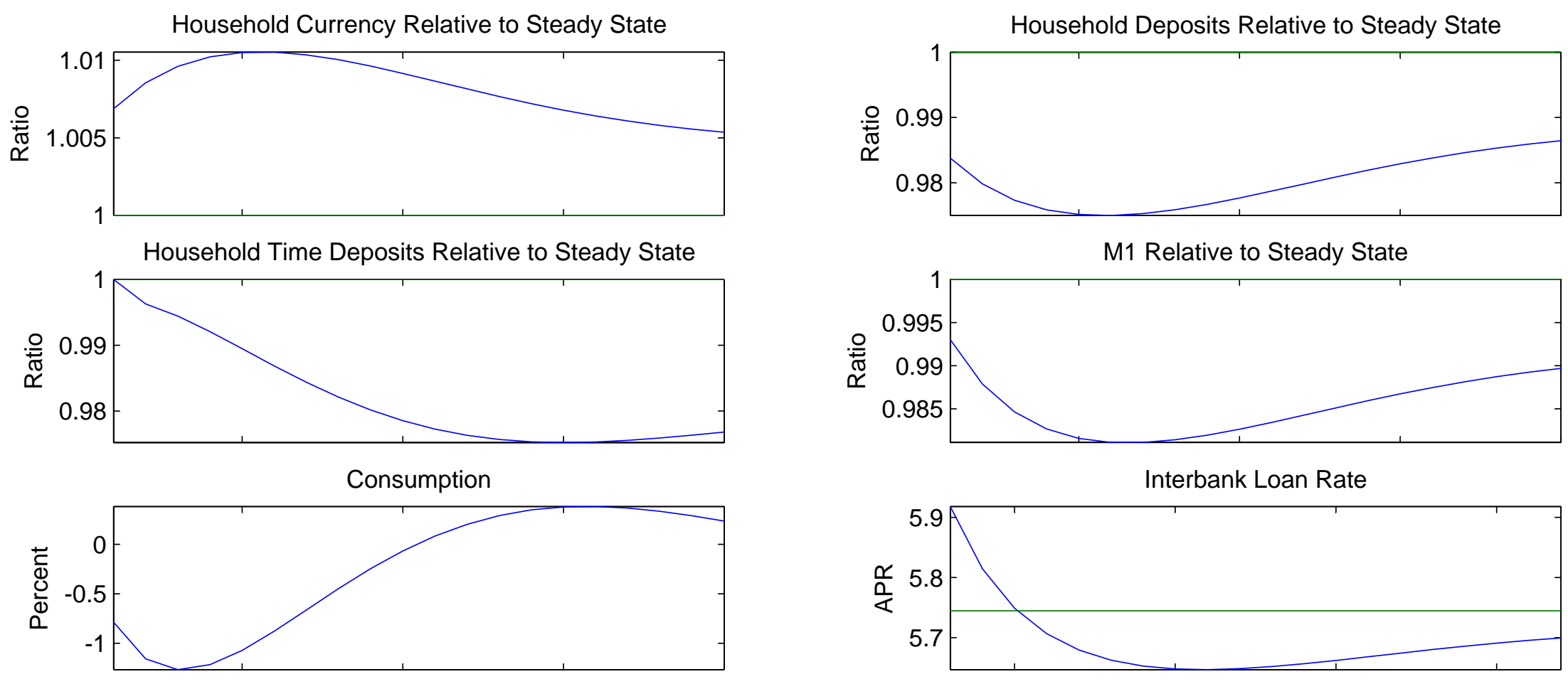

External Finance Premium
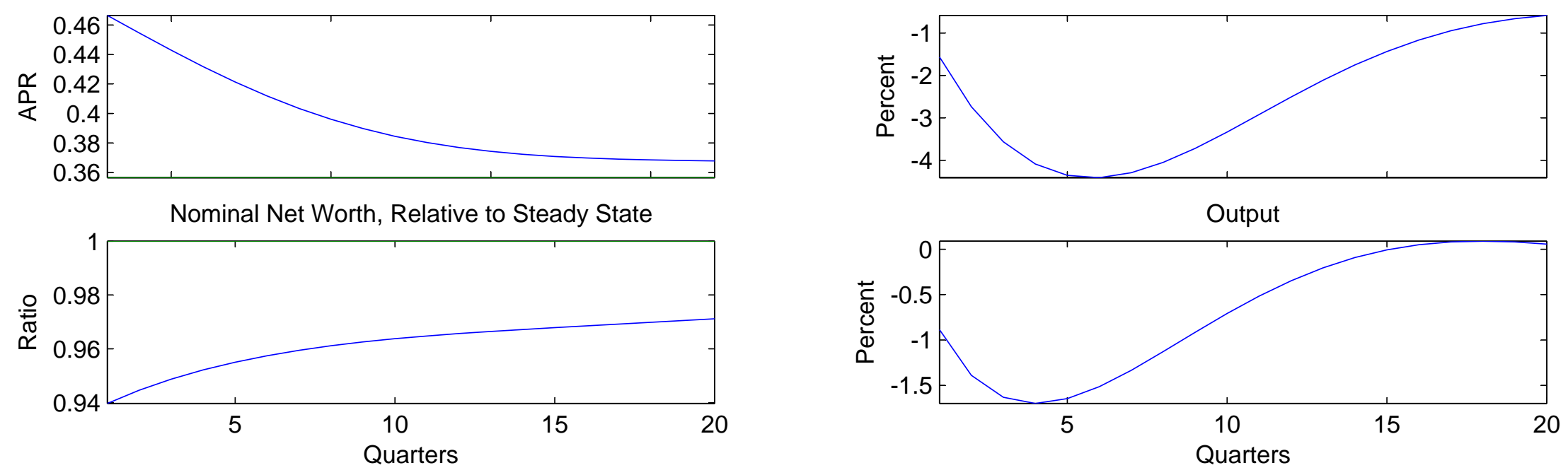
Figure 10: Baseline Estimated Policy (Solid Line) and Counterfactual Policy (Dotted Line)
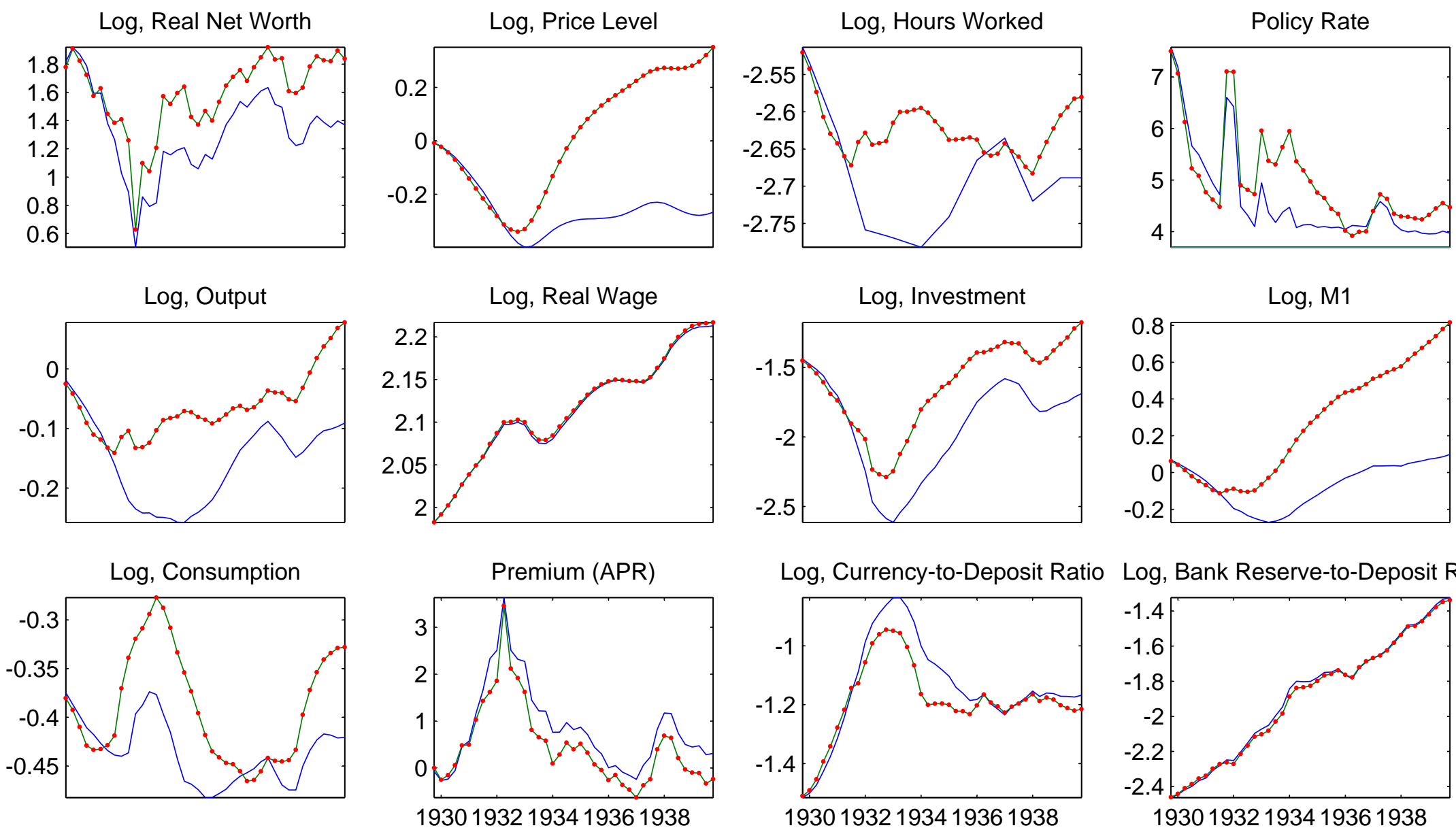

Log, Currency-to-Deposit Ratio
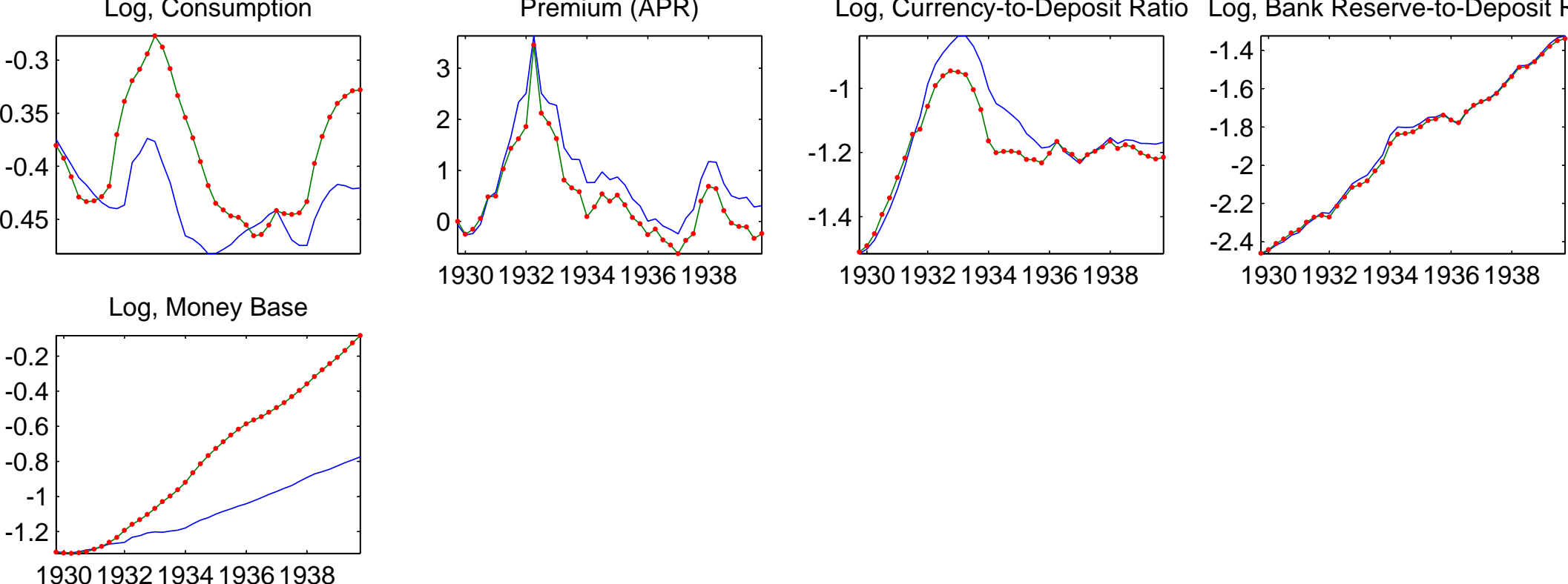
Figure 11: Policy Rate under Baseline Simulation (Solid Line) and Counterfactual with Front-Loading of Monetary Response to Shocks (Dotted)

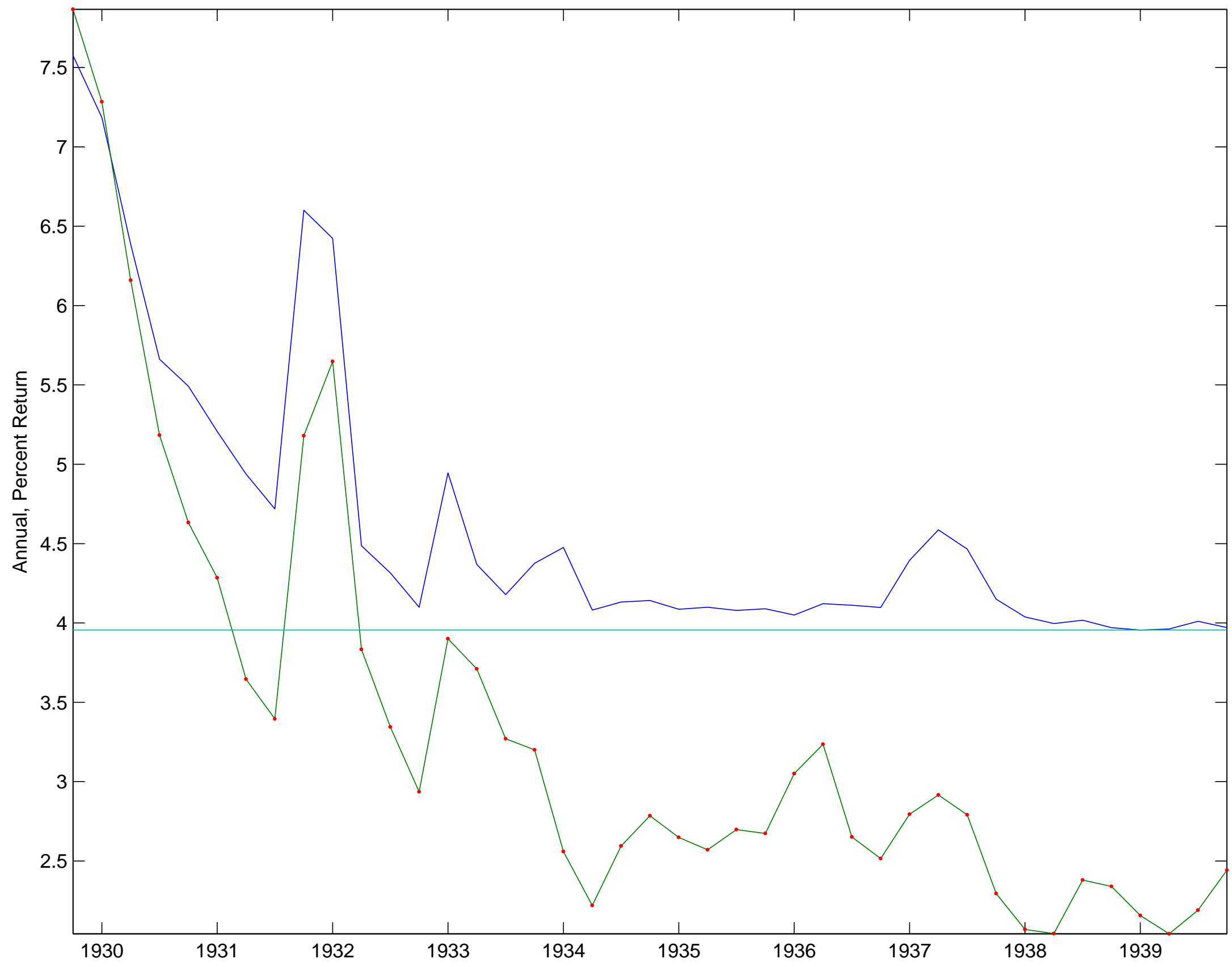

